Cognitive aging:

Effects of education and task demands

Neuropsych Publishers, Maastricht, the Netherlands 
(C) W.Meijer, Maastricht, 2006

$\begin{array}{ll}\text { Cover design } & \text { Sjoerd van Wijk en Ron Keulen } \\ \text { Production } & \text { Datawyse, Maastricht } \\ \text { ISBN-10 } & 90-75579-30-6 \\ \text { ISBN-13 } & 978-90-75579-30-7\end{array}$

Neuropsych Publishers is a non-profit organization, which aims at promoting the science of 'Brain and Behaviour' and improving the application of the products of this science in health care and education. Neurpsych Publishers accomplishes these aims by publishing books, dissertations and other products of scientific activity, by disseminating educational materials and publications of tests, assessment scales and other psychometric instruments in the field of Neuropsychology, Neuropsychiatry and other areas within the domain of Brain and Behaviour.

Postal address:

\author{
Neuropsych Publishers \\ Department of Psychiatry and Neuropsychology \\ Maastricht University \\ P.O. Box 616 \\ 6200 MD Maastricht \\ The Netherlands \\ www.np.unimaas.nl
}

Financial support for the publication of this dissertation has been kindly provided by

Internationale Stichting Alzheimer Onderzoek, Alzheimer Nederland, Lundbeck BV,

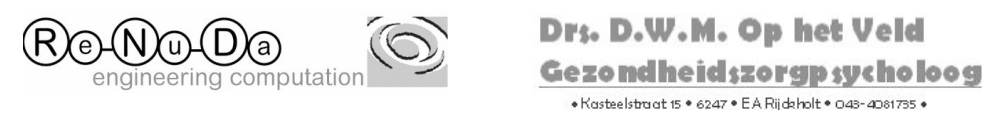

MEYER

services and consultancy 


\title{
Cognitive aging:
}

\section{Effects of education and task demands}

\begin{abstract}
Proefschrift
ter verkrijging van de graad van doctor aan de Universiteit Maastricht, op gezag van de Rector Magnificus, Prof. mr. G. P. M. F. Mols, volgens het besluit van het College van Decanen, in het openbaar te verdedigen op

vrijdag 22 december 2006 om 15:00 uur
\end{abstract}

door

\section{Willemien Meijer}

Geboren op 14 juli 1979 te Leiden 


\section{Promotor}

Prof. dr. J. Jolles

\section{Co-promotores}

Dr. P. W. M. van Gerven

Dr. R. H. M. de Groot

\section{Beoordelingscommissie}

Prof. dr. F. Verhey (voorzitter)

Dr. M. Jelicic

Prof. dr. G. I. J. M. Kempen

Prof. dr. A. Kok (Universiteit van Amsterdam)

Prof. dr. K.R. Ridderinkhof (Universiteit van Amsterdam en Universiteit Leiden)

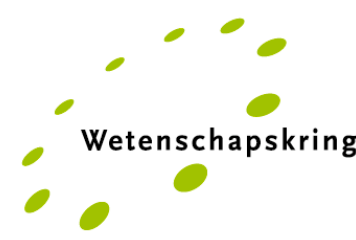

- Mondriaan Zorggroep - Vijverdal · RIACG Maastricht

- RGC Westelijke Mijnstreek • RIBW Heuvelland en Maasvallei

- Academisch Ziekenhuis Maastricht - Atrium Medisch Centrum

Universiteit Maastricht - Onderzoeksschool Experimentele Psychopathologie

Onderzoeksschool Hersenen en Gedrag

- de Wetenschapskring bevordert wetenschappelijk onderzoek op het gebied van de GGZ in Zuid-Limburg •

The research described in this dissertation was performed at the Maastricht Brain and Behaviour Institute, Department of Psychiatry and Neuropsychology, Maastricht University. 


\section{CONTENTS}

$\begin{array}{ll}\text { 1. Introduction } & 7\end{array}$

2. Education and sex influence age differences in information processing

3. Are age differences in verbal learning related to interstimulus interval and education?

4. Verbal learning and aging: Combined effects of irrelevant speech, interstimulus interval, and education

5. Level of processing and reaction time in young and middle-aged adults and the effect of education

6. The benefit of deep processing and high educational level for verbal learning in young and middle-aged adults

7. Interaction effects of education and health status on cognitive change: 6-year follow-up of the Maastricht Aging Study

8. Concluding remarks

Summary

Samenvatting

Dankwoord

Curriculum Vitae

Publications

128 


\section{Chapter 1}

\section{Introduction}

The cognitive and psychological aspects of aging have received quite extensive research interest in the past few decades. The scientific research has shown that there are both gains and losses in cognitive functioning with increasing age. Gains primarily occur in aspects related to acquired knowledge (Rabbitt, 1993), whereas losses have been documented in a wide variety of cognitive functions (Birren \& Schaie, 2006). In the past few decades, much emphasis has been placed on the reductions in speed and efficiency of information processing and the capacity to learn and remember new information. The majority of research papers on age-related changes in cognitive functioning compare relatively young adults (usually in their 20s) to older people (usually older than 60 years). Although the age range between 30 and 60 is often disregarded, this range may be of particular interest given that the first manifestations of age-related change can be observed as early as age 40 (Houx \& Jolles, 1993; Houx, Vreeling, \& Jolles, 1991; Houx, Jolles, \& Vreeling, 1993; Salthouse, 2004). Moreover, age differences in cognitive abilities under the age of 65 can have important implications for daily life functioning, including job performance. Cognitive challenges in midlife, notably in the fourth and fifth decade of life, are generally substantial. These challenges include activities in work and family environments that require organizing, planning, problem solving, and multitasking skills, often under conditions of time pressure (Schooler, 1999). Thus, middle-aged individuals need to utilize their cognitive capacities to a large extent. In this context, more insight is needed with respect to the cognitive processes that are affected by normal, i.e., non-pathological, aging under the age of 65. Another important question in this respect is: To what extent is age-related cognitive change influenced by individual characteristics, such as educational level? These issues are the focus of this dissertation.

This introductory chapter continues with a brief overview of background information on cognitive aging and a description of the methodological/theoretical approaches that are pursued in the present dissertation. Subsequently, potential determinants of cognitive aging are considered, whereby education is considered one of the most important. Lastly, the objectives and outline of this dissertation are presented.

\section{AGING AND COGNITION}

Cognitive aging research endeavours to identify and measure age related changes in basic cognitive processes. In mainstream cognitive aging research, laboratory tasks and controlled experimental procedures that represent novel experiences for persons of all ages are used. There is ample evidence that advancing age is associated with dec- 
rements in a wide range of cognitive functions, such as recalling information, maintaining focused attention, and planning and executing complex behaviors. Additionally, basic perception, execution of motor functions and complex language functions are compromised (Birren \& Schaie, 2006; Jolles, 1986). These functions are generally considered a prerequisite for efficient and goal-directed behavior. There are several influential theoretical approaches with respect to the underlying mechanisms and causes of age-related cognitive decrements. The following approaches are the bases of the research questions addressed in the present dissertation.

First and foremost, the 'processing speed' theory states that age-related cognitive change can be attributed to a decrease in the speed at which elementary cognitive operations are executed (Salthouse, 1996b). This decline in information processing speed places fundamental limitations on most aspects of cognition. Indeed, mental speed has been found to explain a substantial part of age-related variance in cognitive performance (Earles \& Salthouse, 1995; Salthouse, 1996a; Salthouse \& Meinz, 1995). Hence, older individuals are generally slower with respect to information processing, which, in turn, leads to performance deficits in a wide range of cognitive domains.

A second important theory attributes age-related differences in cognition to a decline of inhibitory control in working memory (Hasher \& Zacks, 1988; McDowd, Oseas-Kreger, \& Filion, 1995). A major function of inhibitory processes is to prevent irrelevant material from accessing working memory and to deactivate any such material that has already accessed working memory. Irrelevant material may be external, such as noise, or it may consist of internal thoughts that interfere with the ongoing task. In either case, the failure of older adults to inhibit these stimuli means that working memory is loaded, to some degree, with irrelevant information. This places limitations on the processing of task-relevant information.

A third influential viewpoint that is pursued in this dissertation contends that cognitive performance, in particular memory performance, results from an interaction between internal and external factors (Zacks, Hasher, \& Li, 2000). Internal factors include the processing resources the individual has available. The presumed age-related decline in processing resources, such as attention or working memory capacity (Babcock \& Salthouse, 1990; Jenkins, Myerson, Hale, \& Fry, 1999), implies that older adults are less able to carry out resource-demanding operations than younger adults. External factors include the amount of environmental support that is provided during the performance of the task. Environmental support is a broad notion that includes the amount of guidance in encoding information, the availability of relevant prior knowledge that might facilitate rich encoding of information, and the presence of external cues during retrieval. Impaired performance in older adults is most likely to occur when a task is cognitively challenging and when the environment provides no or few retrieval cues. An example of this is a free-recall task. On the other hand, strong environmental support in the form of familiar tasks and cues for retrieval can compensate for the age-related reduction in processing resources (Zacks et al., 2000). 


\section{DETERMINANTS OF COGNITIVE AGING}

A major challenge in cognitive gerontology today is the identification of biological and psychosocial factors that are related to cognitive change across adulthood (Jolles, Houx, Van Boxtel, \& Ponds, 1995). Factors ranging from physical health variables, such as hypertension and sensory functioning, to psychosocial variables, such as emotional support, have been associated with cognitive functioning and have been shown to change in older people (e.g., Seeman, Lusignolo, Albert, \& Berkman, 2001; Valentijn et al., 2005; Van Boxtel et al., 1997). In a review of 34 longitudinal studies that discuss factors associated with cognitive change, it was concluded that education, hypertension, objective health status, cardiovascular disease, and certain apolipoprotein E alleles are the factors most consistently relate to cognitive change across adulthood (Anstey \& Christensen, 2000). Recently, the possibility of interactions between determinants of cognitive aging has gained attention (Seeman et al., 2005). The ability to develop more effective strategies to prevent or slow age-related cognitive decline is dependent on an understanding of the multiple and likely interactive factors that have an impact on patterns of cognitive aging. Most research on cognitive aging has been done in older individuals. Relatively limited attention has been paid to persons younger than 65 years.

The Maastricht Aging Study (MAAS), a population-based longitudinal study on the determinants of cognitive aging, enables the investigation of determinants over the full adult age range. Because of its multidisciplinary character, many biological, social, and psychological factors associated with cognition and age-related cognitive decline have been identified and studied, including sensory functioning (e.g., Valentijn et al., 2005), vascular health (Van Boxtel et al., 1997), lifestyle (Bosma et al., 2002), and psychological functioning (Mol, van Boxtel, Willems, \& Jolles, 2006). In the following section, one of the most powerful determinants of cognitive functioning and agerelated cognitive change, namely level of educational attainment, will be discussed in more detail.

\section{Education}

Education has proven to be the most consistent non-biological correlate of both cognitive functioning (e.g., Van der Elst, Van Boxtel, Van Breukelen, \& Jolles, 2005, 2006a, 2006b) and age-related change in cognitive abilities (Anstey \& Christensen, 2000). Moreover, educational attainment has been associated with cognitive change not only in old age, but also throughout adulthood (Farmer, Kittner, Rae, Bartko, \& Regier, 1995; Lyketsos, Chen, \& Anthony, 1999). There are several arguments to support the notion that a high level of education serves as a protective factor for agerelated cognitive change. Firstly, continuous mental stimulation associated with a high level of education may have a positive effect on neuronal growth and the complexity of neural networks (Coffey, Saxton, Ratcliff, Bryan, \& Lucke, 1999). Secondly, highly educated persons are more likely to have an active and healthy lifestyle (e.g., in terms of nutrition and hygiene) that is associated with a lower risk of cognitive dysfunction (Gold et al., 1995). Thirdly, educational experience may provide reserve capacity in the form of a more elaborate set of basic skills or cognitive strategies (Stern, 2002). 
Previous studies examining the effects of education on longitudinal cognitive change have focused mainly on global measures of cognitive functioning in persons older than 65 years. There were only two studies that assessed a sample with a minimum age of 18 years (Farmer et al., 1995; Lyketsos et al., 1999). These studies used only the Mini-Mental State Examination (Folstein, Folstein, \& McHugh, 1975). As a result, little information about specific cognitive processes throughout adulthood could be derived. There have been a few cross-sectional studies that explore the effects of education on age-related differences in a broad age range (Ardila, Ostrosky-Solis, Rosselli, \& Gomez, 2000; Capitani, Barbarotto, \& Laiacona, 1996; Heaton, Grant, \& Matthews, 1986). The general picture that emerges from these studies is that a high educational level does indeed have an attenuating effect, although not on all cognitive measures. The specific cognitive domains that are particularly sensitive to the protective effects of a high level of education are, at this point in time, still inconclusive. Lyketsos and colleagues (1999) found that having more than eight years of formal education was associated with less decline on the Mini-Mental State Examination (MMSE). However, beyond nine years, additional education was not associated with a further reduction in decline (Lyketsos et al., 1999). This suggests that education of a relatively short duration in a critical period of life is already protective and that only a very low level of education may be a risk factor for cognitive decline. However, nonlinear effects of education have rarely been examined in previous research. In conclusion, despite the evidence that education may very well moderate age-related change, it is not yet clear which cognitive processes are particularly sensitive to the protective effects of a high level of education or the disruptive effects of a low level of education in younger adulthood.

\section{OBJECTIVES OF THIS DISSERTATION}

The studies described in this dissertation have two main objectives. The first is to gain additional insight on the cognitive processes that are most affected by aging, notably in pre-senescence. Mechanisms and causes of age-related cognitive differences are investigated. A question that evolves from this general issue is: At what do age changes in cognitive performance emerge? The second aim is to investigate the extent to which individual characteristics influence age-related differences and longitudinal change. In particular, the present dissertation attempts to identify the cognitive processes that are influenced by education.

\section{OUTLINE OF THIS DISSERTATION}

Since age and most other individual characteristics, such as education, cannot be experimentally manipulated, only quasi-experiments are presented in this dissertation. In four studies, individuals from different age groups and educational levels were submitted to various task conditions within the domain of word processing and word learning (Chapters 3, 4, 5, and 6). In addition to task manipulations, standard neuro- 
psychological tests were used to investigate age-related cognitive differences in relation to education and sex (Chapter 2). Likewise, longitudinal cognitive change was investigated in relation to the interaction between education and health status (Chapter 7). The studies described in Chapters 2, 3, 4, and 7 were conducted within the framework of MAAS using data that were obtained in the period 1991-2000. The studies described in Chapters 5 and 6 were based on newly acquired data obtained in a large crosssectional study that was executed as part of the present dissertation research project.

Chapter 2 evaluates the influence of education and sex on age differences in performance using three information-processing tasks (Letter Digit Substitution Task, Stroop Color-Word Test, and Memory Scanning Task). This was examined in a large population-based sample that was divided into three educational levels (low, intermediate or high) and three age groups, namely young (24 to 37 years), young middle-aged (39 to 51 years), and old middle-aged (54 to 66 years).

Chapter 3 discusses the extent to which word-learning performance is affected by interstimulus interval. A longer interstimulus interval (i.e., study time) provides more opportunities for organization and strategy use. Higher educated and younger individuals may make better use of this opportunity than lower educated and older people. Individuals from four age groups, that is, young (24 to 37 years), young middle-aged (39 to 51 years), old middle-aged (54 to 66 years), and old (69 to 77 years), with low or high educational attainment were randomly assigned to one of three interstimulus interval conditions $(1,2$, or $3 \mathrm{~s})$.

Older individuals may be less able than younger individuals to inhibit irrelevant speech when learning new visual information. A higher level of education might attenuate this potentially greater negative effect of irrelevant speech. Chapter 4 describes two experiments in which the effects of irrelevant speech on word-learning performance were evaluated in a sample of persons with a high or low level of education from four age groups, namely young ( 24 to 37 years), young middle-aged (39 to 51 years), old middle-aged (54 to 66 years), and old (69 to 77 years). In the first experiment, individuals were randomly assigned to a condition in which irrelevant words were auditorily presented during a visually presented word-learning task or to a quiet condition. In the second experiment, the presence of irrelevant speech was combined with a short interstimulus interval in order to increase the difficulty of the word-learning task.

The study described in Chapter 5 examined the influence of the level of processing on reaction times. Three decision tasks were used to induce shallow perceptual, more elaborated phonological, and deep semantic processing of words. Because deeper processing involves more cognitive operations, it was hypothesized that differences in reaction time between younger ( 25 to 35 years) and middle-aged (50 to 60 years) individuals would increase with deeper processing. It was also hypothesized that this increase would be less pronounced in individuals with a higher education. In addition, the effects of age and education on the use of search strategies per level of processing were investigated.

Because deeper processing results in better maintenance of words in memory, deeper processed words were expected to require less retrieval effort than shallow processed words. Chapter 6 addresses whether deeper processing of words during encoding leads to a smaller increase in word-learning performance and a smaller decrease in retrieval effort in middle-aged adults ( 50 to 60 years) than in young adults (25 to 35 
years). Whether a higher level of education attenuates age-related differences in performance was also assessed.

The study described in Chapter 7 aimed to test the possibility of an interaction between education and health status with respect to cognitive functioning and change in performance over six years, as measured with tests across multiple domains of cognitive function. This was examined in both younger (24 to 47 years) and older individuals (49 to 76 years). We also investigated whether different dimensions of health status (i.e., physical, social, and psychological functioning) show similar joint effects with education and whether effects change with age.

Chapter 8 provides some concluding remarks in which the findings of this dissertation will be discussed on a more general level, particularly with respect to methodology and both the theoretical and practical implications of the presented studies. In addition, recommendations for future research are provided.

\section{REFERENCES}

Anstey, K., \& Christensen, H. (2000). Education, activity, health, blood pressure and apolipoprotein E as predictors of cognitive change in old age: a review. Gerontology, 46(3), 163-177.

Ardila, A., Ostrosky-Solis, F., Rosselli, M., \& Gomez, C. (2000). Age-related cognitive decline during normal aging: the complex effect of education. Archives of Clinical Neuropsychology, 15(6), 495-513.

Babcock, R. L., \& Salthouse, T. A. (1990). Effects of increased processing demands on age differences in working memory. Psychology and Aging, 5, 421-428.

Birren, J. E., \& Schaie, K. W. (Eds.). (2006). Handbook of the psychology of aging (6th ed.): Elsevier Academic Press.

Bosma, H., Van Boxtel, M. P., Ponds, R. W., Jelicic, M., Houx, P., Metsemakers, J., \& Jolles, J. (2002). Engaged lifestyle and cognitive function in middle and old-aged, non-demented persons: a reciprocal association? Zeitschrift für Gerontologie und Geriatrie, 35, 575-581.

Capitani, E., Barbarotto, R., \& Laiacona, M. (1996). Does education influence the age-related cognitive decline? A further inquiry. Developmental Neuropsychology, 12, 231-240.

Coffey, C. E., Saxton, J. A., Ratcliff, G., Bryan, R. N., \& Lucke, J. F. (1999). Relation of education to brain size in normal aging: implications for the reserve hypothesis. Neurology, 53(1), 189-196.

Earles, J. L., \& Salthouse, T. A. (1995). Interrelations of age, health, and speed. Journals of Gerontology B: Psychological Sciences and Social Sciences, 50, P33-P41.

Farmer, M. E., Kittner, S. J., Rae, D. S., Bartko, J. J., \& Regier, D. A. (1995). Education and change in cognitive function. The Epidemiologic Catchment Area Study. Annals of Epidemiology, 5(1), 1-7.

Folstein, M. F., Folstein, S. E., \& McHugh, P. R. (1975). Mini-mental state: A practical method for grading the cognitive state of patients for the clinician. Journal of Psychiatric Research, 12, 189-198.

Gold, D. P., Andres, D., Etezadi, J., Arbuckle, T., Schwartzman, A., \& Chaikelson, J. (1995). Structural equation model of intellectual change and continuity and predictors of intelligence in older men. Psychology and Aging, 10, 294-303.

Hasher, L., \& Zacks, R. (1988). Working memory, comprehension, and aging: a review and a new view. The Psychology of Learning and Motivation, 22, 193-225.

Heaton, R. K., Grant, I., \& Matthews, C. G. (1986). Differences in neuropsychological test performance associated with age, education, and sex. In I. Grant \& K. M. Adams (Eds.), Neuropsychological assessment of neuropsycbiatric disorders (pp. 100-120). New York: Oxford University Press.

Houx, P. J., \& Jolles, J. (1993). Age-related decline of psychomotor speed: effects of age, brain health, sex, and education. Perceptual and Motor Skills, 76(1), 195-211. 
Houx, P. J., Jolles, J., \& Vreeling, F. W. (1993). Stroop interference: aging effects assessed with the Stroop Color-Word Test. Expermental Aging Research, 19(3), 209-224.

Houx, P. J., Vreeling, F. W., \& Jolles, J. (1991). Rigorous health screening reduces age effect on memory scanning task. Brain and Cognition, 15(2), 246-260.

Jenkins, L., Myerson, J., Hale, S., \& Fry, A. F. (1999). Individual and developmental differences in working memory across the life span. Psychonomic Bulletin and Review, 6, 28-40.

Jolles, J. (1986). Cognitive, emotional and behavioral dysfunctions in aging and dementia. Progress in Brain Research, 70, 15-39.

Jolles, J., Houx, P., Van Boxtel, M. P., \& Ponds, R. W. (Eds.). (1995). Maastricht Aging Study: Determinants of cognitive aging. Maastricht: Neuropsych Publishers.

Lyketsos, C. G., Chen, L. S., \& Anthony, J. C. (1999). Cognitive decline in adulthood: an 11.5-year followup of the Baltimore Epidemiologic Catchment Area study. American Journal of Psychiatry, 156, 58-65.

McDowd, J. M., Oseas-Kreger, D. M., \& Filion, D. L. (1995). Inhibitory processes in cognition and aging. In F. N. Dempster \& C. J. Brainerd (Eds.), Interference and inbibition in cognition (pp. 363-400). San Diego, CA: Academic Press.

Mol, M. E., van Boxtel, M. P., Willems, D., \& Jolles, J. (2006). Do subjective memory complaints predict cognitive dysfunction over time? A six-year follow-up of the Maastricht Aging Study. International Journal of Geriatric Psychiatry, 21, 432-441.

Rabbitt, P. (1993). Does it all go together when it goes? The Nineteenth Bartlett Memorial Lecture. Quarterly Journal of Experimental Psychology A, 46, 385-434.

Salthouse, T. A. (1996a). General and specific speed mediation of adult age differences in memory. J Gerontol B Psychol Sci Soc Sci, 51(1), P30-42.

Salthouse, T. A. (1996b). The processing-speed theory of adult age differences in cognition. Psychological Review, 103, 403-428.

Salthouse, T. A. (2004). What and when of cognitive aging. Current Directions in Psychological Science, $13,140-$ 144.

Salthouse, T. A., \& Meinz, E. J. (1995). Aging, inhibition, working memory, and speed. Journals of Gerontology B: Psychological Sciences and Social Sciences, 50(6), P297-306.

Schooler, C. (1999). The workplace environment: Measurement, psychological effects, and basic issues. In S. L. Friedman \& T. D. Wachs (Eds.), Measuring environment across the lifespan (pp. 229-246). Washington, DC: American Psychological Society.

Seeman, T. E., Huang, M. H., Bretsky, P., Crimmins, E., Launer, L., \& Guralnik, J. M. (2005). Education and APOE-e4 in longitudinal cognitive decline: MacArthur Studies of Successful Aging. Journal of Gerontology B: Psychological Sciences and Social Sciences, 60, P74-83.

Seeman, T. E., Lusignolo, T. M., Albert, M., \& Berkman, L. (2001). Social relationships, social support, and patterns of cognitive aging in healthy, high-functioning older adults: MacArthur studies of successful aging. Health Psychology, 20, 243-255.

Stern, Y. (2002). What is cognitive reserve? Theory and research application of the reserve concept. Journal of the International Neuropsychological Society, 8, 448-460.

Valentijn, S. A., van Boxtel, M. P., van Hooren, S. A., Bosma, H., Beckers, H. J., Ponds, R. W., \& Jolles, J. (2005). Change in sensory functioning predicts change in cognitive functioning: results from a 6year follow-up in the maastricht aging study. Journal of the American Geriatric Society, 53, 374-380.

Van Boxtel, M. P., Gaillard, C., Houx, P. J., Buntinx, F., de Leeuw, P. W., \& Jolles, J. (1997). Can the blood pressure predict cognitive task performance in a healthy population sample? Journal of Hypertension, 15, 1069-1076.

Van der Elst, W., Van Boxtel, M. P., Van Breukelen, G. J., \& Jolles, J. (2005). Rey's verbal learning test: normative data for 1855 healthy participants aged 24-81 years and the influence of age, sex, education, and mode of presentation. Journal of the International Neuropsychological Society, 11, 290-302.

Van der Elst, W., Van Boxtel, M. P., Van Breukelen, G. J., \& Jolles, J. (2006a). Normative data for the Animal, Profession and Letter M Naming verbal fluency tests for Dutch speaking participants and the effects of age, education, and sex. Journal of the International Neuropsychological Society, 12, 80-89. 
Van der Elst, W., Van Boxtel, M. P., Van Breukelen, G. J., \& Jolles, J. (2006b). The stroop color-word test: influence of age, sex, and education; and normative data for a large sample across the adult age range. Assessment, 13, 62-79.

Zacks, R., Hasher, L., \& Li, K. Z. (2000). Human Memory. In F. I. Craik \& T. A. Salthouse (Eds.), The handbook of aging and cognition (2nd ed., pp. 293-417). Mahwah, NJ: Lawrence Erlbaum Associates. 


\title{
CHAPTER 2
}

\section{Education and sex influence age differences in information processing}

\author{
Willemien A. Meijer, Martin P. J. van Boxtel \& Jelle Jolles
}

Submitted for publication

\begin{abstract}
The aim of this study was to investigate whether the age-extrinsic factors 'education' and 'sex' modify the well-documented effects of age on information processing speed. The interacting effects of age (three age groups), educational attainment (low, intermediate or high), and sex were tested on the information processing speed of 1469 healthy individuals ranging in age from 24 to 67 years. Performance on the Letter Digit Substitution Task (LDST), Stroop Color-Word Test (SCWT) and Memory Scanning Task (MST) was negatively affected by higher age, lower educational level and male sex. A high educational level reduced age differences on the LDST. Furthermore, women demonstrate larger age differences than men on the LDST and the MST. However, there were no interactions on SCWT performance. The overall findings suggest that the effects of education and sex on age-related differences in information processing are substantial in the pre-senescence.
\end{abstract}


It has been amply documented that the speed and efficiency of information processing declines with advancing age. Age-associated impairments have consistently been found in tasks that probe speed of information processing (Earles \& Salthouse, 1995; Houx, Jolles, \& Vreeling, 1993; Houx, Vreeling, \& Jolles, 1991a; Salthouse, 1994, 1996). In addition, there is evidence that different aspects of complex information processing are particularly vulnerable to aging (Babcock \& Salthouse, 1990). More specifically, poorer performance on tests of executive control (Moscovitch \& Winocur, 1995) and inhibition of irrelevant information have been associated with increasing age (Hasher, Stoltzfus, Zacks, \& Rypma, 1991; McDowd, 1997).

In most studies on age-related cognitive differences, comparisons have been made between relatively 'young' adults (usually in their 20s), and 'older' people (typically older than 60 years). Only a limited number of studies have investigated agerelated cognitive changes in the pre-senescence, more specifically middle age, i.e. the age range between 30 and 65 years. Although this age range is often disregarded, it may be of particular interest because the first manifestations of age-related changes in executive functioning and general speed can be observed from as early as age 30 (Houx \& Jolles, 1993; Houx et al., 1993; Houx et al., 1991a; Rabbitt, 1993). These early changes may reflect age-related structural changes in the prefrontal cortex, which have been first detected around the age of 35 years (Haug, 1985; Tisserand et al., 2002). Another reason why middle age might be of particular relevance for cognitive aging research is related to the variability in performance that appears to exist in this period (Willis \& Schaie, 2005). There has been support for the hypothesis that so-called 'ageextrinsic factors', such as education and sex, play a role in causing this variability (e.g., Van der Elst, Van Boxtel, Van Breukelen, \& Jolles, 2005, 2006a, 2006b; Van der Elst, van Boxtel, Van Breukelen, \& Jolles, in press; Van der Elst, Van Boxtel, Van Breukelen, \& Jolles, in press). Accordingly, the factors 'education' and 'sex' should be regarded in any study that evaluates cognitive performance in middle-aged adults. Up till now, only limited research effort has been given to this issue. It is the aim of the present study to evaluate cognitive performance and the effects of education and sex over the period of young adulthood to old middle age.

With respect to earlier research into cognitive functioning and the modifying effects of education, there are strong indications that a high educational level attenuates age-related cognitive decline in older persons (Bosma, Van Boxtel, Ponds, Houx, \& Jolles, 2003; Farmer, Kittner, Rae, Bartko, \& Regier, 1995). Three large-scale studies examining the effects of education on age-related cognitive differences in a broad age range are worth mentioning in this context. Capitani, Barbarotto, \&Laiacona (1996) studied 307 adults aged between 40 and 85 years. They found that age-related differences on tasks of visual attention and verbal memory were attenuated in higher educated individuals, but not on tasks of verbal fluency, spatial memory and non-verbal intelligence. Similar results were found in an earlier study by Heaton, Grant \& Matthews (1986) on 553 individuals aged 15 through 81 years: the performance decrement with age was smaller for higher educated people for two WAIS subtests (Picture Arrangement and Block design) but no effects were found for the other subtests. Also the third study on 806 healthy people aged 16 through 85 (Ardila, Ostrosky-Solis, Rosselli, \& Gomez, 2000) was consistent with the notion that higher educated subjects are characterized by less pronounced cognitive deterioration with age. A short neuropsychological battery was used in this study and effects were found on word recall (but 
not on word recognition), motor performance, verbal fluency and digit span backwards. The general picture that emerges from these three studies is that the effect of education on age-related decrements in cognitive performance is indeed present, albeit not on all cognitive measures. These equivocal results may be due to the assessment of multiple cognitive domains. Conducting a more extensive assessment of a particular cognitive domain may yield more reliable results with respect to the attenuating effects of education.

With respect to other age-extrinsic factors that might modify the effects of age, especially the factor 'sex' is noteworthy. Differential effects of sex on cognitive performance have been well documented (Spreen \& Strauss, 1998). Men tend to perform better on tests that involve manipulation of spatial relationships and on tests of simple motor speed, whereas women show advantages on tests of verbal abilities (Grant \& Adams, 1996). However, few studies have examined the effect of sex on age-related differences in cognitive performance. Available studies primarily investigated age by sex interactions relating to verbal memory performance or spatial ability tasks. For example, Kramer, Yaffe, \& Delis (2003) found that verbal memory declined with age in younger men but not in younger women (16-47 years), whereas both older men and older women (55-89 years) showed age-related decline. Herlitz, Nilsson, \& Backman (1997) found no age by sex interactions on episodic and semantic memory tests. Finally, a meta-analysis by Meinz and Salthouse (1998) based on aggregated raw data from 25 studies demonstrated that the only significant interactions between sex and age were on measures of speed and reasoning and in the direction of smaller agerelated differences for men than for women. These results indicate that a more thorough investigation of the interrelations among age, sex and information processing speed is warranted.

An increase in our insight into the sources of variability in cognitive performance in middle age could be of importance for both theoretical and practical reasons. When education appears able to moderate the effects of age on performance, support would be obtained for the 'cognitive reserve hypothesis'. Educational experience may provide reserve capacity in the form of a more elaborate set of basic skills or cognitive strategies (Stern, 2002). Cognitive reserve is thought to be due to more efficient information processing in the brain, potentially through an increase in the efficiency of neurotransmission and the complexity of neuronal networks (e.g. Coffey, Saxton, Ratcliff, Bryan, \& Lucke, 1999; Meguro et al., 2001). Apart from the theoretical issues related to education as a possible protective factor to increase cognitive reserve, practical relevance lies in the possibility to increase cognitive performance by educational interventions. These are of profound importance in relation to the 'Lifelong Learning' concept that is advocated through recent years (e.g., Collins, 2004; OECD, 2002). With respect to sex, finding a modifying effect on age-related differences would strengthen the notion that this factor is essential to take into consideration when evaluating effects of age on cognitive performance.

In conclusion, strong evidence exists that the age-extrinsic factors 'education' and 'sex' have a substantial influence on cognitive performance in several domains (Van der Elst et al., 2005, 2006a, 2006b), but clear information is lacking with regard to age-related differences in the pre-senescence. Besides, more knowledge is needed with respect to the effects of education and sex on age differences within a cognitive domain. This is why the present study investigated whether age differences in informa- 
tion processing speed are dependent on educational level or sex. We restricted the study to individuals younger than 67 years of age. The age range between 24 and 67 years was subdivided into three age groups to examine in which age interval interactions with sex and education are manifested and when age differences become more pronounced. We focused on various aspects of general speed information processing because these functions appear to be crucial to cognitive efficiency (Roberts, Robbins, $\&$ Weiskrantz, 1998) and demonstrate the earliest age effects (West, 1996). The present study extends prior research in two important ways. First, we conduct a more extensive assessment of one particular cognitive domain, and second, we examine adults in the pre-senescence.

\section{Methods}

\section{Participants}

Data were derived from the Maastricht Aging Study (MAAS), a large-scale prospective study of biological, psychological and socio-demographic determinants of cognitive aging (Jolles, Houx, Van Boxtel, \& Ponds, 1995; Jolles, van Boxtel, Ponds, Metsemakers, \& Houx, 1998). Participants in this study were drawn from a register of general practices (Metsemakers, Hoppener, Knottnerus, Kocken, \& Limonard, 1992). MAAS involved 1823 participants aged between 24 and 81 years, who were stratified for age (12 classes, ranging from $25 \pm 1,30 \pm 1,35 \pm 1, \ldots, 80 \pm 1$ years), sex, and two levels of occupational achievement. Participants were without documented medical conditions known to interfere with normal cognitive functioning (e.g. dementia, mental retardation and cerebrovascular pathology). For the present study, cross-sectional data obtained at baseline from nine age groups involving 1469 healthy individuals between 24 and 67 years of age were used.

\section{Independent variables}

Age was used as a categorical variable. In the present study, the nine discrete age classes were reduced to three age groups: young (24-37), young middle-aged (39-52), and old middle-aged (54-67).

The level of education was assessed by classifying formal schooling according to a Dutch system (de Bie, 1987) which is comparable to the International Standard Classification of Education (UNESCO, 1976). Educational level was originally scored in eight ordinal categories, ranging from unfinished primary school to university education. For the present study, education was recoded into three levels: low, primary education and lower vocational education; intermediate, intermediate vocational education and general secondary education; and high, higher vocational education, higher general secondary education and university (Bosma et al., 2003). The low level of education in the present study was equivalent to a maximum of 10 years of formal education. The intermediate level was equivalent to a minimum of 11 years and a maximum of 16 years. The high level of education was equivalent to a minimum of 14 years of education.

In addition, sex was included as an independent variable. 


\section{Dependent variables}

Tests were chosen that have proven to be reliable and that have shown robust age effects (Houx, Vreeling, \& Jolles, 1991b; Van der Elst et al., 2006b; Van der Elst et al., 2006c).

The Stroop Color-Word Test (SCWT) (Stroop, 1935) is a test of selective attention (Van der Elst et al., 2006). The first card contains color names printed in black ink, which have to be read aloud. The second card contains rectangular patches, which have to be named by color. The last card displays color names printed in incongruously colored ink. Participants are instructed to name the ink colour of the printed words. A measure of general information processing speed was calculated as the mean time needed to complete card 1 and 2 (Stroop 1/2). A measure for interference was calculated as the time taken to complete the third card minus the mean of the time taken to complete the first two cards (Stroop interference). The amount of extra time needed to complete the third card reflects the ability to inhibit irrelevant but salient verbal information.

The Letter-Digit Substitution Test (LDST) is a modified version of the SymbolDigits-Modalities Test (Smith, 1968). This test measures the efficiency of processing in working memory (Van der Elst, 2006c). Individuals were instructed to copy numbers in cells that were indexed by a letter. The letter refers to nine letter / number combinations at the top of the form. In the present study, the dependent variable (LDST) was the number of correctly copied numbers within 60 seconds.

The Memory Scanning Test (MST) measures the speed of memory scanning processes (Brand \& Jolles, 1987; Houx et al., 1991b). Two subtasks were used in the present study. The participants were instructed to memorize 1 letter in the first subtask and 2 letters in the second subtask. The letters had to be marked with a pencil as quickly as possible and without making errors on a sheet of A4 paper containing a matrix of $12 \times 12$ letters in a random pattern. Each subtask was presented on a separate sheet. Two dependent variables were used in the present study. One was a measure of the speed of perceptual and motor responses represented by the time taken to complete the first subtask (MST intercept). The other was calculated as the completion time of the second subtask minus the completion time of the first subtask (MST slope) as a measure of the memory scanning process (Sternberg, 1975).

\section{Data analysis}

Differences in educational level and sex between three age groups were analyzed using Chi-square tests. A 3x3 $x 2$ analysis of variance was carried out on each cognitive variable in order to assess main effects of age (three groups), education (three levels) and sex and all possible interactions between these factors. Main effects of age and education were analyzed by post-hoc comparisons with Bonferroni correction, in which the alpha level was adjusted by dividing the standard value .05 by the number of comparisons. Three post-hoc comparisons were conducted between age groups (young vs young middle-aged, young vs old middle-aged, and young middle-aged vs old middle-aged) and three comparisons were conducted between levels of education (low versus intermediate, low versus high, intermediate versus high). 


\section{RESULTS}

The demographic characteristics of the study population are shown in Table 1. As expected because of the stratification procedure, the age groups were comparable with respect to sex. With respect to education it was found that the older persons had less education than the younger persons, $\chi^{2}(4)=151.7, p<.01$.

With respect to the MST, data of individuals with more than two errors in the first subtask or more than four errors in the second subtask were excluded from the analysis. This criterion has been proposed to minimize a possible correlation between performance time and number of errors (Brand \& Jolles, 1987). Data of 20 individuals $(4.2 \%)$ in the youngest age group, 54 individuals $(11.2 \%)$ in the intermediate age group, and 89 individuals $(18.5 \%)$ in the oldest age group were not used.

Table 1. Demographic characteristics of the study population.

\begin{tabular}{llllll}
\hline & & Men & Women \\
\hline Age group & Level of education & $\mathrm{N}$ & Mean age (SD) & $\mathrm{N}$ & Mean age (SD) \\
\hline $24-37$ & low & 40 & $32.4(4.3)$ & 37 & $30.3(4.3)$ \\
& intermediate & 109 & $29.9(4.0)$ & 133 & $30.9(4.3)$ \\
& high & 95 & $30.6(4.4)$ & 70 & $29.8(4.2)$ \\
& low & 65 & $45.1(3.9)$ & 82 & $46.6(3.9)$ \\
& intermediate & 101 & $46.4(4.0)$ & 120 & $44.5(4.1)$ \\
& high & 76 & $44.7(4.0)$ & 50 & $45.9(4.0)$ \\
& low & 104 & $60.7(4.2)$ & 148 & $60.6(4.4)$. \\
& intermediate & 97 & $60.8(4.2)$ & 74 & $60.4(4.1)$ \\
& high & 48 & $59.9(4.4)$ & 19 & $60.0(3.9)$ \\
\hline
\end{tabular}



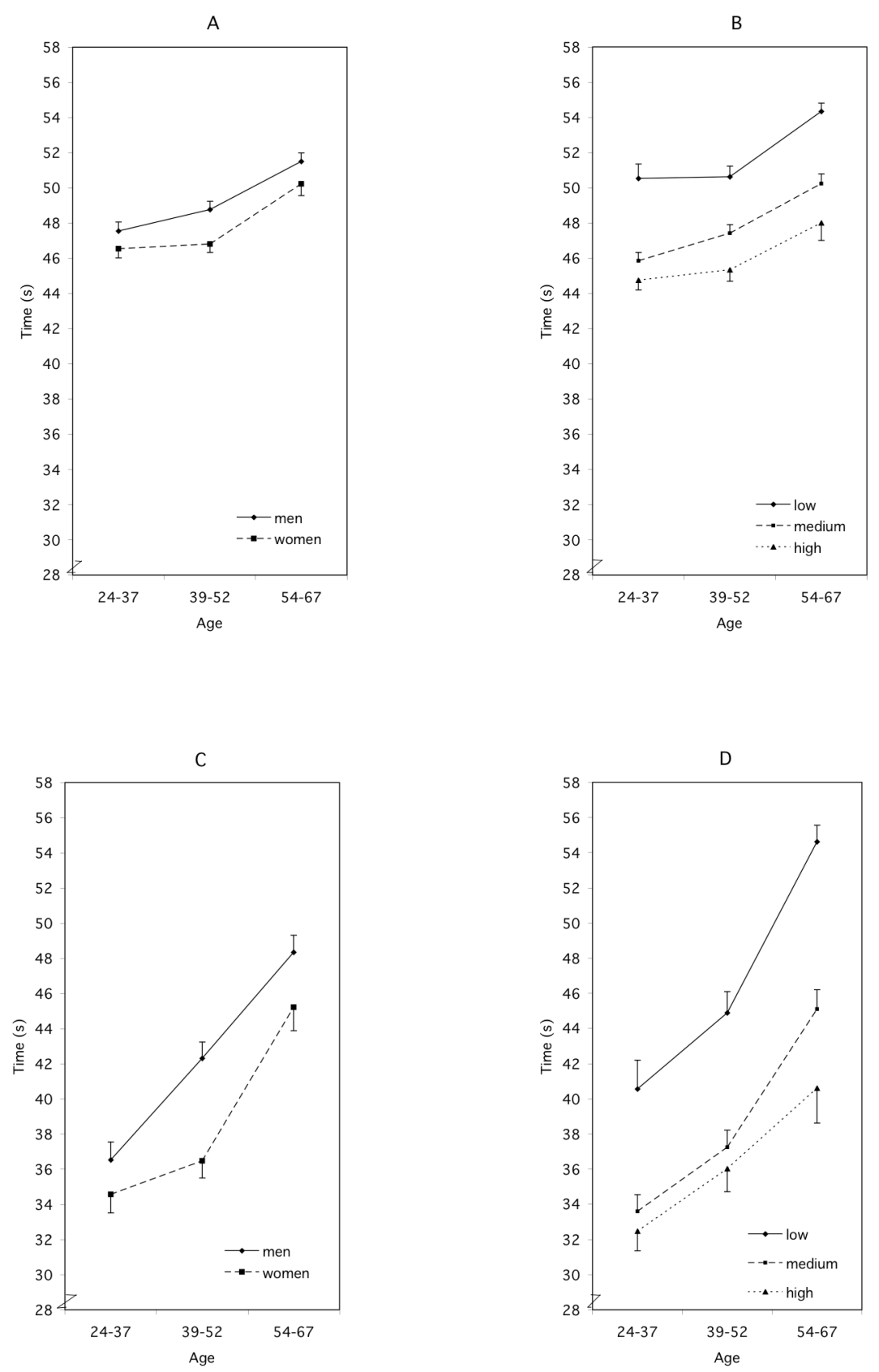

Figure 1. Mean performance on Stroop 1/2 and Stroop interference as a function of age and sex (A and C) and age and educational level (B and D). Error bars represent standard errors of the mean. 

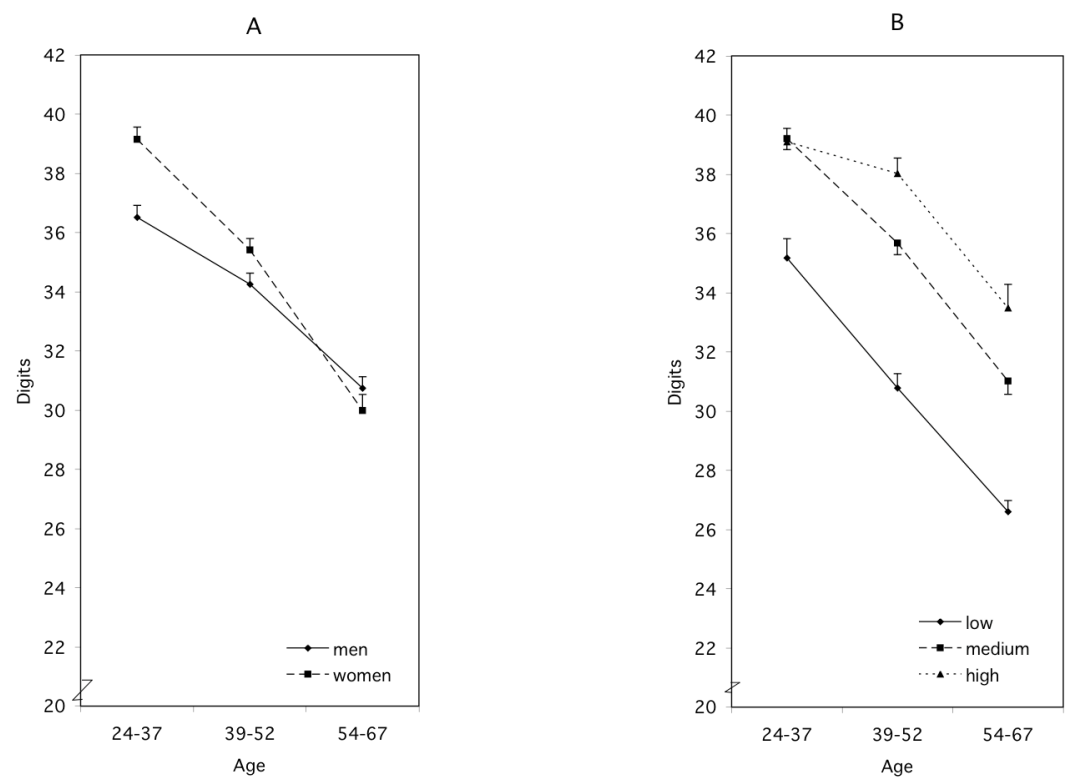

Figure 2. Mean performance on LDST as a function of age and sex (A) and age and educational level (B). Error bars represent standard errors of the mean.

In Figures 1, 2 and 3, the mean performances on respectively the SCWT, LDST and MST are presented per age group, educational level and sex. Table 2 presents main effects and interaction effects of age, education, and sex. Main effects of age were found on all variables, indicating that the younger persons outperformed the older persons. Post-hoc comparisons (Table 3) showed that all pairwise differences between the three age groups were statistically significant, except for MST slope: the two youngest age groups (24-37 and 39-52 years) did not differ significantly in respect to this measure. Regarding the other cognitive variables, absolute mean differences were also larger between the two oldest age groups (39-52 and 54-67) than between the two youngest age groups, suggesting that effects of age were stronger at older ages.

Main effects of education were also found on all variables, indicating that higher educated persons performed better than persons with a low educational level. Post-hoc comparisons (Table 3) showed significant differences between the intermediate and high levels of education on Stroop 1/2, LDST and MST intercept. No differences were found between these levels on Stroop interference and MST slope. For all cognitive variables, absolute mean differences were larger between the low and intermediate educational level than between the intermediate and high level of education. A statistically significant interaction between education and age was found for LDST. There was no difference between individuals with an intermediate or high level of education in the youngest age group, but in the two other age groups the highly educated individuals outperformed those with an intermediate level of education.

Sex appeared to have a significant main effect on Stroop 1/2, Stroop interference, MST slope and LDST. This indicates that women outperformed men on all variables except on MST intercept. Statistically significant interactions between age and sex 
were found for LDST and MST intercept. For LDST, women outperformed men in the youngest age group, but in the middle-age group this advantage was reduced and even reversed into a disadvantage in the oldest age group. As for MST intercept, the advantage of women in the youngest group was not present in the middle-aged groups. No education by sex or age by education by sex interactions were found.

A

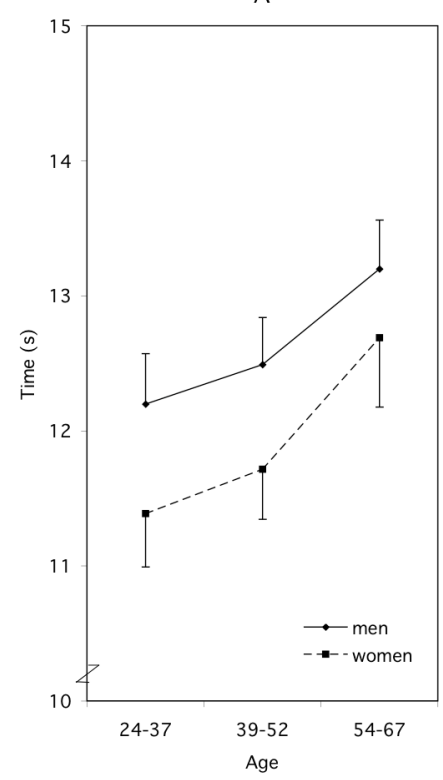

C

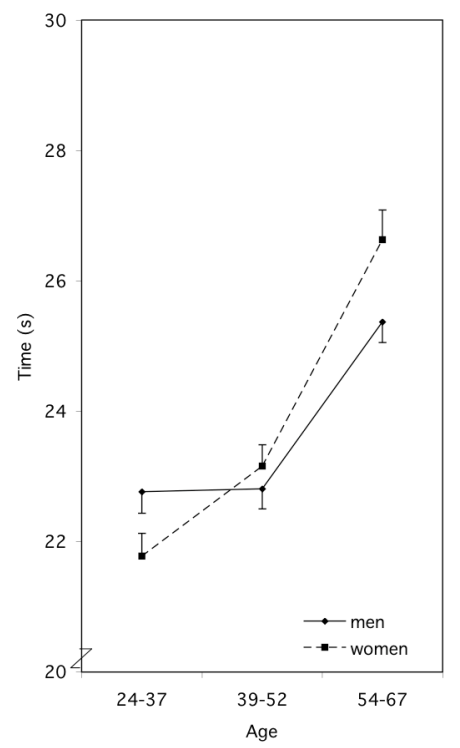

B

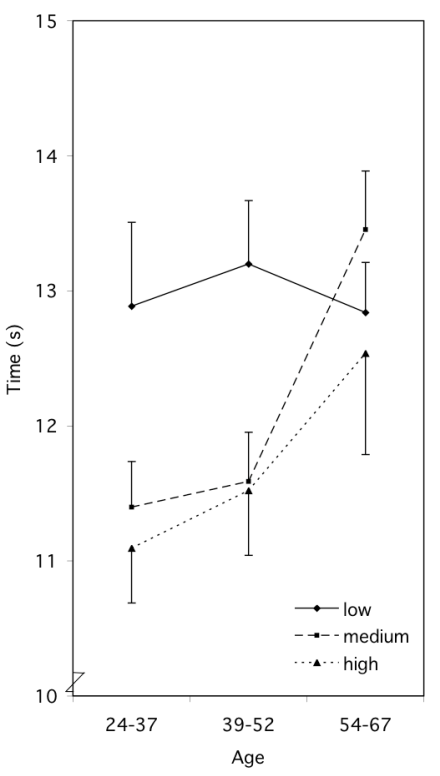

D

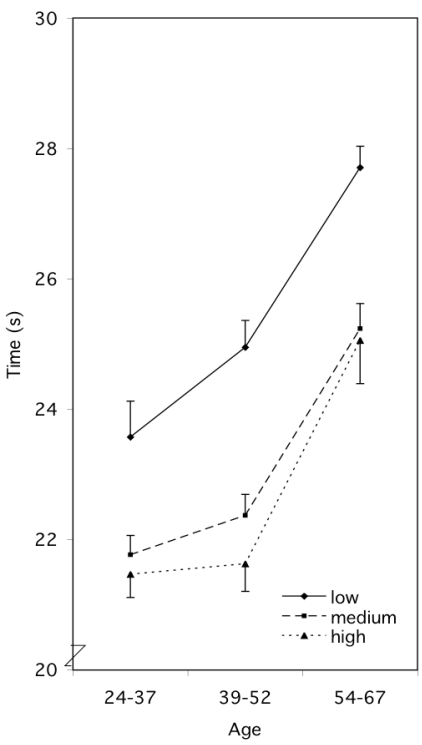

Figure 3. Mean performance on MST slope and MST intercept as a function of age and sex (A and C) and age and educational level (B and D). Error bars represent standard errors of the mean. 
Table 2. F-values (df) and partial $\eta^{2}$ of main effects and interactions with age.

\begin{tabular}{|c|c|c|c|c|c|c|c|c|c|c|}
\hline & A & $\eta^{2}$ & $\mathrm{E}$ & $\eta^{2}$ & $\mathrm{~S}$ & $\eta^{2}$ & $A \times E$ & $\eta^{2}$ & $\mathrm{~A} \times \mathrm{S}$ & $\eta^{2}$ \\
\hline Stroop $1 / 2$ & $\begin{array}{c}25.8^{* *} \\
(2,1415)\end{array}$ & 0.03 & $\begin{array}{c}57.9 * * \\
(2,1415)\end{array}$ & 0.07 & $\begin{array}{c}10.4^{* *} \\
(1,1415)\end{array}$ & 0.006 & $\begin{array}{c}0.57 \\
(4,1415)\end{array}$ & & $\begin{array}{c}0.40 \\
(2,1415)\end{array}$ & \\
\hline $\begin{array}{l}\text { Stroop } \\
\text { Interference }\end{array}$ & $\begin{array}{c}52.3^{* *} \\
(2,1415)\end{array}$ & 0.06 & $\begin{array}{c}50.7^{* *} \\
(2,1415)\end{array}$ & 0.06 & $\begin{array}{l}17.96^{* *} \\
(1,1415)\end{array}$ & 0.01 & $\begin{array}{c}1.13 \\
(4,1415)\end{array}$ & & $\begin{array}{c}2.04 \\
(2,1415)\end{array}$ & \\
\hline LDST & $\begin{array}{c}144.3^{* *} \\
(2,1430)\end{array}$ & 0.12 & $\begin{array}{l}106.6^{* *} \\
(2,1430)\end{array}$ & 0.09 & $\begin{array}{c}9.11^{* *} \\
(1,1430)\end{array}$ & 0.004 & $\begin{array}{c}3.54 * * \\
(4,1430)\end{array}$ & 0.006 & $\begin{array}{c}7.15^{* *} \\
(2,1430)\end{array}$ & 0.006 \\
\hline MST slope & $\begin{array}{c}4.12^{*} \\
(2,1253)\end{array}$ & 0.006 & $\begin{array}{c}4.67^{* *} \\
(2,1253)\end{array}$ & 0.007 & $\begin{array}{c}4.83^{*} \\
(1,1253)\end{array}$ & 0.004 & $\begin{array}{c}2.14 \\
(4,1253)\end{array}$ & & $\begin{array}{c}0.062 \\
(2,1253)\end{array}$ & \\
\hline $\begin{array}{l}\text { MST } \\
\text { intercept }\end{array}$ & $\begin{array}{c}56.22^{* *} \\
(2,1253)\end{array}$ & 0.07 & $\begin{array}{l}33.53 * * \\
(2,1253)\end{array}$ & 0.04 & $\begin{array}{c}0.59 \\
(1,1253)\end{array}$ & & $\begin{array}{c}0.56 \\
(4,1253)\end{array}$ & & $\begin{array}{c}4.93^{* *} \\
(2,1253)\end{array}$ & 0.006 \\
\hline
\end{tabular}

Notes: $*=\mathrm{p}<.05 ; * *=\mathrm{p}<.01$.

$\mathrm{A}=$ Age, $\mathrm{S}=$ sex, and $\mathrm{E}=$ education.

Table 3. Post-hoc contrasts in mean differences (SE) between age groups and educational levels.

\begin{tabular}{llccc}
\hline & & $1-2^{1}$ & $1-3^{1}$ & $2-3^{1}$ \\
\hline Stroop $1 / 2$ & Age & $-1.7^{* *}(0.5)$ & $-5.8^{* *}(0.5)$ & $-4.2^{* *}(0.5)$ \\
& Education & $4.9^{* *}(0.4)$ & $6.8^{* *}(0.5)$ & $1.9^{* *}(0.5)$ \\
Stroop interference & Age & $-4.8^{* *}(0.9)$ & $-15.1^{* *}(0.9)$ & $-10.4^{* *}(0.9)$ \\
& Education & $11.1^{* *}(0.9)$ & $13.4^{* *}(1.0)$ & $2.3(1.0)$ \\
LDST & Age & $3.7^{* *}(0.4)$ & $9.4^{* *}(0.4)$ & $5.7^{* *}(0.4)$ \\
& Education & $-6.5^{* *}(0.4)$ & $-8.4^{* *}(0.4)$ & $-1.9^{* *}(0.4)$ \\
MST slope & Age & $-0.4(0.3)$ & $-1.6^{* *}(0.4)$ & $-1.1^{* *}(0.4)$ \\
& Education & $1.0(0.3)$ & $1.4^{* *}(0.4)$ & $0.4(0.4)$ \\
MST intercept & Age & $-0.9^{* *}(0.3)$ & $-4.4^{* *}(0.3)$ & $-3.5^{* *}(0.3)$ \\
\hline Education & $3.3^{* *}(0.3)$ & $4.1^{* *}(0.3)$ & $0.8(0.3)$
\end{tabular}

Notes: $* *=\mathrm{p}<.01$

${ }^{1}$ : for age group: $1=24-37,2=39-52,3=54-67$, and for level of education: $1=$ low, $2=$ intermediate, 3

$=$ high 


\section{DisCUSSION}

The study reported here evaluated the influence of age, education, and sex and their interactions on the performance of information processing tasks in a large population of 1469 healthy subjects aged from 24 to 67. Performance was negatively affected by older age, a lower educational level and male sex. A high educational level reduces age differences on Letter Digit Substitution. Furthermore, women perform better than men on Letter Digit Substitution and the Memory Scanning Task at a younger age, but this sex difference was absent in persons older than 54 years.

The age-related differences found in this study are consistent with previous reports of age effects on the speed of information processing (Joy, Fein, Kaplan, \& Freedman, 2000; Kail \& Salthouse, 1994), but extend earlier findings in that we found differences already between a young and young middle-aged group. The mean differences in performance between the middle-aged and old groups were substantially larger than those between the young and middle-aged groups suggesting that agerelated differences become more pronounced with age. Age had a differential effect on the measures of information processing speed. With respect to SCWT, the variance explained by age was larger for the Stroop interference task than for the Stroop 1/2 task. This suggests that resistance to interference may be more sensitive to age effects than general information processing speed, which is consistent with earlier studies that showed that inhibitory functions in particular are compromised by aging (Connelly, Hasher, \& Zacks, 1991; Hasher \& Zacks, 1988; Van Hooren et al., 2005). With respect to differential effects of age on the two measures of the MST, it was found that the variance in MST slope explained by age was relatively small compared with that in MST intercept. Strayer, Wickens, \& Braune (1987) also found a substantial slowing in non-scanning stages, i.e., perceptual encoding, response criterion adjustment and response execution with age (20 to 65 ) and a less pronounced slowing in memory scanning speed. Thus basic speed seems to be more vulnerable to negative effects of age than memory scanning speed.

Education had a profound influence on all cognitive scores. It is noteworthy that the mean differences in performance between the groups with a low or an intermediate level of education were substantially larger than those between the groups with an intermediate or a high level of education. Assuming equal distances between the education categories used, this suggests that particularly being member of the low education' category might be a risk factor or vulnerability factor. This substantiates the notion put forward by Ardila (1998) that education does not have a linear effect on neuropsychological test performance, i.e. differences between educational levels are larger among the lower educational levels than among the higher education levels. Van Hooren et al. (2005) found that participants in the Maastricht Aging Study older than 65 and with a low level of education performed worse on several cognitive tests than persons with a middle or high level of education, whereas there was no difference between middle and high educational levels. This again suggests that a low educational level may be also a risk factor for poor cognitive performance, in this case in later adulthood.

Concerning the age by education interaction on LDST, no difference was found between the young and young middle-aged groups in the most highly educated group, 
whereas a difference was found in the least educated groups. This indicates that age differences that occur early in the course of aging are smaller among those with the highest level of education. This pattern was not found for the other cognitive variables, which indicates that the protective effect of education depends on the cognitive function tested. A possible explanation for this differential effect of education may be that education could provide the participant with a repertoire of cognitive strategies that can be used to compensate for the negative effects of age on cognitive processes (Stern, 2002). Because the responses generated in the LDST are supposed to draw upon multiple cognitive processes, including visual scanning, working memory, mental flexibility, sustained attention, and psychomotor speed (Lezak, 1995; Van Hoof, Jogems-Kosterman, Sabbe, Zitman, \& Hulstijn, 1998), compensatory cognitive strategies may be more readily recruited in the execution of the LDST than when performing on the SCWT and MST, which draw on a more narrow range of cognitive processes.

With respect to the effects of sex, it was found that women had an overall better performance than men regarding the cognitive measures used in the current study. The existing literature on sex differences in Stroop performance is equivocal, with some studies observing sex differences in favor of women (Golden, 1974; Martin \& Franzen, 1989) and others finding no difference (Houx et al., 1993; Trennery et al, 1989; Stroop, 1935; Swerdlow et al., 1995). With respect to previous studies concerning sex differences on the Symbol Digit Modalities Task, of which the LDST is an adaptation, it has been reported before that women outperform men (Polubinski \& Melamed, 1986; Yeudall, Fromm, Reddon \& Stefanyk, 1986). Concerning the MST, this is the first study we know of that addresses sex differences with regard to this particular task. The present study clearly demonstrated that women tend to outperform men in a large population-based sample younger than 67 years.

With respect to age $\mathrm{x}$ sex interactions, it was found that the initial advantage of women in the youngest age group disappeared in the middle and oldest age groups on the MST intercept and LDST. This is in accordance with the study by Van Hooren (in press) in which no effects of sex on information processing tasks were found in participants in the Maastricht Aging Study older than 65. These interactions may be associated with sex-linked hormonal changes. Experimental studies and prospective observational studies indicate that estrogen supports cognitive functioning in women (Carlson \& Sherwin, 1998, Portin et al., 1999; Sherwin, 1998, 1999). Estrogen levels drop dramatically in women after the menopause (Jack et al., 1998). This would explain why the initial advantage of women in the youngest age group disappeared at older ages on MST intercept and LDST. The absence of this interaction effect on the SCWT could be explained by the notion that LDST and MST intercept are supposed to draw more on working memory than the SCWT (Lezak, 1995) while estrogen particularly may enhance performance on working memory tasks (Keenan, Ezzat, Ginsburg, \& Moore, 2001).

In conclusion, the findings provide evidence that age-related differences in information processing occur already in young middle age, and become larger from middle age onward. Education and sex have a profound influence on measures of information processing speed and affect age-related cognitive differences. A high educational level has been identified as a protective factor in reducing age-related differences on LDST (efficiency of processing in working memory) until approximately 50 years of 
age. Furthermore, women perform better than men on LDST and MST intercept (speed of perceptual and motor responses) at a younger age, but this sex difference is absent in older age groups. In other words, age differences in performance on these measures are larger in women than in men. The overall findings suggest that the effects of education and sex on age-related cognitive deterioration in the pre-senescence are quite substantial.

\section{REFERENCES}

Ardila, A. (1998). A note of caution: normative neuropsychological test performance: effects of age, education, gender and ethnicity: a comment on Saykin et al. (1995). Applied Neuropsychology, 5(1), 51-53.

Ardila, A., Ostrosky-Solis, F., Rosselli, M., \& Gomez, C. (2000). Age-related cognitive decline during normal aging: the complex effect of education. Arcbives of Clinical Neuropsychology, 15(6), 495-513.

Babcock, R. L., \& Salthouse, T. A. (1990). Effects of increased processing demands on age differences in working memory. Psychology and Aging, 5, 421-428.

Bosma, H., Van Boxtel, M. P., Ponds, R. W. H. M., Houx, P., \& Jolles, J. (2003). Education and age-related cognitive decline: the contribution of mental workload. Educational Gerontology, 29, 1-9.

Brand, N., \& Jolles, J. (1987). Information processing in depression and anxiety. Psychological Medicine, 17(1), 145-153.

Capitani, E., Barbarotto, R., \& Laiacona, M. (1996). Does education influence the age-related cognitive decline? A further inquiry. Developmental Neuropsychology, 12, 231-240.

Collins, J. (2004). Education techniques for lifelong learning: principles of adult learning. Radiographics, 24(5), 1483-1489.

Connelly, S. L., Hasher, L., \& Zacks, R. T. (1991). Age and reading: the impact of distraction. Psychology and Aging, 6, 533-541.

de Bie, S. E. (1987). Standaardvragen 1987: Voorstellen voor uniformering van vraagstellingen naar achergrondkernmerken en interviews [Standard questions 1987: Proposal for uniformisation of questions regarding background variables and interviews]. (2nd ed.). Leiden, The Netherlands: Leiden University Press.

Earles, J. L., \& Salthouse, T. A. (1995). Interrelations of age, health, and speed. Journals of Gerontology B: Psychological Sciences and Social Sciences, 50(1), P33-P41.

Farmer, M. E., Kittner, S. J., Rae, D. S., Bartko, J. J., \& Regier, D. A. (1995). Education and change in cognitive function. The Epidemiologic Catchment Area Study. Annals of Epidemiology, 5(1), 1-7.

Grant, I., \& Adams, K. M. (Eds.). (1996). Neuropsychological assessment of neuropsycbiatric disorders (second ed.). New York: Oxford University Press.

Hasher, L., Stoltzfus, E. R., Zacks, R. T., \& Rypma, B. (1991). Age and inhibition. Journal of Experimental Psychology: Learning, Memory and Cognition, 17(1), 163-169.

Hasher, L., \& Zacks, R. (1988). Working memory, comprehension, and aging: a review and a new view. The Psychology of Learning and Motivation, 22, 193-225.

Haug, H. (1985). Are neurons of the human cerebral cortex really lost during aging? A morphometric examination. In W. Gispen, H. (Ed.), Senile dementia of the Alzheimer type (pp. 150-163). New York: Springer-Verlag.

Herlitz, A., Nilsson, L. G., \& Backman, L. (1997). Gender differences in episodic memory. Memory and Cognition., 25(6), 801-811.

Houx, P. J., \& Jolles, J. (1993). Age-related decline of psychomotor speed: effects of age, brain health, sex, and education. Perceptual and Motor Skills, 76(1), 195-211.

Houx, P. J., Jolles, J., \& Vreeling, F. W. (1993). Stroop interference: aging effects assessed with the Stroop Color-Word Test. Experimental Aging Research, 19(3), 209-224. 
Houx, P. J., Vreeling, F. W., \& Jolles, J. (1991a). Rigorous health screening reduces age effect on memory scanning task. Brain and Cognition, 15(2), 246-260.

Houx, P. J., Vreeling, F. W., \& Jolles, J. (1991b). Rigorous health screening reduces age effect on memory scanning task. Brain and cognition, 15, 246-260.

Jack, J. C. R., Petersen, R. C., Xu, Y., O'Brien, P. C., Smith, G. E., Ivnik, R. J., Tangalos, E. G., \& Kokmen, E. (1998). Rate of medial temporal lobe atrophy in typical aging and Alzheimer's disease. Neurology, 51, 993-999.

Jolles, J., Houx, P., Van Boxtel, M. P., \& Ponds, R. W. (Eds.). (1995). Maastricht Aging Study: Determinants of cognitive aging. Maastricht: Neuropsych Publishers.

Jolles, J., van Boxtel, M. P., Ponds, R. W., Metsemakers, J. F., \& Houx, P. J. (1998). [The Maastricht aging study (MAAS). The longitudinal perspective of cognitive aging]. Tijdscbrift voor Gerontologie en Geriatrie, 29(3), 120-129.

Joy, S., Fein, D., Kaplan, E., \& Freedman, M. (2000). Speed and memory in WAIS-R-NI Digit Symbol performance among healthy older adults. Journal of the International Neuropsychological Society, 6(7), 770780.

Kail, R., \& Salthouse, T. A. (1994). Processing speed as a mental capacity. Acta Psychologica (Amsterdam), 86(2-3), 199-225.

Keenan, P. A., Ezzat, W. H., Ginsburg, K., \& Moore, G. J. (2001). Prefrontal cortex as the site of estrogen's effect on cognition. Psychoneuroendocrinology, 26(6), 577-590.

Kramer, J. H., Yaffe, K., \& Delis, D. C. (2003). Age and gender interactions on verbal memory performance. Journal of the International Neuropsychological Society, 9(1), 97-102.

Lezak, M. D. (1995). Neuropsychological Assessment (3rd ed.). New York: Oxford University Press.

McDowd, J. M. (1997). Inhibition in attention and aging. Journals of Gerontology B: Psychological Sciences and Social Sciences, 52(6), P265-273.

Meinz, E. J., \& Salthouse, T. A. (1998). Is age kinder to females than to males? Psychonomic Bulletin and Review, 5, 56-70.

Metsemakers, J. F., Hoppener, P., Knottnerus, J. A., Kocken, R. J., \& Limonard, C. B. (1992). Computerized health information in The Netherlands: a registration network of family practices. British Journal of General Practice, 42(356), 102-106.

Moscovitch, M., \& Winocur, G. (1995). Frontal lobes, memory, and aging. Annals of the New York Academy of Sciences, 769, 119-150.

OECD. (2002). Understanding the brain: towards a new learning science. Paris: OECD.

Rabbitt, P. (1993). Does it all go together when it goes? The Nineteenth Bartlett Memorial Lecture. Q J Exp Psycbol A, 46(3), 385-434.

Roberts, A. C., Robbins, T. W., \& Weiskrantz, L. (Eds.). (1998). The prefrontal cortex: Executive and cognitive functions. New York: Oxford University Press.

Salthouse, T. A. (1994). Aging associations: influence of speed on adult age differences in associative learning. Journal of Experimental Psychology: Learning, Memory and Cognition, 20(6), 1486-1503.

Salthouse, T. A. (1996). The processing-speed theory of adult age differences in cognition. Psychological Review, 103(3), 403-428.

Smith, A. (1968). The Symbol Digit Modalities Test: a neuropsychologic test for economic screening of learning and other cerebral disorders. Learning Disorders, 3, 83-91.

Spreen, O., \& Strauss, E. (1998). A compendium of neuropsychological tests (2nd ed.): Oxford University Press.

Stern, Y. (2002). What is cognitive reserve? Theory and research application of the reserve concept. Journal of the International Neuropsychological Society, 8, 448-460.

Sternberg, S. (1975). Memory scanning: new findings and current controversies. Quarterly Journal of Experimental Psychology, 27, 1-32.

Strayer, D. L., Wickens, C. D., \& Braune, R. (1987). Adult age differences in the speed and capacity of information processing: 2. An electrophysiological approach. Psychology and Aging, 2(2), 99-110.

Stroop, J. R. (1935). Studies of interference in serial verbal reactions. Journal of Experimental Psychology, 18, 643-662. 
Tisserand, D., J., Pruessner, J. C., Sanz Arigita, E. J., Van Boxtel, M. P., Evans, A. C., Jolles, J., \& Uylings, H. B. M. (2002). Regional frontal cortical volumes decrease differentially in aging: an MRI study to compare volumetric approaches and voxel-based morphometry. NeuroImage, 17, 657-669.

UNESCO. (1976). International Standard Classification of Education (ISCED). Paris: UNESCO.

Van der Elst, W., Van Boxtel, M. P., Van Breukelen, G. J., \& Jolles, J. (2005). Rey's verbal learning test: normative data for 1855 healthy participants aged $24-81$ years and the influence of age, sex, education, and mode of presentation. Journal of the International Neuropsychological Society, 11, 290-302.

Van der Elst, W., Van Boxtel, M. P., Van Breukelen, G. J., \& Jolles, J. (2006a). Normative data for the Animal, Profession and Letter M Naming verbal fluency tests for Dutch speaking participants and the effects of age, education, and sex. Journal of the International Neuropsychological Society, 12, 80-89.

Van der Elst, W., Van Boxtel, M. P., Van Breukelen, G. J., \& Jolles, J. (2006b). The stroop color-word test: influence of age, sex, and education; and normative data for a large sample across the adult age range. Assessment, 13, 62-79.

Van der Elst, W., van Boxtel, M. P. J., Van Breukelen, G. J. P., \& Jolles, J. (in press). The concept shifting test: adult normative data. Psychological Assessment.

Van der Elst, W., Van Boxtel, M. P. J., Van Breukelen, G. J. P., \& Jolles, J. (2006c). The Letter Digit Substitution Test: Normative data for 1,858 healthy participants aged 24-81 from the Maastricht Aging Study (MAAS): influence of age, education, and sex. Journal of Clinical and Experimental Neuropsycholo$g y, 28,998-1009$

Van Hoof, J. J. M., Jogems-Kosterman, B. J. M., Sabbe, B. G. C., Zitman, F. G., \& Hulstijn, W. (1998). Differentiation of cognitive and motor slowing in the Digit Symbol Test (DST): differences between depression and schizophrenia. Journal of Psychiatric Research, 32, 99-103.

Van Hooren, S. A. H., Valentijn, S. A. M., Bosma, H., Ponds, R. W., van Boxtel, M. P., \& Jolles, J. (in press). Cognitive functioning in healthy adults: a cohort study into the effects of age, sex, and education. Aging, Neuropsychology and Cognition.

West, R. L. (1996). An application of prefrontal cortex function theory to cognitive aging. Psychological Bulletin, 120(2), 272-292.

Willis, S. L., \& Schaie, K. W. (2005). Cognitive trajectories in midlife and cognitive functioning in old age. In S. L. Willis \& M. Martin (Eds.), Middle adulthood: a lifespan perspective (pp. 243-277). Thousand Oaks: Sage Publications. 


\title{
Chapter 3
}

\section{Are age differences in verbal learning related to interstimulus interval and education?}

Willemien A. Meijer, Renate H. M. de Groot, Martin P. J. van Boxtel, Pascal W. M. van

Gerven \& Jelle Jolles

Accepted for publication in Experimental Aging Research

\begin{abstract}
In light of Baddeley's (2003) working memory model in which verbal information is held in a phonological store for 1 to 2 seconds, the present study investigated the effects of a narrow range of interstimulus intervals (ISI, 1, 2, or $3 \mathrm{~s}$ ) on word-learning performance in relation to age and education. Individuals $(N=338)$ from four age groups (24-76 years) with low or high educational attainment were randomly assigned to one of three ISI conditions. Performance was adversely affected by higher age, lower education, and shorter ISI, but age differences in performance were not affected by ISI. Furthermore, lower educated individuals needed more time to achieve the same performance level as higher educated individuals.
\end{abstract}


Age-related memory deficits are consistently found when adults are presented with a list of words to learn and recall (see for review, Kausler, 1994). Several explanations for these age-related performance decrements have been proposed, including the views that poorer memory performance in old age arises from inefficient use of encoding and retrieval strategies, from failures in metamemory, from defective semantic encoding, and/or from failures in deliberate recollection (Light, 1991). An influential explanation for these age-related deficits is that performance on word-learning tasks is strongly dependent on processing resources that decline with age, such as working memory efficiency (Babcock \& Salthouse, 1990; Jenkins, Myerson, Hale, \& Fry, 1999), processing speed (Salthouse, 1996), and inhibitory mechanisms (Hasher \& Zacks, 1988).

A method used in earlier studies to enhance word-learning performance in older adults involved increasing the available learning time (Craik \& Rabinowitz, 1985; Rabinowitz, 1989; Verhaeghen et al., 1998; Wahlin et al., 1995). This was realized by increasing the presentation time of the words, but also by increasing the interstimulus interval (ISI), which is the interval between the disappearance and arrival of two consecutive words. In the aforementioned studies, recall of different age groups in conditions in which the presentation time was prolonged, was compared with recall in conditions with shorter presentation times. Craik and Rabinowitz (1985) for instance conducted an experiment with a young group (mean age $=20$ years) and an old group (mean age $=68$ years) in which presentation time was increased from 1.5 to 6 s. Rabinowitz (1989) compared a young group (mean age $=20$ years) and an old group (mean age $=66$ years) using two presentation times ( $5 \mathrm{~s}$ and unlimited). Increased presentation times were expected to compensate for the slower processing rate of older individuals. However, no evidence was found that the age-related recall deficit was alleviated with an increased presentation time. In fact, there was some indication for the opposite: age differences actually increased when the presentation time was longer. That is, older adults appeared to profit less from an increased presentation time (Craik \& Rabinowitz, 1985; Rabinowitz, 1989). These findings have been attributed to agerelated deficits in the spontaneous use of encoding strategies and organizational processes that facilitate the encoding of the to-be-learned words (Davis et al., 2003; Verhaeghen \& Marcoen, 1994; Witte, Freund, \& Brown-Whistler, 1993; Witte, Freund, \& Sebby, 1990). Because organization and strategy use are generally considered effortful and time-consuming by requiring deeper levels of processing (Craik \& Rabinowitz, 1985), they might be suppressed by short presentation times and ISIs (Hertzog, Dunlosky, \& Robinson, 2004), both in younger and older individuals. This would mean that the deficits in encoding strategies and organizational processes seen in older adults would only become apparent with a longer study time (Craik \& Rabinowitz, 1985).

The aforementioned studies (Craik \& Rabinowitz, 1985; Rabinowitz, 1989; Verhaeghen et al., 1998; Wahlin et al., 1995) compared small samples of extreme age groups on rather broad ranges of presentation times $(1.5,3$, and $6 \mathrm{~s} ; 5 \mathrm{~s}$ and unlimited study time; 0.6 up to $10 \mathrm{~s} ; 2$ and $5 \mathrm{~s}$ ). In light of Baddeley's working memory model , in which verbal information is held in a phonological store for 1 to 2 seconds before it fades, it may be more relevant to use presentation times and ISIs that vary by a few seconds. Thus, increasing ISI within a range of a few seconds might support the phonological store of working memory by providing the opportunity for more rehearsal. Since older adults rehearse a smaller number of different words than younger 
adults, and their rehearsals are less widely distributed throughout a word-learning list (Ward \& Maylor, 2005), this form of support might be especially beneficial for older adults. Therefore, one purpose of the present study was to investigate the effects of a narrow range of ISIs (1 to $3 \mathrm{~s}$ ) on age differences in word-learning performance. A second purpose of this study was to assess consecutive age groups, including middleaged groups, in order to detect possible age by ISI interactions early in the course of aging. The above-mentioned studies did not include people between 20 and 60 years of age, even though this range is especially interesting: The first manifestations of agerelated cognitive changes (Houx, Jolles, \& Vreeling, 1993) and brain changes (Haug, 1985; Tisserand et al., 2002) are detectable from 30 years onward. In contrast to previous studies, we used a large population-based sample in order to increase statistical power and to be able to generalize findings.

The final purpose of the present study was to examine how education affects performance when different ISIs are used. Previous research has noted that wordlearning performance is affected by formal education in that higher educated individuals perform better than those with less education (e.g., Van der Elst, Van Boxtel, Van Breukelen, \& Jolles, 2005). Moreover, since high education has been shown to reduce age-related cognitive decline (e.g., Bosma, Van Boxtel, Ponds, Houx, \& Jolles, 2003), age-related changes in verbal learning may be smaller in higher educated individuals. There are several arguments to support the notion that there is such a protective effect of education. First, continuous mental stimulation associated with a high level of education may have a positive effect on neuronal growth and the complexity of neural networks (Coffey, Saxton, Ratcliff, Bryan, \& Lucke, 1999). Second, the highly educated are more likely to have an active and healthy lifestyle associated with a smaller risk of cognitive dysfunction (Gold et al., 1995). Finally, educational experience may provide cognitive reserve in the form of a more elaborate set of basic skills or cognitive strategies (Stern, 2002). For instance, education may stimulate the use of semantic and other encoding strategies, which are involved in verbal learning. In light of this hypothesized protective effect of education on verbal learning, an interesting issue is whether education influences the ability to use longer ISIs to improve recall performance. As mentioned above, a longer study time provides more opportunities for organization and strategy use, and higher educated individuals may make better use of this opportunity than those with less education. A better use of longer study times by higher educated individuals has been corroborated in very old adults of over 75 years of age (Hill, Wahlin, Winblad, \& Backman, 1995), but has not been investigated in younger age cohorts. Moreover, ISIs within a range of 1 to 3 seconds have not been used in younger, adjacent age groups.

\section{METHODS}

\section{Participants}

Participants in this study were recruited from the Registration Network of Family Practices (Metsemakers, Hoppener, Knottnerus, Kocken, \& Limonard, 1992) and took part in the Maastricht Aging Study (MAAS). This prospective study of the bio- 
logical and socio-demographic determinants of cognitive aging involves 1823 healthy subjects aged 24-81 years. Participants were stratified by age (12 classes; ranging from $25 \pm 1,30 \pm 1,35 \pm 1, \ldots, 80 \pm 1$ years), sex, and level of occupational achievement and were without documented medical conditions known to interfere with normal cognitive functioning (e.g. dementia, mental retardation, and cerebrovascular pathology) at intake. The aim, population characteristics, and design of MAAS have been reported elsewhere (Jolles, Houx, Van Boxtel, \& Ponds, 1995; Van Boxtel et al., 1998). In the current experiment, cross-sectional data obtained at baseline between 1993 and 1996 were used of 338 healthy individuals aged $24-77$ years.

\section{Design}

A cross-sectional design was chosen with four consecutive age groups and two educational levels. The Visual Verbal Learning Test (VVLT) was used to measure memory performance. The participants were randomly assigned to one of three ISI conditions $(1,2$, or $3 \mathrm{~s})$. ISI, defined as the duration in seconds between the disappearance of one word and the arrival of the next word, was used as a between-subject variable in order to avoid carry-over effects due to repeated testing, such as practice effects and interference between multiple word lists.

\section{Measures}

\section{Demographic variables}

Age was used as a categorical variable. In the present study, eleven discrete age classes were collapsed into four age groups: young (24-37 years), young middle-aged (39-51 years), old middle-aged (54-66 years), and old (69-77 years).

Level of education was assessed by classifying formal schooling in a system often used in the Netherlands (de Bie, 1987), which is comparable with the International Standard Classification of Education (UNESCO, 1976). Educational level was originally scored in eight ordinal categories, ranging from unfinished primary school to university education. For the present study, education was recoded into two levels according to the median level in the Dutch population (Mares, 2004). The first level was defined as "low," and included primary education, technical and vocational training for 12 to 16 year-olds, and intermediate secondary education. The second level was defined as "high," and included technical and vocational training for those 16 to 18 year-olds, secondary education, technical and vocational training for those 18 years and older, higher secondary education, and university training. In this study, a low level of education was equivalent to a maximum of 12 years formal education, and a high level was equivalent to a minimum of 13 years.

Verbal intelligence was measured with the 20 -item multiple-choice subtask 'Vocabulary' of the commonly used Groningen Intelligence Test (Luteijn \& Van der Ploeg, 1983) in which the participant was asked to indicate which of five alternative words was exactly synonymous with a given word. The Groningen Intelligence Test that was developed in 1963, is the most prevalent test of formal IQ in the Netherlands, and is highly correlated with other IQ tests. 


\section{Task and dependent variables}

The Visual Verbal Learning Test (VVLT) measures intentional learning and verbal memory (Brand \& Jolles, 1985). This test is a revised version of a test originally devised by Rey (1964). A list of fifteen words was constructed using a pool of 410 monosyllabic words in the Dutch language. Only common words were selected which are acquired early in life (before age 6) and refer to concrete objects such as crown, bear, and tree. The words were presented one after another at the center of a computer screen. Participants were instructed to memorize them. The words were in lowercase letters of a Times New Roman font and $20 \mathrm{~mm}$ in height. They were presented at a rate of 1 word per second, and depending on which ISI condition participants were allocated to, the next word was presented 1,2, or $3 \mathrm{~s}$ after the disappearance of the previous word. After presentation, the participant was asked to recall as many words as possible in any order. This procedure of memorizing and recalling was conducted five times with the same words presented in the same order. When the fifth trial was completed, a fixed battery of other cognitive tests was administered for about 20 minutes. These tests (including the signal detection and line bisection test) did not involve the learning of verbal material in order to avoid interference with the previously learned VVLT words. After the delay - and unexpectedly for the participants - delayed recall was measured. The following dependent variables were used in the present study: The number of words recalled after the first presentation of the fifteen words was designated as trial 1 and was used as a measure of short term memory (Vakil \& Blachstein, 1993). Van der Elst and colleagues (2005) have shown that the increase in the number of words recalled over the first three learning trials of the VVLT is especially pronounced and appears to be a more reliable indicator of immediate recall than are the data collected over five trials. The total number of words recalled over the first three trials, therefore, were used as a measure of immediate recall (Van der Elst et al., 2005). The number of words recalled after $20 \mathrm{~min}$ were used as a measure of delayed recall.

\section{RESULTS}

The characteristics of the study population are provided in Table 1. Because of the stratification procedure, the various age groups were comparable with respect to sex. Although the proportion of individuals in the low educational group increased with age, $\chi^{2}(3)=24.3, p<.001$, the four age groups did not have significantly different vocabulary scores. The vocabulary scores were significantly different for the two levels of education: $F(1,328)=72.0, p<.01$ (means were 12.2 and 14.9 for low and high education, respectively). 
Table 1. Characteristics of the participants by age group

\begin{tabular}{lcccc}
\hline & Young & $\begin{array}{c}\text { Young } \\
\text { middle-aged }\end{array}$ & $\begin{array}{c}\text { Old } \\
\text { middle-aged }\end{array}$ & Old \\
\hline $\mathrm{N}$ & 90 & 93 & 89 & 66 \\
Age: mean (SD) & $30.5(4.3)$ & $45.5(4.1)$ & $60.3(4.2)$ & $72.8(2.6)$ \\
Male/Female ratio: $\mathrm{N}$ & $44 / 46$ & $46 / 47$ & $47 / 42$ & $36 / 30$ \\
Low/high education: $\mathrm{N}$ & $33 / 57$ & $44 / 49$ & $62 / 27$ & $42 / 23$ \\
Educational level: mean (SD) & $4.2(1.8)$ & $3.9(1.9)$ & $2.9(1.6)$ & $3.0(1.8)$ \\
Vocabulary (SEM) & $13.1(.3)$ & $13.7(.3)$ & $13.8(.3)$ & $13.7(.4)$ \\
\hline
\end{tabular}

Three full factorial analyses of covariance were carried out on performance in the first trial, immediate recall, and delayed recall of the VVLT, in order to assess effects of age, ISI and education. In addition, a repeated measures analysis of variance was used to assess group differences across the first three trials of the VVLT. Sex was included as a covariate.

The assumptions of ANOVA (homoscedasticity and normal distribution of the residuals) were tested for each dependent variable. Homoscedasticity was evaluated by visual inspection of the scatter plots of the residuals against the predicted values. Normal distribution of the residuals was checked by visual inspection of the histograms and the normal probability plots.

\section{Effects of age and ISI on word-learning performance}

In Figure 1, the mean number of words recalled on trial 1, immediate recall, and delayed recall is presented per age group and ISI. Main effects of age were found on all dependent measures, indicating that the younger individuals outperformed the older individuals: trial $1, F(3,309)=15.2, p<.01$ (means were $6.7,6.0,5.4$, and 4.6 for each consecutive age group, respectively); immediate recall, $F(3,309)=23.5, p<.01$ (means were $28.4,26.2,24.8$, and 20.8); and delayed recall, $F(3,309)=20.5, p<.01$ (means were 11.9, 10.5, 10.3, and 8.1). Main effects of ISI were also found on all dependent measures, indicating that people had a better performance with a longer ISI than with a shorter ISI: trial $1, F(2,309)=12.1, p<.01$ (means were 5.0, 5.7, and 6.3, for $1 \mathrm{~s}, 2 \mathrm{~s}$, and $3 \mathrm{~s}$, respectively); immediate recall, $F(2,309)=26.2, p<.01$ (means were 22.3, 25.2 ,and 27.7); and delayed recall, $F(2,309)=21.4, p<.01$ (means were 8.8, 10.3, and 11.5). No age by ISI interactions were found, indicating that the age-related differences in performance did not change as the ISI increased. In addition, no age by trial or ISI by trial interactions were found. 


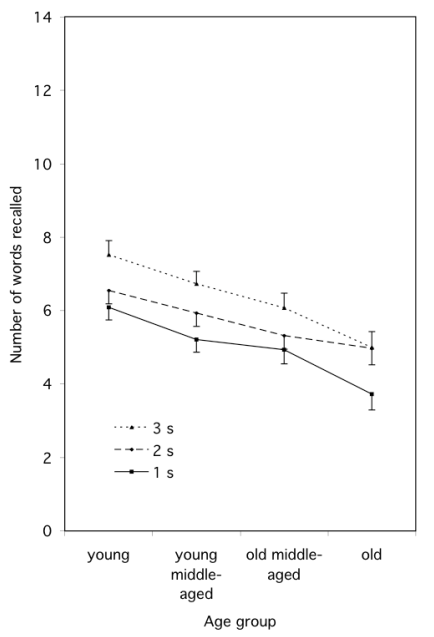

B

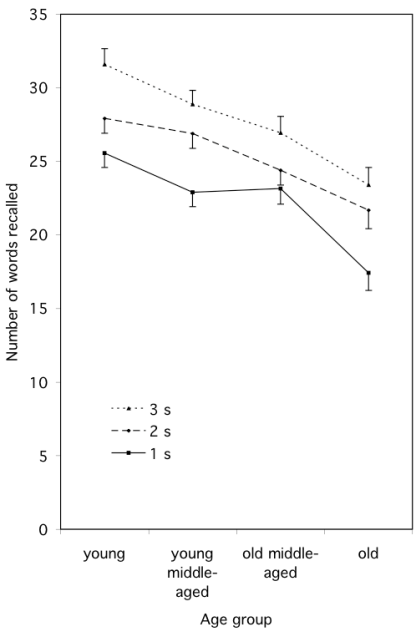

C

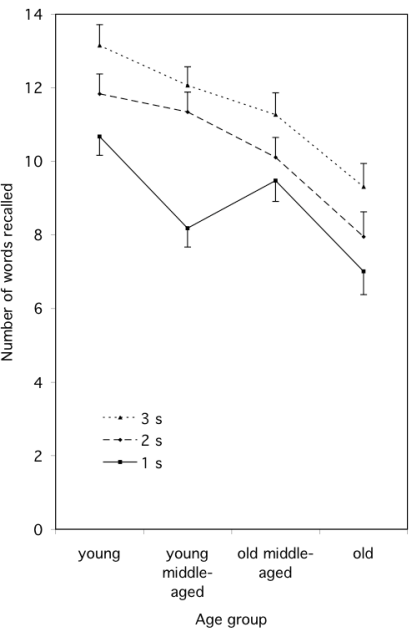

Figure 1. Mean performance on trial 1 (A), immediate recall (B), and delayed recall (C) as a function of ISI and age. Error bars represent standard errors of the mean.

\section{Effects of education on word-learning performance}

In Figure 2, the mean number of words recalled on trial 1, immediate recall, and delayed recall is presented per age group and educational level. Main effects of education were found on all dependent measures, indicating that higher educated people performed better than lower educated people: trial $1, F(1,309)=11.1, p<.01$ (means were 5.3 and 6.0 for low and high education, respectively); immediate recall, $F(1,309)=$ $15.2, p<.01$ (means were 23.8 and 26.3); and delayed recall, $F(1,309)=11.1, p<.01$ (means were 9.6 and 10.8). A statistically significant interaction was found between education and age on delayed recall, $F(3,309)=3.0, p=.03$. Comparison of the performance of the two educational levels per age group showed that the higher educated individuals outperformed the lower educated individuals only in the old middle-aged group, $F(1,81)=19.5, p<.01$.

Figure 3 shows the mean number of words recalled on trial 1, immediate recall, and delayed recall presented per ISI condition and educational level. There was a trend toward a significant interaction effect of education and ISI on delayed recall, $F(2,309)$ $=2.8, p=.06$. Repeated contrasts per educational level showed that the higher educated individuals performed significantly better with an ISI of $2 \mathrm{~s}$ than with an ISI of 1 $\mathrm{s}$, difference $=-2.3, p<.01$, whereas the lower educated individuals did not. The reverse was seen with an ISI of $2 \mathrm{~s}$ or $3 \mathrm{~s}$ : the lower educated individuals performed significantly better with an ISI of $3 \mathrm{~s}$ than with an ISI of $2 \mathrm{~s}$, whereas the higher educated individuals did not, difference $=-1.96, p<.01$. No age $\mathrm{x}$ ISI $\mathrm{x}$ education and education by trial interactions were found. 
A

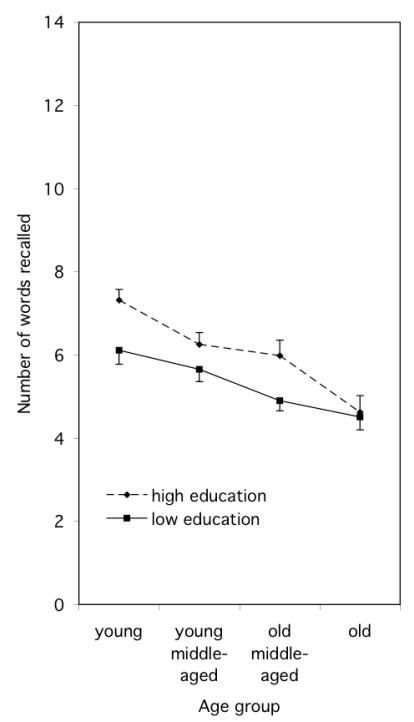

B

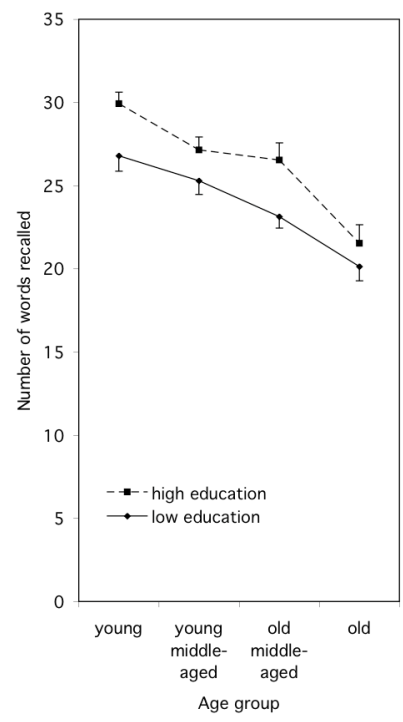

C

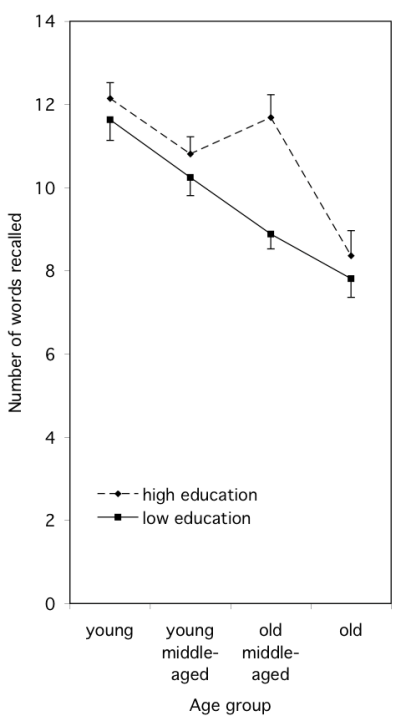

Figure 2. Mean performance on trial 1 (A), immediate recall (B), and delayed recall (C) as a function of education and age. Error bars represent standard errors of the mean.
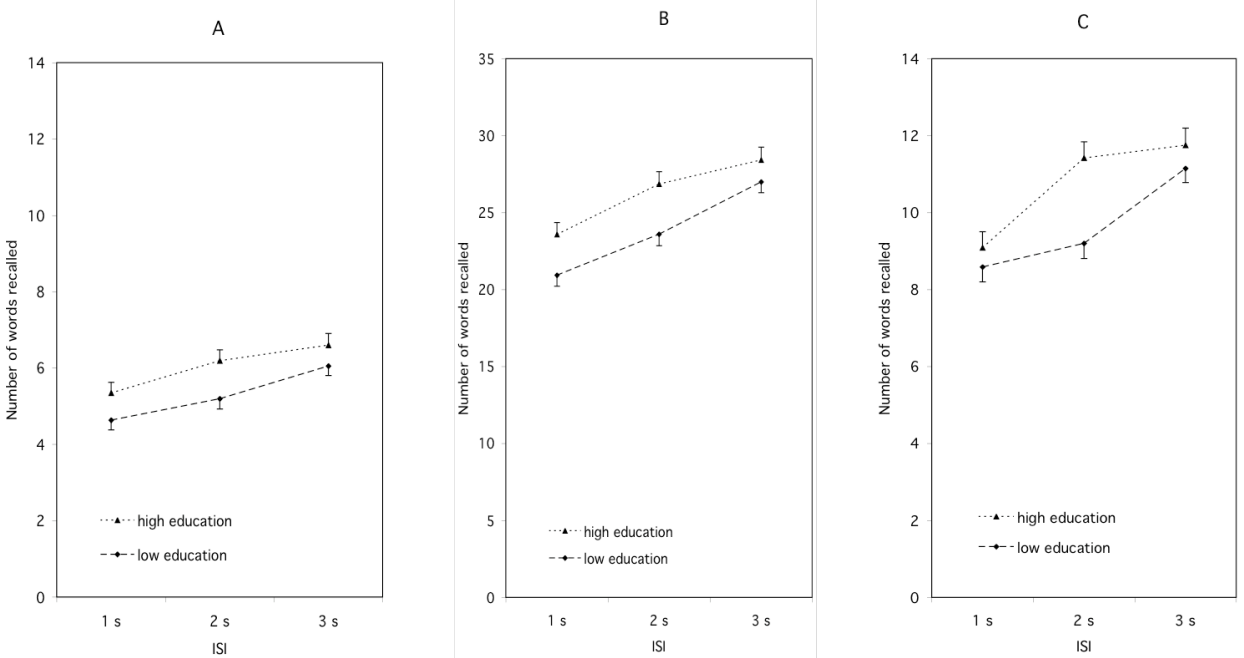

Figure 3. Mean performance on trial 1 (A), immediate recall (B), and delayed recall (C) as a function of ISI and education. Error bars represent standard errors of the mean. 


\section{Discussion}

The first purpose of this study was to investigate whether differences in recall between consecutive age groups change as ISI increases. The second purpose was to examine the modifying effects of education. We found that older adults performed worse than younger individuals on a word-learning task and that even a small change in ISI from 1 to $3 \mathrm{~s}$ resulted in better performance in all age groups. This finding indicates that the method used here to provide cognitive support was effective. This may suggest that increasing ISI within a range of a few seconds supports the workingmemory store, possibly by providing the opportunity for more rehearsal. Another explanation may be that the $3 \mathrm{sec}$ group had more total time to learn the words than the $1 \mathrm{sec}$ group. However, there was no age by ISI interaction. We thus found no evidence that an increased ISI compensates for the slower processing rate of older individuals. A close examination of the literature reveals that earlier research involving tasks that required the learning of single words also failed to find evidence for a reduction in the recall deficit with increasing study time (Craik \& Rabinowitz, 1985; Rabinowitz, 1989; Verhaeghen et al., 1998; Wahlin et al., 1995). We therefore suggest that while increasing the time available to process the words leads to better performance in all age groups, it does not affect the age-related differences in performance.

A possible explanation for this conclusion may be sought in the simultaneity mechanism, proposed by Salthouse (1996) to be responsible for the relation between processing speed and age-related changes in memory. This mechanism operates when slow processing in older adults reduces the amount of simultaneously available information needed for higher processing, such as encoding, elaboration, integration, and abstraction. A key assumption of the simultaneity mechanism is that the availability of information decreases over time as a function of either decay or displacement. Salthouse assumed this mechanism to occur regardless of the amount of time allowed for processing, because the critical limitations are based on processing speed rather than on the relation between processing speed and external (i.e., ISI) factors. In other words, increasing the ISI does not compensate for the effects of the simultaneity mechanism.

The results presented here indicate that age differences in performance do not change when ISI increases. This is in contrast with the findings of two previous studies with relatively small sample sizes, which revealed that age differences in performance actually increased with longer presentation times (Craik \& Rabinowitz, 1985; Rabinowitz, 1989). They also found that both age groups recalled more words under optimal study conditions, but that the improvement was greater for the young adults. There are several possible explanations for the differences between the current findings and the findings of these earlier studies. For example, the earlier studies used extreme age groups and rather broad ranges of presentation times. Under these conditions, age by study time interactions are more likely to be found than when consecutive age groups and a relatively narrow range of intervals are investigated. A related explanation has to do with differences in the length of the study times. In the previous studies, the larger age differences in performance seen with longer presentation times were attributed to 
deficits in older adults with respect to organizational processes and the use of encoding strategies. With increasing ISI, young adults are supposed to organize and elaborate on the material more effectively than older adults. We used a maximum ISI of $3 \mathrm{~s}$, which may not be long enough to enable younger people to use elaborated learning strategies. The currently used ISI range may provide a different form of support in providing the opportunity for more articulatory rehearsal which might be equally efficient in younger and older adults in contrast to more elaborated learning strategies which might be more efficient in younger adults than in older adults. Age differences in performance may become more pronounced only under conditions in which the ISI is relatively long (more than $3 \mathrm{~s}$ ) when younger people have enough opportunity to use learning strategies such as organizational processing.

The second purpose of the present study was to examine whether higher educated individuals benefit more from longer ISIs than lower educated individuals. We found that participants with a high level of education recalled more words than participants with a low level of education in all age groups. Moreover, the higher educated participants showed an additional advantage on delayed recall relative to the lower educated people in the old-middle aged group (mean age of 60 years). However, this additional advantage may reflect the slightly deviating demographic characteristics of this age group. This age group had the lowest level of education yet the highest vocabulary score. Furthermore, it was the most imbalanced in sample size between low versus high levels of education.

The higher educated people recalled significantly more words when the ISI was increased from $1 \mathrm{~s}$ to $2 \mathrm{~s}$, whereas the lower educated persons did not. The reverse was observed when the ISI was increased from $2 \mathrm{~s}$ to $3 \mathrm{~s}$. This may indicate that higher educated persons use rehearsal effectively already at $2 \mathrm{~s}$, while lower educated persons need more study time (i.e., at least $3 \mathrm{~s}$ ) to use this kind of activity effectively. Noteworthy, this effect was only observed in delayed recall, which was measured 20 minutes after the last learning trial. Thus, the benefit of rehearsal in higher educated persons may be only expressed when information has been consolidated into long-term memory. A possible explanation might be that mainly elaborative rehearsal, a process that leads to an increase in the depth at which a word is encoded, and as such long-term learning (Woodward, Bjork, \& Jongeward, 1973), is better in higher than in lower educated persons. In contrast, maintenance rehearsal, which holds information without transforming it into a deeper code, and as such does not lead to long-term learning (Woodward et al., 1973), may not differ between low and high- educated persons. After all, formal schooling involves and therefore may enhance mainly long-term learning, which is dependent on elaborative rehearsal, rather than that it enhances the maintenance of information in short-term memory only, which is dependent on rote rehearsal. To our knowledge, only one study addressed the relationship between education and study time before (Hill et al., 1995). In this study of individuals older than 75 years, it was found that education predicted performance better in a long presentation time condition than in a short presentation time condition. In other words, educational level determines the ability to use study time. We found this to be true for an ISI range within $3 \mathrm{~s}$, whereas the previous study investigated an ISI range within $5 \mathrm{~s}$. Despite this difference, our findings confirm in younger persons the phenomenon that was found in very old adults. 
In conclusion, older adults do not improve more than younger adults when the ISI is increased. Thus, increasing the ISI to provide older adults a way to compensate for a slower processing rate is not effective in the sense that it does not reduce the performance gap between the age groups. Furthermore, education has a profound influence on word-learning performance. Interestingly, education also influences the ability to use longer ISIs to enhance performance in such a way that lower educated people need more study time to achieve the same level of performance as higher educated individuals. This suggests that lower educated people need more time to memorize verbal information in daily life.

\section{REFERENCES}

Babcock, R. L., \& Salthouse, T. A. (1990). Effects of increased processing demands on age differences in working memory. Psychology and Aging, 5, 421-428.

Baddeley, A. (2003). Working memory: looking back and looking forward. Nature Reviews Neuroscience, 4, 829-839.

Bosma, H., Van Boxtel, M. P., Ponds, R. W. H. M., Houx, P., \& Jolles, J. (2003). Education and age-related cognitive decline: the contribution of mental workload. Educational Gerontology, 29, 1-9.

Brand, N., \& Jolles, J. (1985). Learning and retrieval rate of words presented auditorily and visually. The Journal of General Psychology, 112, 201-210.

Coffey, C. E., Saxton, J. A., Ratcliff, G., Bryan, R. N., \& Lucke, J. F. (1999). Relation of education to brain size in normal aging: implications for the reserve hypothesis. Neurology, 53(1), 189-196.

Craik, F. I. M., \& Rabinowitz, J. C. (1985). The effects of presentation rate and encoding task on agerelated memory deficits. Journal of Gerontology, 40, 447-454.

Davis, H. P., Small, S. A., Stern, Y., Mayeux, R., Feldstein, S. N., \& Keller, F. R. (2003). Acquisition, recall, and forgetting of verbal information in long-term memory by young, middle-aged, and elderly individuals. Cortex, 39, 1063-1091.

de Bie, S. E. (1987). Standaardvragen 1987: Voorstellen voor uniformering van vraagstellingen naar achergrondkernmerken en interviews [Standard questions 1987: Proposal for uniformisation of questions regarding background variables and interviews]. (2nd ed.). Leiden, The Netherlands: Leiden University Press.

Gold, D. P., Andres, D., Etezadi, J., Arbuckle, T., Schwartzman, A., \& Chaikelson, J. (1995). Structural equation model of intellectual change and continuity and predictors of intelligence in older men. Psychology and Aging, 10, 294-303.

Hasher, L., \& Zacks, R. (1988). Working memory, comprehension, and aging: a review and a new view. The Psychology of Learning and Motivation, 22, 193-225.

Haug, H. (1985). Are neurons of the human cerebral cortex really lost during aging? A morphometric examination. In W. Gispen, H. (Ed.), Senile dementia of the Alzheimer type (pp. 150-163). New York: Springer-Verlag.

Hertzog, C., Dunlosky, J., \& Robinson, A. E. (2004). Rapid pacing suppresses strategy use in associative learning. Paper presented at the Cognitive Aging Conference, Atlanta.

Hill, R. D., Wahlin, A., Winblad, B., \& Backman, L. (1995). The role of demographic and life style variables in utilizing cognitive support for episodic remembering among very old adults. Journals of Gerontology B: Psychological Sciences and Social Sciences, 50, P219-227.

Houx, P. J., Jolles, J., \& Vreeling, F. W. (1993). Stroop interference: aging effects assessed with the Stroop Color-Word Test. Experimental Aging Research, 19, 209-224.

Jenkins, L., Myerson, J., Hale, S., \& Fry, A. F. (1999). Individual and developmental differences in working memory across the life span. Psychonomic Bulletin and Review, 6, 28-40. 
Jolles, J., Houx, P., Van Boxtel, M. P., \& Ponds, R. W. (Eds.). (1995). Maastricht Aging Study: Determinants of cognitive aging. Maastricht: Neuropsych Publishers.

Kausler, D. H. (1994). Learning and memory in normal aging. San diego, CA: Academic Press.

Light, L. L. (1991). Memory and aging: four hypotheses in search of data. Annual Review of Psychology, 42, 333-376.

Luteijn, F., \& Van der Ploeg, F. A. E. (1983). Handleiding Groninger Intelligentietest (GIT) [Manual Groningen Intelligence Test]. Lisse, The Netherlands: Swets and Zeitlinger.

Mares, A. M. H. M. (Ed.). (2004). Jaarboek onderwijs in cïfers [Yearbook education in numbers]: Centraal Bureau voor de Statistiek.

Metsemakers, J. F., Hoppener, P., Knottnerus, J. A., Kocken, R. J., \& Limonard, C. B. (1992). Computerized health information in The Netherlands: a registration network of family practices. British Journal of General Practice, 42, 102-106.

Rabinowitz, J. C. (1989). Age deficits in recall under optimal study conditions. Psychology and Aging, 4, 378380.

Rey, A. (1964). L'examen psychologique dans les cas d'encéphalopathie traumatique [Psychological assessment in cases of traumatic brain injury]. Paris: Presses Universitaires de France.

Salthouse, T. A. (1996). The processing-speed theory of adult age differences in cognition. Psychological Review, 103, 403-428.

Stern, Y. (2002). What is cognitive reserve? Theory and research application of the reserve concept. Journal of the International Neuropsychological Society, 8, 448-460.

Tisserand, D., J., Pruessner, J. C., Sanz Arigita, E. J., Van Boxtel, M. P., Evans, A. C., Jolles, J., \& Uylings, H. B. M. (2002). Regional frontal cortical volumes decrease differentially in aging: an MRI study to compare volumetric approaches and voxel-based morphometry. NeuroImage, 17, 657-669.

UNESCO. (1976). International Standard Classification of Education (ISCED). Paris: UNESCO.

Vakil, E., \& Blachstein, H. (1993). Rey Auditory-Verbal Learning Test: structure analysis. Journal of Clinical Psychology, 49, 883-890.

Van Boxtel, M. P., Buntinx, F., Houx, P. J., Metsemakers, J. F., Knottnerus, A., \& Jolles, J. (1998). The relation between morbidity and cognitive performance in a normal aging population. Journals of Gerontology series A: Biological Sciences and Medical Sciences, 53, M147-154.

Van der Elst, W., Van Boxtel, M. P., Van Breukelen, G. J., \& Jolles, J. (2005). Rey's verbal learning test: normative data for 1855 healthy participants aged 24-81 years and the influence of age, sex, education, and mode of presentation. Journal of the International Neuropsychological Society, 11, 290-302.

Verhaeghen, P. (2003). Aging and vocabulary scores: a meta-analysis. Psychology and Aging, 18, 332-339.

Verhaeghen, P., \& Marcoen, A. (1994). Production deficiency hypothesis revisited: Adult age differences as a function of processing resources. Aging and Cognition, 1, 323-338.

Verhaeghen, P., Vandenbroucke, A., \& Dierckx, V. (1998). Growing slower and less accurate: adult age differences in time-accuracy functions for recall and recognition from episodic memory. Experimental Aging Research, 24, 3-19.

Wahlin, A., Backman, L., \& Winblad, B. (1995). Free recall and recognition of slowly and rapidly presented words in very old age: a community-based study. Experimental Aging Research, 21, 251-271.

Ward, G., \& Maylor, E. A. (2005). Age-related deficits in free recall: the role of rehearsal. Quarterly Journal of Experimental Psycholology A, 58, 98-119.

Witte, K. L., Freund, J. S., \& Brown-Whistler, S. (1993). Adult age differences in free recall and category clustering. Experimental Aging Research, 19, 15-28.

Witte, K. L., Freund, J. S., \& Sebby, R. A. (1990). Age differences in free recall and subjective organization. Psychology and Aging, 5, 307-309.

Woodward, A. E., Bjork, R. A., \& Jongeward, R. H. (1973). Recall and recognition as a function of primary rehearsal. Journal of Verbal Learning and Verbal Behavior, 12, 608-617. 


\title{
Chapter 4
}

\section{Verbal learning and aging: combined effects of irrelevant speech, interstimulus interval, and education}

\author{
Willemien A. Meijer, Renate H. M. de Groot, Martin P. J. van Boxtel, \\ Pascal W. M. van Gerven \& Jelle Jolles \\ Published in Journal of Gerontology: Psychological Sciences (2006), 61B, 285-294
}

\begin{abstract}
Older or lower educated individuals may be less able than younger or higher educated individuals to inhibit irrelevant speech when learning new visual information. In Experiment 1, we investigated the effects of age (four groups), educational attainment (low or high), and verbal noise (spoken words or silence) on word-learning performance in 230 individuals aged 24 to 76 years. Performance was negatively affected by higher age, lower education, and irrelevant speech, but there were no interactions between age group and noise condition. In Experiment 2, we increased the difficulty of the word-learning task by using both irrelevant speech and a short interstimulus interval ( 2 or $0.5 \mathrm{~s}$ ). Age differences became more pronounced as the result of the simultaneous occurrence of irrelevant speech and a short interstimulus interval. This suggests that older individuals may need more time than younger individuals to learn new information in noisy environments.
\end{abstract}


Older people frequently complain about being distracted by environmental noise, such as other people talking or radio sound, when they are occupied with reading or memorizing information. In particular, irrelevant speech is one of the most common sources of complaint by people in a broad age range (Kjellberg, Landstrom, Tesarz, Soderberg, \& Akerlund, 1996). From a theoretical perspective, it can be expected that the performance of older adults on verbal learning tasks is more sensitive than that of younger people to interference caused by irrelevant speech. The ability to suppress noise might involve inhibitory mechanisms (Dempster \& Brainerd, 1995), which may be less efficient in aging individuals (Hasher \& Zacks, 1988). A major function attributed to these inhibitory processes is to prevent irrelevant material from accessing working memory and to deactivate any such material that enters the information stream. It has been proposed that various age-related differences in cognitive performance might be due to defective inhibitory processes (Mc Dowd, Oseas-Kreger, \& Filion, 1995).

Researchers have frequently assessed the relationship between working memory and inhibition by examining the effect of irrelevant speech on the learning of visually presented information by young adults (LeCompte, 1994; LeCompte, Neely, \& Wilson, 1997). To our knowledge, only three earlier studies have compared the effect of irrelevant speech on this type of learning between older and younger age groups (Beaman, 2005; Enmarker, 2004; Rouleau \& Belleville, 1996). These studies, which involved rather small samples of one young group and one old group, did not show a disproportionate performance decrement in older adults as a result of irrelevant speech during the serial learning of digits (Beaman, 2005; Rouleau \& Belleville) or during the learning of a text, sentences, faces, and names (Enmarker, 2004). Also during a complex counting task (Van Gerven, Meijer, Vermeeren, Vuurman, \& Jolles, in press) no disproportionate performance decrement in older adults as a result of irrelevant speech was found. This absence of an age by noise interaction is in line with the results of a study by Beaman (2004), which demonstrated that the performance of students with a low working-memory span is not more disrupted by irrelevant speech than is the performance of students with a high working-memory span in serial or free recall. When this is extended to older adults, who generally have less working-memory capacity than younger persons, no disproportionate performance decrement as a result of irrelevant speech would be expected.

The absence of an age by noise interaction could also be due to the type of memory task that is used. In the aforementioned serial recall studies (Beaman, 2005; Rouleau \& Belleville, 1996), participants were required to memorize the order of a short series of digits, which were essentially meaningless (Neely \& LeCompte, 1999). Because earlier research suggests that older adults have less access to semantic memory (Petros, Zehr, \& Chabot, 1983) and less recall of words as a result of semantic processing (Eysenck, 1974), irrelevant speech might affect their learning of meaningful material. In addition, single words, which are commonly used as irrelevant speech (e.g. LeCompte, 1994; LeCompte et al., 1997), are more controllable in terms of prosody, timing, and similarity to target words (e.g., number of letters and syllables) than are other sources of noise such as babble or orally presented text that have been used in previous studies (Enmarker, 2004; Rouleau \& Belleville; Van Gerven et al., in press). In contrast to the earlier studies using serial recall of digits and less controllable sources of noise, our aim in the first experiment in the present study was to examine the effect of 
spoken irrelevant words during the learning phase of a visual word-learning task on recall in different age groups. In this way, we can sort out whether the previously found absence of age by noise interaction was due to the type of memory task or noise source, or whether older adults are truly as able as younger adults to inhibit irrelevant speech.

Besides environmental conditions, such as the presence of irrelevant speech, task-related factors might also influence age-related differences in word-learning performance. As was pointed out by Kane, Hasher, Stoltzfus, Zacks, and Connelly (1994), it is possible that exposure durations of relevant and irrelevant stimuli in typical negative priming experiments generally are too short for older adults to encode whatever critical information is needed to engage inhibitory mechanisms. Similarly, a short study time may impede the inhibition of irrelevant speech, which may result in reduced word-learning performance, especially in older adults, who generally process information more slowly than do younger adults (Salthouse, 1996). It would therefore be of interest to know whether irrelevant speech is harder to suppress by older adults when words to be learned are presented more quickly. In the current study, we examined this in a second experiment in which we shortened the interstimulus interval (ISI) under conditions of irrelevant speech.

In addition to environmental and task-related conditions, certain individual characteristics, such as education, can modify cognitive functioning in later adulthood. People with low educational attainment experience more age-related cognitive decline than do people with high educational attainment (Bosma, Van Boxtel, Ponds, Houx, \& Jolles, 2003). There are several arguments to support this protective effect of education. First, continuous mental stimulation associated with a high level of education may have a positive effect on neuronal growth and the complexity of neural networks (Coffey, Saxton, Ratcliff, Bryan, \& Lucke, 1999). Second, higher educated persons might have an active lifestyle that is associated with a smaller risk of cognitive dysfunction (Gold et al., 1995) Third, educational experience may provide reserve capacity in the form of a more elaborate set of basic skills or cognitive strategies (Stern, 2002). Education, which leads to proficient language use, could particularly influence age differences in verbal learning. In contrast to serial recall of digits, word learning involves the use of semantic and other encoding strategies, which may be used more in highly educated persons than in lower educated persons. Moreover, because researchers have found age differences in inhibitory function, as derived from Stroop test performance, to be smaller in higher educated persons (Van der Elst, Van Boxtel, Van Breukelen, \& Jolles, 2006), the potentially greater effect of irrelevant speech on older adults' word-learning performance might be attenuated by higher education. Our third purpose in this study was therefore to examine how education affects performance under conditions with or without irrelevant speech (Experiment 1) and with a short or long ISI combined with irrelevant speech (Experiment 2). 


\section{EXPERIMENT 1}

\section{METHODS}

\section{Participants}

We recruited participants from the Registration Network of Family Practices (Metsemakers, Hoppener, Knottnerus, Kocken, \& Limonard, 1992) who took part in the Maastricht Aging Study (Jolles, Houx, Van Boxtel, \& Ponds, 1995; Van Boxtel et al., 1998). This prospective study on the biological and sociodemographic determinants of cognitive aging involves 1,823 healthy individuals who are between the ages of 24 and 81 years. Participants were stratified for sex, two levels of occupational achievement, and age (12 groups; ranging from $25 \pm 1,30 \pm 1,35 \pm 1$, etc., to $80 \pm 1$ years). None of the participants had documented medical conditions known to interfere with normal cognitive functioning (e.g., dementia, mental retardation, and cerebrovascular pathology) at intake. We used the baseline data of 221 healthy individuals aged 24 to 77 years for the present study.

\section{Design}

We chose a 4 × 2 × 2 cross-sectional design with four consecutive age groups, two noise conditions, and two educational levels. The Visual Verbal Learning Test (VVLT) was used to measure memory performance. We randomly assigned the participants to either a silent condition $(n=109)$ or a noise condition $(n=112)$. Noise was used as a between-subject variable in order to avoid carryover effects caused by repeated testing.

\section{Measures}

\section{Characteristics of the participants}

Age was used as a categorical variable. We collapsed 11 discrete age groups into 4 age groups, that is, young ( $24-37$ years), young middle-aged (39-51 years), old middle-aged (54-66 years), and old (69-77 years).

Level of education was assessed by classifying formal schooling according to a system often used in the Netherlands (de Bie, 1987), which is comparable with the International Standard Classification of Education (UNESCO, 1976). Educational level was scored in eight ordinal categories, ranging from unfinished primary school to university education. For the present study, we recoded education into two levels: low, primary education, lower vocational education, and intermediate secondary education; and high, intermediate vocational education, secondary education, higher vocational education, higher secondary education, and university. The low level of education was equivalent to a maximum of 12 years of education. The high level was equivalent to a minimum of 13 years.

We measured verbal intelligence with the 20-item multiple-choice Vocabulary subtask of the Groningen Intelligence Test (Luteijn \& Van der Ploeg, 1983). 
Hearing acuity was assessed to control for interindividual differences in perceiving the auditorily presented information. Because age differences in speech perception are only minimal after correction for age-related differences in pure-tone sensitivity (Helfer, 1992; Lutman, Gatehouse, \& Worthington, 1991; Sommers, 1997), we considered the assessment of pure-tone sensitivity to be an adequate approximation of speech perception in aging individuals. We carried out an audiometric test under standard laboratory conditions by measuring pure-tone air-conduction thresholds (in decibels) for each ear at $0.5,1,2$, and $4 \mathrm{kHz}$, using a screening audiometer (Interacoustics AS7, Denmark). We expressed hearing acuity as the average hearing threshold at 1, 2 and $4 \mathrm{kHz}$ for the best ear (Davis, 1995).

\section{Task and dependent variables}

The VVLT, an adaptation of a test originally devised by Rey (1964), measures intentional learning and verbal memory (Brand \& Jolles, 1985). Fifteen monosyllabic words that refer to objects were presented one after another at the center of a computer screen in lowercase letters of a Times-like font. The height of the letters on the screen was approximately $20 \mathrm{~mm}$. Participants were seated in front of a 17-in. (43-cm) monitor at a normal viewing distance of approximately $25 \mathrm{in} .(60 \mathrm{~cm})$. Before testing, participants were screened for visual difficulties by asking whether they could, if necessary with glasses, read a newspaper. We excluded persons with obviously reduced eyesight. The words were presented for $1 \mathrm{~s}$, with $2 \mathrm{~s}$ between the disappearance of one word and the arrival of the consecutive word. In the noise condition, we used a male voice to present 15 other monosyllabic words that refer to objects for a maximum of 1 s. The words were presented by means of loudspeakers connected to a computer. Each auditory word started $500 \mathrm{~ms}$ after the appearance of a visually presented word. After presentation, the participants were asked to recall as many visually presented words as possible in any order. This procedure was repeated four times. When the fifth trial was completed, we administered a fixed battery of cognitive tests, not involving the learning of verbal material, for approximately $20 \mathrm{~min}$. After this delay-and unexpectedly for the participants-delayed recall was measured. The following dependent variables were used in the present study: we used trial 1 as a measure of short-term memory (Vakil \& Blachstein, 1993); because ceiling effects are often observed in the VVLT, we used the total number of words recalled over the first three trials as a measure of immediate recall (Van der Elst, Van Boxtel, Van Breukelen, \& Jolles, 2005); and we used the number of words recalled after $20 \mathrm{~min}$ as a measure of delayed recall.

\section{Data analysis}

We analyzed differences in educational level and sex between age groups by using chi-square tests. We used two $4 \times 2$ analyses of variance to analyze differences between four age groups and two educational levels in verbal intelligence and in hearing acuity. To assess main effects of age (young, young middle-aged, old middle-aged, and old), noise (quiet and speech), education (low and high), and all possible interactions between these factors, we carried out a $4 \times 2 \times 2$ analysis of covariance on performance on the first trial, immediate recall, and delayed recall. We included sex and hearing acuity as covariates. We also conducted the analyses without hearing acuity as a covariate (sex remained covariate) in order to rule out the possibility that the effects of 
hearing acuity reduced the variance explained by age. We analyzed statistically significant main effects of age by means of repeated contrasts with Bonferroni correction in which the alpha level, $p=0.05$, was divided by the number of comparisons. We investigated significant interactions by means of simple contrasts with Bonferroni correction. Post hoc power analyses on the available number of participants, using a medium critical effect size of 0.15 and an alpha level of $p=.05$, resulted in a power of 0.99 (Buchner, Faul, \& Erdfelder, 1992).

\section{RESULTS}

The characteristics of the sample are shown in Table 1. We used the data of 219 individuals in the analyses, because 2 participants did not have a hearing acuity measure. As expected because of the stratification procedure, the age groups were comparable with respect to sex. The older individuals were significantly less educated than the younger individuals: $\chi^{2}(3, N=219)=26.3, p<.01$. The four consecutive age groups did not differ significantly on vocabulary, $F(3,211)=2.5, p=.06$, and the vocabulary scores of the higher educated individuals $(M=15.3)$ were significantly higher than those of the lower educated individuals $(M=11.8), F(1,211)=68.0, p<.01$. Hearing acuity differed significantly between age groups, $F(3,211)=29.2, p<.01$, but not between educational levels.

Table 1. Participant characteristics per age group (in years) for Experiment 1

\begin{tabular}{lcccc}
\hline Characteristic & $\begin{array}{c}\text { Young } \\
(24-37)\end{array}$ & $\begin{array}{c}\text { Young middle-aged } \\
(39-51)\end{array}$ & $\begin{array}{c}\text { Old middle-aged } \\
(54-66)\end{array}$ & $\begin{array}{c}\text { Old } \\
(69-77)\end{array}$ \\
\hline $\mathrm{N}$ & 58 & 59 & 64 & 38 \\
Age: $M(S D)$ & $30.4(4.4)$ & $45.3(4.1)$ & $60.4(3.9)$ & $72.8(2.6)$ \\
Male-to-female ratio $(n / n)$ & $39 / 39$ & $30 / 29$ & $33 / 31$ & $24 / 14$ \\
Low or high education: $(n / n)$ & $16 / 42$ & $28 / 31$ & $46 / 18$ & $2.8(1.7)$ \\
Educational level: $M(S D)$ & $4.3(1.8)$ & $3.9(1.8)$ & $2.9(1.4)$ & $13.9(0.5)$ \\
Vocabulary $(S E M)$ & $12.6(0.4)$ & $13.7(0.4)$ & & $14.1(0.4)$ \\
Hearing acuity $(S D)$ & $6.9(3.4)$ & $9.5(5.9)$ & $16.0(11.8)$ & $24.5(11.9)$ \\
\hline
\end{tabular}

\section{Effects of age and irrelevant speech on word-learning performance}

We present the mean performance (number of words recalled) on trial 1, immediate recall, and delayed recall per age group and noise condition in Figure 1. We found 
main effects of age on all dependent measures, indicating that the younger participants outperformed the older participants: trial $1, F(3,201)=3.4, p=.019$, partial $\eta^{2}=.049$ $(M s=5.4,5.0,4.6$, and 4.1 for each consecutive age group, respectively); immediate recall, $F(3,201)=6.1, p<.01$, partial $\eta^{2}=.084(M s=24.1,23.6,21.4$, and 19.1); and delayed recall, $F(3,201)=3.8, p=.011$, partial $\eta^{2}=.056(M s=10.2,9.7,8.7$, and 7.8). None of the contrasts between the consecutive age groups were significant. We also found main effects of noise on all dependent measures, indicating that performance was better in the quiet condition than in the noise condition: trial $1, F(1,201)=56.7, p$ $<.01$, partial $\eta^{2}=.22(M s=5.7$ and 3.9 for performance in quiet and noise conditions, respectively); immediate recall, $F(1,201)=72.7, p<.01$, partial $\eta^{2}=.264$ (Ms $=$ 25.2 and 18.9); and delayed recall, $F(1,201)=29.4, p<.01$, partial $\eta^{2}=.126(M s=$ 10.3 and 7.9). We found no age $\mathrm{x}$ noise interactions on trial $1, F(3,201)=.86, p=.46$; immediate recall, $F(3,201)=.49, p=.69$; and delayed recall, $F(3,201)=2.0, p=.11$. This finding indicated that the recall of the older adults was not more affected by irrelevant speech than was the recall of the younger adults. Hearing acuity did not significantly affect memory performance, with results being essentially the same regardless of whether hearing acuity was included in or excluded from the model.

A

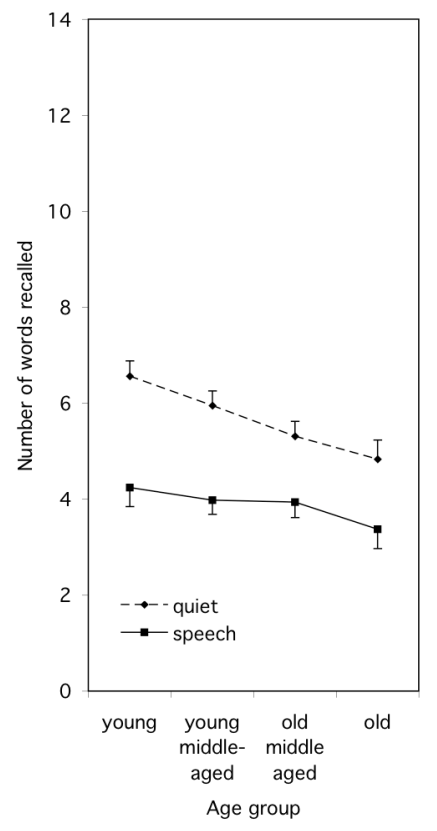

B

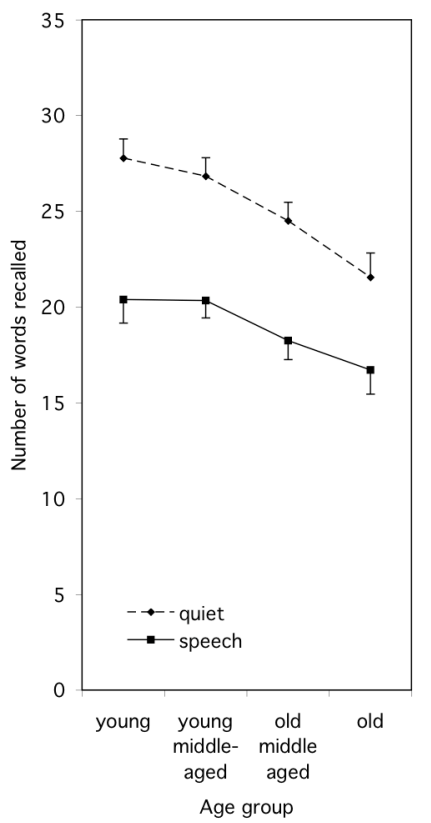

C

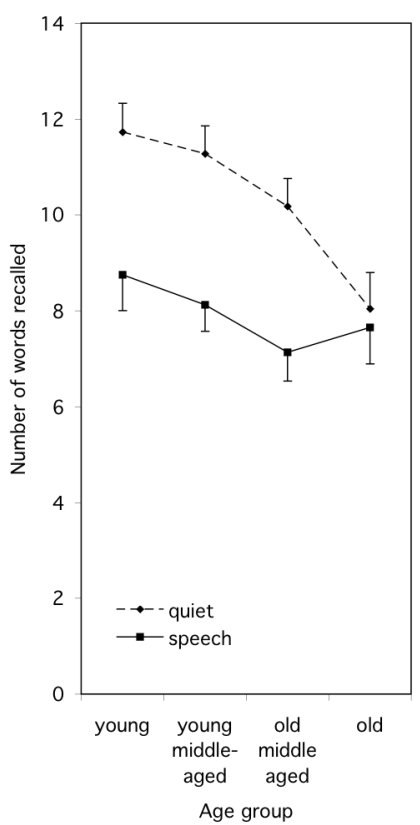

Figure 1. Mean performance on trial 1 (A), immediate recall (B), and delayed recall (C) as a function of noise and age. Error bars represent standard errors of the mean. 


\section{Effects of education in relation to age and irrelevant speech on word- learning performance}

Figure 2 shows the mean performance (number of words recalled) on trial 1, immediate recall, and delayed recall presented per noise condition and educational level. We found main effects of education on all dependent measures, indicating that higher educated participants performed better than lower educated participants: trial 1, $F(1,201)=3.9, p=.05$, partial $\eta^{2}=.019(M s=4.5$ and 5.0 for low and high education, respectively); immediate recall, $F(1,201)=12.6, p<.01$, partial $\eta^{2}=.061(\mathrm{Ms}=$ 20.7 and 23.4); and delayed recall, $F(1,201)=20.2, p<.01$, partial $\eta^{2}=.094(M s=8.1$ and 10.1). We also found one statistically significant interaction, namely, between irrelevant speech and education on trial $1, F(1,201)=6.1, p=.014$, partial $\eta^{2}=.03$. We analyzed this interaction per condition to detect differences between educational levels. The higher educated participants outperformed the lower educated participants when there was no speech interference, $F(1,201)=11.9, p<.01$, but not when there was speech interference. We found no age $\mathrm{x}$ education (values of $F<1.5, p>.25$ ) and age $\mathrm{x}$ noise $\mathrm{x}$ education (values of $F<2, p>.13$ ) interactions.

A

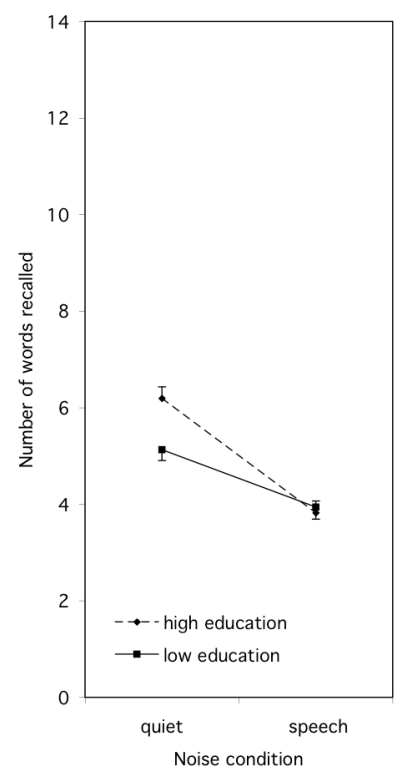

B

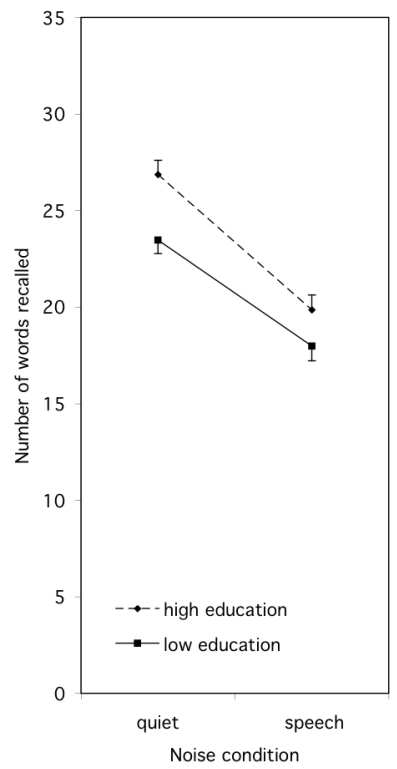

C

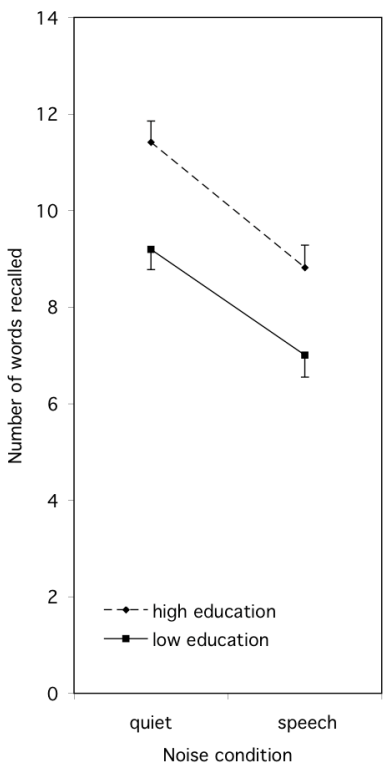

Figure 2. Mean performance on trial 1 (A), immediate recall (B), and delayed recall (C) as a function of education and noise. Error bars represent standard errors of the mean. 


\section{DISCUSSION}

The present study is one of the few studies that assessed the effect of irrelevant speech on word learning. In previous research, this effect was mainly studied on serial recall. The present experiment clearly demonstrates that irrelevant speech consisting of single words interferes with word learning. The results showed no age by speech interactions, indicating that the effects of noise on verbal learning performance are equal for older and younger adults. Higher educated individuals outperformed lower educated individuals on trial 1 only in the quiet condition, which does not support the hypothesis that a high level of education attenuates the effect of irrelevant speech. Apparently, short-term memory, as measured in trial 1, is especially vulnerable to the negative effects of irrelevant speech: Individuals with better cognitive abilities (i.e., higher educated persons) perform at the same level as individuals with poor cognitive abilities when there is background noise.

In the light of the results of this first experiment, which demonstrated no increased vulnerability to interference from irrelevant speech in older adults, we found it important to study verbal learning under an even more restrictive learning condition. In daily life, there are numerous situations in which information has to be processed very quickly, attention has to be divided between multiple sources of information, and irrelevant stimuli have to be ignored. Controlled experimental procedures to examine age differences in cognitive performance are generally easier than these demanding situations in daily life. In relatively simple test situations, there is more opportunity for older adults to use compensatory strategies, which may obscure the potential cognitive vulnerabilities in older adults. We addressed this issue in Experiment 2.

\section{EXPERIMENT 2}

In this second experiment, we aim to increase the difficulty of the VVLT in an experimentally controlled way in order to mimic the complexity of an everyday situation to test whether an age-related decrease in performance could be demonstrated. We accomplished this by varying the ISI, which was either long (i.e., $2 \mathrm{~s}$ ) or short (i.e., $0.5 \mathrm{~s}$ ). Our main question was whether age differences in recall would be greater with a short ISI than with a long ISI after a learning phase with irrelevant speech.

\section{METHODS}

\section{Participants}

For the second experiment, we reused the data of the 112 participants that took part in the noise condition of Experiment 1 for the ISI condition with $2 \mathrm{~s}$. We recruited 105 other healthy participants aged 24 to 77 years from the Maastricht Aging 
Study for the ISI condition with 0.5 s. See Table 2 and the Participants section of Experiment 1 for further details.

\section{Design}

Again, we chose a 4 × 2 × 2 cross-sectional design, this time with four consecutive age groups, two ISI conditions, and two educational levels. We used the same VVLT as in Experiment 1. We assigned the participants to either a condition with an ISI of $2 \mathrm{~s}$ or a condition with an ISI of $0.5 \mathrm{~s}$. We combined both ISI conditions with irrelevant speech; we included no quiet condition. We used the ISI, defined as the duration in seconds between the disappearance of one word and the arrival of the consecutive word, as a between-subject variable in order to avoid carryover effects caused by repeated testing.

\section{Measures}

\section{Characteristics of the participants}

We assessed age, education, hearing acuity, and vocabulary in the same way as in Experiment 1.

\section{Task and dependent variables}

We used the same VVLT and dependent variables as in the noise condition of Experiment 1. We presented the visual words for $1 \mathrm{~s}$ with a 2 -s or 0.5 -s ISI. As in Experiment 1, we presented the auditory words for a maximum of $1 \mathrm{~s}$, starting $500 \mathrm{~ms}$ after the onset of the visually presented words in both ISI conditions.

\section{Data analysis}

We carried out a $4 \times 2 \times 2$ analysis of covariance over the first trial, immediate recall, and delayed recall to assess main effects of age (young, young middle-aged, old middle-aged, and old), ISI ( 2 and $0.5 \mathrm{~s}$ ), education (low, high), and all possible interaction effects between these factors. Post hoc power analyses on the available number of participants using a medium critical effect size of 0.15 and an alpha level of $p=0.05$ resulted in a power of 0.99 . Otherwise, our data analysis was the same as in Experiment 1 .

\section{RESULTS}

The characteristics of the sample are shown in Table 2 . We used the data of 214 individuals in the analyses, because 3 participants did not have a hearing acuity measure. The age groups were comparable with respect to sex. The older participants were significantly less educated than the younger participants, $\chi^{2}(3, N=214)=38.8, p<$ .01 . The four consecutive age groups did not differ on vocabulary, $F(3,206)=2.20, p$ $=.08$. The vocabulary scores of the higher educated persons were higher than those for the lower educated persons, $F(1,206)=67.4, p<.01(M s=11.9$ and 15.3). Hearing acuity differed significantly between age groups, $F(3,206)=40.2, p<.01$, and 
educational levels differed on hearing acuity too, $F(1,206)=10.9, p<.01(M \mathrm{~s}=16.1$ and 12.3 for low and high education, respectively).

Table 2. Participant characteristics per age group (in years) for Experiment 2

\begin{tabular}{lcccc}
\hline Characteristic & $\begin{array}{c}\text { Young } \\
(24-37)\end{array}$ & $\begin{array}{c}\text { Young middle-aged } \\
(39-51)\end{array}$ & $\begin{array}{c}\text { Old middle-aged } \\
(54-66)\end{array}$ & $\begin{array}{c}\text { Old } \\
(69-77)\end{array}$ \\
\hline $\mathrm{N}$ & 55 & 60 & 62 & 37 \\
Age: $M(S D)$ & $30.2(4.4)$ & $45.3(4.1)$ & $60.5(4.3)$ & $72.6(2.6)$ \\
Male-to-female ratio $(n / n)$ & $28 / 27$ & $30 / 30$ & $32 / 30$ & $17 / 20$ \\
Low or high education: $(n / n)$ & $13 / 42$ & $32 / 28$ & $49 / 13$ & $25 / 12$ \\
Educational level: $M(S D)$ & $4.8(1.8)$ & $3.7(1.9)$ & $2.6(1.6)$ & $2.9(1.9)$ \\
Vocabulary $(S E M)$ & $12.7(0.4)$ & $13.8(0.3)$ & $13.6(0.4)$ & $14.3(0.4)$ \\
Hearing acuity $(S D)$ & $6.90(4.7)$ & $9.8(5.6)$ & $14.6(7.2)$ & $26.1(12.2)$ \\
\hline
\end{tabular}

\section{Effects of age and ISI on word-learning performance with irrelevant speech}

In Figure 3, the mean performance (number of words recalled) is presented per age group and ISI. We found main effects of age on immediate recall, $F(3,196)=5.4$, $p<.01$, partial $\eta^{2}=.076(M \mathrm{~s}=21.3,19.0,17.9$, and 15.5 for each consecutive age group, respectively) and delayed recall, $F(3,196)=2.9, p=.033$, partial $\eta^{2}=.044(M \mathrm{~s}$ $=9.1,7.9,7.4$, and 6.4), indicating that the performance of the older adults was worse than that of the younger adults. None of the contrasts between the consecutive age groups were significant. We found a main effect of ISI only on trial 1: Performance was better with the longer ISI than with the shorter ISI, $F(1,196)=8.2, p<.01$, partial $\eta^{2}=.040(M \mathrm{~s}=3.9$ and 3.2). There was a significant interaction between age and ISI on delayed recall, $F(3,196)=3.5, p=.017$, partial $\eta^{2}=.050$. We analyzed this interaction per age group. Performance in the condition with the short ISI was worse than that in the condition with the long ISI only in the oldest age group, $F(1,31)=$ 11.6, $p<.01$. In other age groups, we found no effect of ISI (values of $F<1.4, p>$ $.25)$. We found a trend to a significant interaction between ISI and age on immediate recall, $F(3,196)=2.3, p=.079$, partial $\eta^{2}=.034$. This indicates a similar pattern, namely that the performance of older adults was worse than that of younger adults in the short ISI condition with irrelevant speech. Hearing acuity did not significantly affect memory performance. When we performed analyses without hearing acuity in the model, results remained the same. 
A

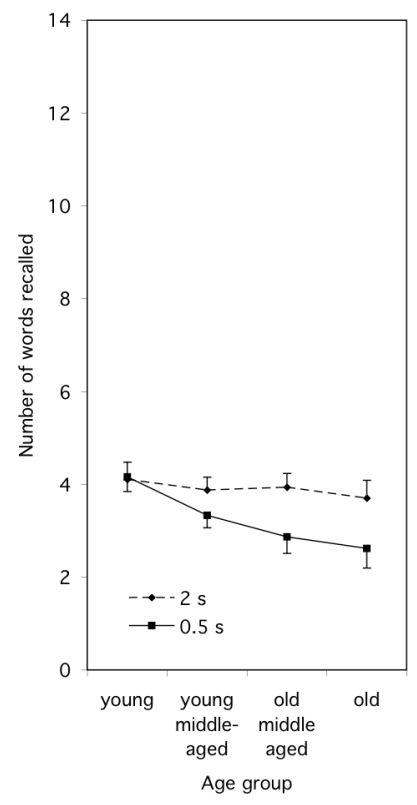

B

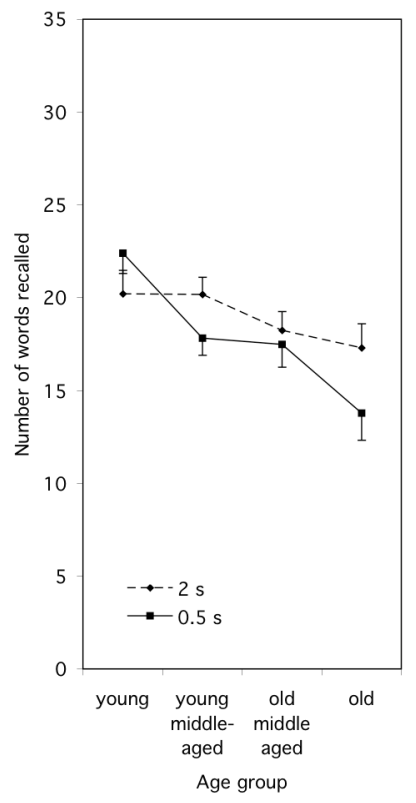

C

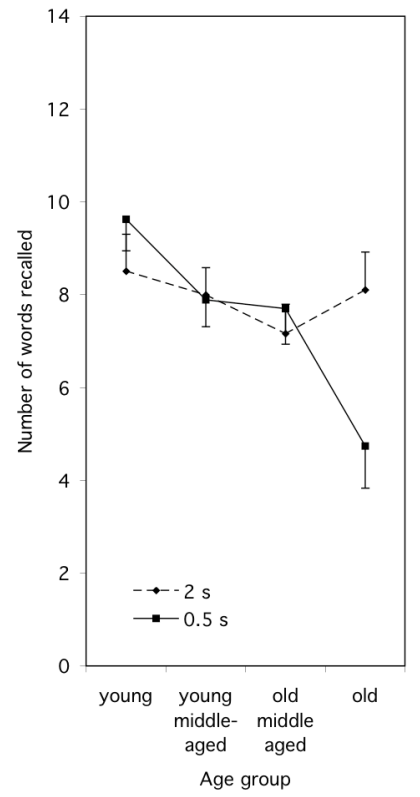

Figure 3. Mean performance on trial 1 (A), immediate recall (B), and delayed recall (C) as a function of age and ISI. Error bars represent standard errors of the mean.

\section{Effects of education in relation to age and ISI on word-learning per- formance with irrelevant speech}

The higher educated participants outperformed the lower educated participants only on delayed recall, $F(1,196)=4.9, p=.028$, partial $\eta^{2}=.024(M \mathrm{~s}=8.3$, and 7.1). We found a three-way age $\mathrm{x}$ ISI $\mathrm{x}$ education interaction on trial $1, F(3,196)=2.8, p=$ .042 , partial $\eta^{2}=.041$. We analyzed this interaction per educational level to detect age $\mathrm{x}$ ISI interactions. We found a significant age $\mathrm{x}$ ISI interaction in the higher educated group, $F(3,85)=4.1, p<.01$, whereas we found no such interaction in the lower educated group. Figure 4 shows that in the higher educated group, the youngest participants performed better with the short ISI than with the long ISI, whereas this pattern was reversed in older participants. We found no age $\mathrm{x}$ education (values of $F<1, p>$ .35 ) and ISI $x$ education (values of $F<1.5, p>.2$ ) interactions. 
A

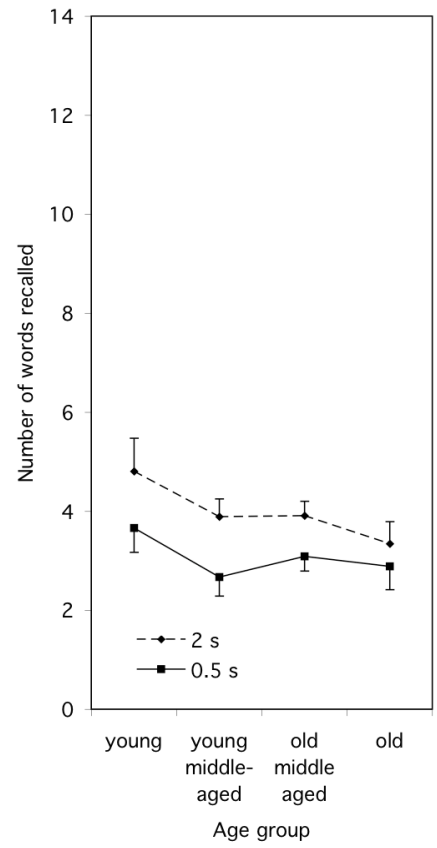

B

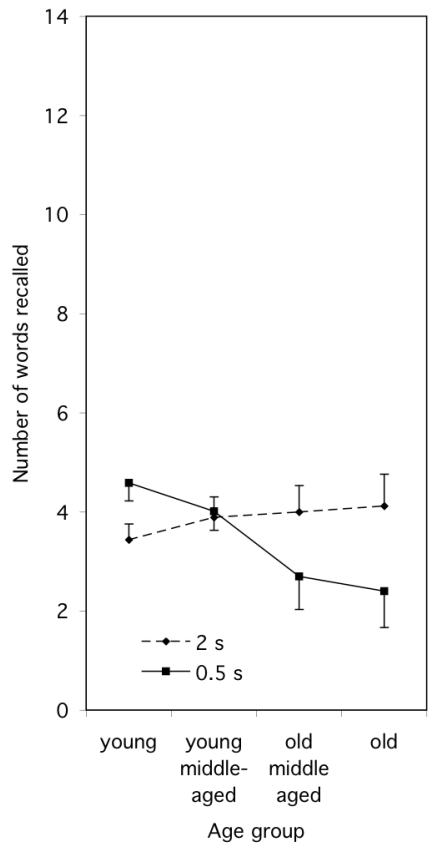

Figure 4. Mean performance on trial 1 as a funtion of age and ISI in low education (A) and high education (B). Error bars represent standard errors of the mean.

\section{Effects of age, ISI, and education on intrusions of irrelevant spoken words}

We also recorded and used the total number of words from the auditory distracter list recalled over the five learning trials (immediate recall intrusions) and the number of words from the auditory distracter list recalled during delayed recall (delayed recall intrusions) as dependent variables. We used two univariate analyses of variance with the covariates of hearing acuity and sex to analyze differences between age groups, ISIs, and educational levels. In Figure 5, the total number of words from the auditory distracter list recalled over the five learning trials is presented per age group and ISI. There was a main effect of age on immediate recall intrusions, $F(3,195)=9.5$, $p<.01$, partial $\eta^{2}=.13$, and on delayed recall intrusions, $F(3,195)=2.8$, $p=.04$, partial $\eta^{2}=.04(M \mathrm{~s}=0.09,0.3,0.5$, and 0.3$)$. This indicates that the number of intrusion errors increased with age. We found a main effect of ISI in immediate recall intrusions, $F(3,195)=11.6, p<.01$, partial $\eta^{2}=.06$, indicating that the number of intrusions was larger in the condition with short ISI. In addition, a significant age $\mathrm{x}$ ISI interaction on immediate recall intrusions, $F(3,195)=2.9, p=.035$, partial $\eta^{2}=.04$, indicated that the difference in intrusions between the ISI conditions became larger with age. We also found an age $\mathrm{x}$ ISI $\mathrm{x}$ education interaction on immediate recall intrusions, $F(3,195)=$ 4.6, $p<.01$, partial $\eta^{2}=.07$. In the higher educated group, the difference in intrusions 
between the ISI conditions became larger with age from young age on, but this difference was gone in the oldest participants, whereas in the lower educated group, the difference in intrusions between the ISI conditions became larger with age mainly from middle age on and remained in the oldest group. There were no main effects of education, or age $\mathrm{x}$ education and ISI $\mathrm{x}$ education interactions (values of $F<1.5, p>.2$ ).

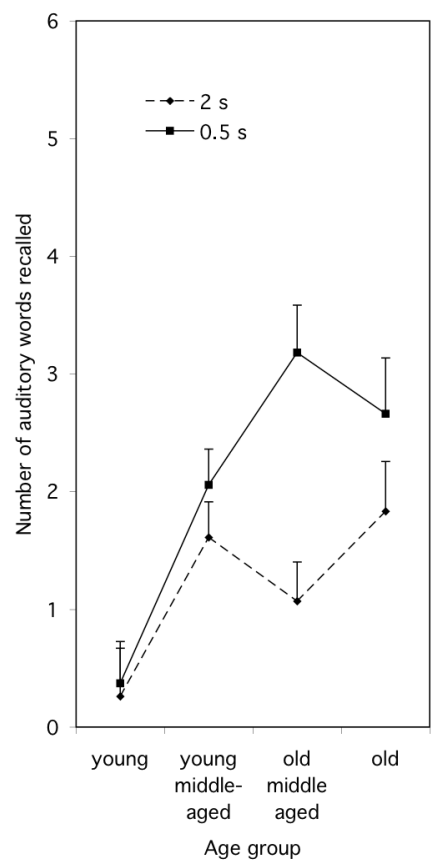

Figure 5. Total number of words recalled over the five learning trials from the auditory distracter list as a function of age and ISI. Error bars represent standard errors of the mean.

\section{DISCUSSION}

Age differences in the performance on delayed recall were larger in a short relative to a long ISI condition with irrelevant speech. One interpretation is that the efficiency of information processing is compromised in older adults, especially when time is a constraint. Another interpretation might be that irrelevant stimuli that are presented more quickly are harder to suppress and thus should have an increasing effect on performance as inhibitory abilities decline. The finding that age differences in intrusion errors were also larger in the short relative to the long ISI condition substantiates this interpretation.

The age by ISI by education interaction on trial 1 suggests that there were age differences in the low education group regardless of the ISI that was used. In contrast, age differences were only observed in the high education group when the short ISI was 
used. This suggests that education protects against age-related cognitive change, but that its protective power reaches a limit when the tasks demands are increased.

\section{GENERAL Discussion}

A main outcome of Experiment 1 is that irrelevant speech interferes with word learning across all age groups. The results of the few previous studies that investigated effects of irrelevant speech on free recall of 16 words are equivocal. Whereas Neely and LeCompte (1999) did find an effect of irrelevant single words, researchers found no effects of irrelevant non-words (LeCompte, 1994; Salamé \& Baddeley, 1990) and background conversation (Knez \& Hygge, 2002). The failure to find an effect of irrelevant speech in three of these four studies might be due to the selection of relatively young university students. By definition, students have a high level of education, whereas the present study included people with high and low levels of education. Although the current findings did not show that people with high education experienced less interference from irrelevant speech than did people with low education, the results clearly demonstrate that higher educated individuals had a better memory performance. Memory performance may be more vulnerable to irrelevant speech interference at low memory ability levels (Enmarker, 2004).

The results of Experiment 1 showed no age by noise interaction. Thus, the effects of irrelevant speech on verbal learning performance are equal for older and younger adults. These results contradict those of other studies reporting inhibition deficits in aging. This discrepancy may be due to differences in research paradigms. In contrast to the present study, in which relevant information was presented through the visual modality and irrelevant information was presented through the auditory modality, most studies showing inhibitory deficits in older people involved the presentation of relevant and irrelevant stimuli within the same modality.

An advantage of the present paradigm above paradigms in which targets and distracters are both presented auditorily is that any age-related differences in performance can be attributed mainly to cognitive deficits rather than to perceptual deficits. Although there is extensive evidence that noise affects speech perception (Murphy, McDowd, \& Wilcox, 1999; Pichora-Fuller, Schneider, \& Daneman, 1995) and shortterm memory performance (Murphy, Craik, Li, \& Schneider, 2000) more in older than in younger persons, these age-related deficits may be a function of hearing loss instead of decreased ability to inhibit irrelevant stimuli (Humes \& Christopherson, 1991; Schneider, Daneman, Murphy, \& Kwong See, 2000; Schneider, Daneman, \& PichoraFuller, 2002). Older adults may have more difficulty with noise because they do not hear the target stimulus as well as younger adults do.

The discrepancy between the results obtained with the present paradigm and paradigms in which targets and distracters are both presented visually may be due to the assessment of different specialized inhibitory subsystems, of which only some are affected by aging. Age-related differences in visual selective attention have been explained in terms of greater vulnerability to distraction during reading (Connelly, Hasher, \& Zacks, 1991), a weaker suppression effect in negative priming experiments (Connelly \& Hasher, 1993; Hasher, Stoltzfus, Zacks, \& Rypma, 1991; Kane et al., 1994; 
Stoltzfus, Hasher, Zacks, Ulivi, \& Goldstein, 1993), and more sustained activation of considered but rejected sentence completions (Hartman \& Hasher, 1991) and passage interpretations (Hamm \& Hasher, 1992) in older adults. The results of these studies indicate that older adults are less able to inhibit the identity or meaning of irrelevant verbal material (lexicosemantic inhibition). In contrast, the general explanation for the irrelevant speech effect is that the interference caused by irrelevant speech is exclusively due to perceptual or phonological characteristics of speech. The phonological store hypothesis (Salamé \& Baddeley, 1982) proposes the existence of a store that holds information coded at a phonological level; irrelevant speech has direct access to this store and may interfere with retention of the visual information that is recoded into a phonological representation (Baddeley, 2003; Larsen \& Baddeley, 2003). Therefore, the results reported here suggest that phonological inhibition, in contrast to lexicosemantic inhibition, is preserved in older people, at least under unconstrained conditions. Thus, inhibitory capacity is not a single function that is generally affected by the aging process (Kramer, Humphrey, Larish, Logan, \& Strayer, 1994). Interestingly, the present results demonstrate that older participants report more irrelevant spoken words than younger participants. This is in line with a study by Beaman (2004) in which it was demonstrated that students with a low working-memory span are also more likely to report the contents of irrelevant speech. This suggests that persons with efficient working-memory capacity, that is, younger persons, are less aware of the irrelevant or unattended stream, because they have more effectively inhibited the irrelevant information. In this way, the inhibition account of age-related differences does extend to an impaired ability to suppress irrelevant speech in older people.

The findings of Experiment 2 confirm that age-related differences in performance become more pronounced in the presence of irrelevant speech if the ISI is relatively short. To our knowledge, this is the first study in which irrelevant speech and a short ISI were combined in order to increase task complexity. Previous research has shown that the performance of older individuals is not disproportionately compromised by a short ISI (Craik \& Rabinowitz, 1985) and irrelevant speech alone (Experiment 1 of the present study), but when these factors are combined, the performance of older adults is compromised more than is the performance of younger adults. In addition to larger age differences in intrusion errors in the short relative to the long ISI condition, this suggests that inhibitory processes in older adults are less efficient under time pressure. When extended to daily life, this suggests that older people need more time to memorize verbal information when they are in a noisy environment. 


\section{REFERENCES}

Baddeley, A. (2003). Working memory: Looking back and looking forward. Nature Reviews Neuroscience, 4, 829-839.

Beaman, C. P. (2004). The irrelevant sound phenomenon revisited: What role for working memory capacity? Journal of Experimental Psychology: Learning Memory and Cognition, 30, 1106-1118.

Beaman, C. P. (2005). Irrelevant sound effects amongst younger and older adults: Objective findings and subjective insights. European Journal of Cognitive Psychology, 17, 241-265.

Bosma, H., Van Boxtel, M. P., Ponds, R. W. H. M., Houx, P., \& Jolles, J. (2003). Education and age-related cognitive decline: The contribution of mental workload. Educational Gerontology, 29, 1-9.

Brand, N., \& Jolles, J. (1985). Learning and retrieval rate of words presented auditorily and visually. The Journal of General Psychology, 112, 201-210.

Buchner, A., Faul, F., \& Erdfelder, E. (1992). GPOWER: A priori-, post hoc-, and compromise power analyses for the Macintosh (Version 2.1). Bonn, Germany: Bonn University.

Coffey, C. E., Saxton, J. A., Ratcliff, G., Bryan, R. N., \& Lucke, J. F. (1999). Relation of education to brain size in normal aging: Implications for the reserve hypothesis. Neurology, 53(1), 189-196.

Connelly, S. L., \& Hasher, L. (1993). Aging and the inhibition of spatial location. Journal of Experimental Psychology: Human Perception and Performance, 19, 1238-1250.

Connelly, S. L., Hasher, L., \& Zacks, R. T. (1991). Age and reading: The impact of distraction. Psychology and Aging, 6, 533-541.

Craik, F. I. M., \& Rabinowitz, J. C. (1985). The effects of presentation rate and encoding task on agerelated memory deficits. Journal of Gerontology, 40, 447-454.

Davis, A. (1995). Hearing in adults. Nottingham, England: Whurr.

de Bie, S. E. (1987). Standaardvragen 1987: Voorstellen voor uniformering van vraagstellingen naar achergrondkernmerken en interviews [Standard questions 1987: Proposal for uniformisation of questions regarding background variables and interviews]. (2nd ed.). Leiden, The Netherlands: Leiden University Press.

Dempster, F. N., \& Brainerd, C. J. (Eds.). (1995). Interference and inbibition in cognition. San Diego, CA: Academic Press.

Enmarker, I. (2004). The effects of meaningful irrelevant speech and road traffic noise on teachers' attention, episodic and semantic memory. Scandinavian Journal of Psychology, 45, 393-405.

Eysenck, M. W. (1974). Age differences in incidental learning. Developmental Psychology, 10, 936-941.

Gold, D. P., Andres, D., Etezadi, J., Arbuckle, T., Schwartzman, A., \& Chaikelson, J. (1995). Structural equation model of intellectual change and continuity and predictors of intelligence in older men. Psychology and Aging, 10, 294-303.

Hamm, V. P., \& Hasher, L. (1992). Age and the availability of inferences. Psychology and Aging, 7, 56-64.

Hartman, M., \& Hasher, L. (1991). Aging and suppression: Memory for previously relevant information. Psychology and Aging, 6, 587-594.

Hasher, L., Stoltzfus, E. R., Zacks, R. T., \& Rypma, B. (1991). Age and inhibition. Journal of Experimental Psychology: Learning, Memory and Cognition, 17, 163-169.

Hasher, L., \& Zacks, R. (1988). Working memory, comprehension, and aging: A review and a new view. The Psychology of Learning and Motivation, 22, 193-225.

Helfer, K. S. (1992). Aging and the binaural advantage in reverberation and noise. Journal of Speech and Hearing Research, 35, 1394-1401.

Humes, L. E., \& Christopherson, L. (1991). Speech identification difficulties of hearing-impaired elderly persons: The contributions of auditory processing deficits. Journal of Speech, Language and Hearing Research, 34, 686-693.

Jolles, J., Houx, P., Van Boxtel, M. P., \& Ponds, R. W. (Eds.). (1995). Maastricht Aging Study: Determinants of cognitive aging. Maastricht: Neuropsych Publishers. 
Kane, M. J., Hasher, L., Stoltzfus, E. R., Zacks, R. T., \& Connelly, S. L. (1994). Inhibitory attentional mechanisms and aging. Psychology and Aging, 9, 103-112.

Kjellberg, A., Landstrom, U., Tesarz, M., Soderberg, L., \& Akerlund, E. (1996). The effects of nonphysical noise characteristics, ongoing task and noise sensitivity on annoyance and distraction due to noise at work. Journal of Environmental Psychology, 16, 123-136.

Knez, I., \& Hygge, S. (2002). Irrelevant speech and indoor lighting: Effects on cognitive performance and self-reported affect. Applied Cognitive Psychology, 16, 709-718.

Kramer, A. F., Humphrey, D. G., Larish, J. F., Logan, G. D., \& Strayer, D. L. (1994). Aging and inhibition: Beyond a unitary view of inhibitory processing in attention. Psychology and Aging, 9, 491-512.

Larsen, J. D., \& Baddeley, A. (2003). Disruption of verbal STM by irrelevant speech, articulatory suppression, and manual tapping: Do they have a common source? Quarterly Journal of Experimental Psychology A, 56, 1249-1268.

LeCompte, D. C. (1994). Extending the irrelevant speech effect beyond serial recall. Journal of Experimental Psychology: Learning, Memory and Cognition, 20, 1396-1408.

LeCompte, D. C., Neely, C. B., \& Wilson, J. R. (1997). Irrelevant speech and irrelevant tones: the relative importance of speech to the irrelevant speech effect. Journal of Experimental Psychology: Learning, Memory and Cognition, 23, 472-483.

Luteijn, F., \& Van der Ploeg, F. A. E. (1983). Handleiding Groninger Intelligentietest (GIT) [Manual for the Groningen Intelligence Test]. Lisse, The Netherlands: Swets and Zeitlinger.

Lutman, M. E., Gatehouse, S., \& Worthington, A. G. (1991). Frequency resolution as a function of hearing threshold level and age. Journal of the Acoustical Society of America, 89, 320-328.

McDowd, J. M., Oseas-Kreger, D. M., \& Filion, D. L. (1995). Inhibitory processes in cognition and aging. In C. J. Brainerd (Ed.), Interference and inbibition in cognition (pp. 363-400). San Diego, CA: Academic Press.

Metsemakers, J. F., Hoppener, P., Knottnerus, J. A., Kocken, R. J., \& Limonard, C. B. (1992). Computerized health information in The Netherlands: A registration network of family practices. British Journal of General Practice, 42, 102-106.

Murphy, D. R., Craik, F. I., Li, K. Z., \& Schneider, B. A. (2000). Comparing the effects of aging and background noise on short-term memory performance. Psychology and Aging, 15, 323-334.

Murphy, D. R., McDowd, J. M., \& Wilcox, K. A. (1999). Inhibition and aging: Similarities between younger and older adults as revealed by the processing of unattended auditory information. Psychology and $\mathrm{Ag}$ ing, 14, 44-59.

Neely, C. B., \& LeCompte, D. C. (1999). The importance of semantic similarity to the irrelevant speech effect. Memory and Cognition, 27, 37-44.

Petros, T. V., Zehr, D., \& Chabot, R. (1983). Adult age differences in accessing and retrieving information from long-term memory. Gerontology, 38, 589-592.

Pichora-Fuller, M. K., Schneider, B. A., \& Daneman, M. (1995). How young and old adults listen to and remember speech in noise. Journal of the Acoustical Society of America, 97, 593-608.

Rabinowitz, J. C. (1989). Age deficits in recall under optimal study conditions. Psychology and Aging, 4, 378380.

Rey, A. (1964). L'examen psychologique dans les cas d'encéphalopathie traumatique [Psychological assessment in cases of traumatic brain injury]. Paris: Presses Universitaires de France.

Rouleau, N., \& Belleville, S. (1996). Irrelevant speech effect in aging: An assessment of inhibitory processes in working memory. Journals of Gerontology: Psychological Sciences, 51B, P356-P363.

Salamé, P., \& Baddeley, A. (1982). Disruption of short-term memory by unattended speech: implications for the structure of working memory. Journal of Verbal Learning and Verbal Behavior, 21, 150-164.

Salamé, P., \& Baddeley, A. (1990). The effects of irrelevant speech on immediate free recall. Bulletin of the Psychonomic Society, 28, 540-542.

Salthouse, T. A. (1996). The processing-speed theory of adult age differences in cognition. Psychological Review, 103, 403-428. 
Schneider, B. A., Daneman, M., Murphy, D. R., \& Kwong See, S. (2000). Listening to discourse in distracting settings: The effects of aging. Psychology and Aging, 15, 110-125.

Schneider, B. A., Daneman, M., \& Pichora-Fuller, M. K. (2002). Listening in aging adults: From discourse comprehension to psychoacoustics. Canadian Journal of Experimental Psychology, 56, 139-152.

Sommers, M. S. (1997). Speech perception in older adults: The importance of speech-specific cognitive abilities. Journal of the American Geriatric Society, 45, 633-637.

Stern, Y. (2002). What is cognitive reserve? Theory and research application of the reserve concept. Journal of the International Neuropsychological Society, 8, 448-460.

Stoltzfus, E. R., Hasher, L., Zacks, R. T., Ulivi, M. S., \& Goldstein, D. (1993). Investigations of inhibition and interference in younger and older adults. Journal of Gerontology: Psychological Sciences, 48, P179P188.

UNESCO. (1976). International Standard Classification of Education (ISCED). Paris: Author.

Vakil, E., \& Blachstein, H. (1993). Rey Auditory-Verbal Learning Test: Structure analysis. Journal of Clinical Psychology, 49, 883-890.

Van Boxtel, M. P., Buntinx, F., Houx, P. J., Metsemakers, J. F., Knottnerus, A., \& Jolles, J. (1998). The relation between morbidity and cognitive performance in a normal aging population. Journal of Gerontology: Medical Sciences, 53 A, M147-M154.

Van der Elst, W., Van Boxtel, M. P., Van Breukelen, G. J., \& Jolles, J. (2005). Rey's verbal learning test: Normative data for 1855 healthy participants aged 24-81 years and the influence of age, sex, education, and mode of presentation. Journal of the International Neuropsychological Society, 11, 290-302.

Van der Elst, W., Van Boxtel, M. P. J., Van Breukelen, G. J. P., \& Jolles, J. (2006). The Stroop Color-Word Test: Influence of age, sex, and education; and normative data for a large sample across the adult age range. Assessment, 13, 62-79.

Van Gerven, P. W. M., Meijer, W. A., Vermeeren, A., Vuurman, E. F., \& Jolles, J. (in press). The irrelevant speech effect and the level of interference in aging. Experimental Aging Research. 


\title{
Chapter 5
}

\section{Level of processing and reaction time in young and middle-aged adults and the effect of education}

\author{
Willemien A. Meijer, Renate H. M. de Groot, Pascal W. M. van Gerven, Martin P. J. van \\ Boxtel \& Jelle Jolles \\ Submitted for publication
}

\begin{abstract}
The first aim was to examine whether differences in reaction time (RT) between younger (25 to 35 years) and middle-aged (50 to 60 years) individuals increase with deeper processing. The second aim was to examine whether this increase is less pronounced in higher educated individuals. Perceptual, phonological, and semantic processing of words was induced by a case decision, an 'e' detection, and a living/nonliving task respectively. RTs increased with age and level of processing. There were no interactions between age, task and education, suggesting that different processing levels are equally sensitive to slowing in midlife and that education was not a moderating factor. Although no overall age by level of processing interaction was found, the age by stimulus type interactions in the deeper processing tasks suggest that a cognitive vulnerability already exists in middle age. It was found that age-related differences in RT on words containing the letter 'e' were smaller than on words without the letter 'e', suggesting that middle-aged adults were slower than younger adults in performing a terminating search strategy. Furthermore, it was found that agerelated differences in RT on words referring to living items were smaller than on words referring to non-living items. This suggests that middleaged adults compared to younger adults have reduced access to specific semantic categories.
\end{abstract}


In most studies on age-related cognitive differences, comparisons have been made between relatively young adults (usually in their 20s) and older adults (usually older than 65). The age range between 30 and 60 is often disregarded. Yet, this range may be of particular interest because the first manifestations of age-related cognitive change (Houx \& Jolles, 1993; Houx, Jolles \& Vreeling, 1993; Houx, Vreeling \& Jolles, 1991; Rabbitt, 1993) (Ponds, Commissaris \& Jolles, 1997) can already be seen from age 35. Middle-aged adults may need to invest more cognitive effort in daily life to achieve the same performance as young adults especially in cognitively demanding situations in which much information has to be processed simultaneously and under time pressure.

To test the hypothesis that middle-aged adults are less cognitively efficient than young adults especially in resource-demanding situations, an experimental paradigm is needed that involves conditions varying in processing demands and a measure of cognitive efficiency. Such a paradigm can be based on the notion that various processing levels are involved in visual word recognition (Borowsky \& Besner, 1993; Ellis \& Young, 1996; Seidenberg \& McClelland, 1989). Recent studies indicated that tasks involving different types of decisions about words could be used to invoke different levels of visual word processing. Relevant levels are the orthographic level at which visual features are integrated to form orthographic patterns, a lexical level at which the phonological (and possibly the whole-word orthographic) representation of the printed word is activated, and a semantic level at which the meaning of the word is accessed (Bentin, Mouchetant-Rostaing, Giard, Echallier \& Pernier, 1999).

Previous studies have compared processing of printed words at different levels between young and old adults in order to investigate which levels of word processing are most vulnerable to age-related slowing. An early study (Petros, Zehr \& Chabot, 1983) suggested that deeper processing stages involving the activation of semantic information are more vulnerable to age-related slowing than more shallow processing stages in which the word is only visually processed. That is, when different types of judgments regarding word pairs were made (i.e. whether two words were physically identical, similar in name, or belonged to the same semantic category), there was a disproportionate increase in older adults' reaction time in the semantic category judgments compared to the more shallow processing conditions. However, as pointed out by Madden (1985), comparison and decision processes are important factors when two words have to be compared. A particular interaction between response selection load and processing level may have led to the disproportional slowing in the semantic activation that was found by Petros et al. (1983).

In contrast to the relatively intact shallow processing in older adults, as was found in the study by Petros et al. (1983), more recent studies of age-related effects on lexical decision performance (i.e. speed of word/non-word discrimination) suggest that the shallow processing stages of visual encoding are more vulnerable to age-related slowing than the deeper stages of semantic processing. The effects of word frequency and semantic priming on reaction time, for example, have been found to be equal for young and older adults (Allen, Madden, Weber \& Groth, 1993; Madden, Pierce \& Allen, 1993). Other variables, such as stimulus quality (e.g. spacing between letters or case type), can lead to disproportionate slowing of older adults' responses (Allen et al., 1993; Madden, 1992; Madden et al., 1993). However, shallow and deeper levels of processing were not directly induced in these studies, but were inferred from the effects of stimulus quality (shallow processing) and word frequency or semantic priming 
(deep processing) on lexical decision performance. In addition, because these effects were assessed in different experiments, an actual differential effect of age on levels of processing may not have been established.

Because previous studies yielded equivocal results, differences in reaction time (RT) on tasks requiring a decision about a single word and inducing various levels of processing were compared in the present study. A comparison was drawn between a young and middle-aged group in order to examine whether middle-aged adults process information less efficiently than young adults in more resource-demanding conditions. Deeper, semantic processing is assumed to incorporate shallower perceptual and phonological processing stages. Therefore, the number of processing steps may increase with depth of processing, which would be reflected in longer RTs on tasks that induce deeper levels of processing. According to the information loss model of Myerson, Hale, Wagstaff, Poon, and Smith (1990), every processing step takes more time in older than in younger adults to compensate for loss of information. Because compensation for information loss is insufficient in older adults, processing time increases disproportionately with the number of processing steps (Myerson et al., 1990). A similar pattern is predicted by Salthouse's (1996) processing-speed theory. If complex processing operations are dependent on the products of simpler operations, and fewer of those products are available because of a slower processing speed, we may expect that the effects of age-related slow processing would be most pronounced on complex, i.e. deep operations. A first purpose of the present study is to examine if the implications of these cognitive aging theories apply to middle age. A disproportionate increase of RTs with depth of processing in middle-aged adults compared to younger adults would then be predicted.

Within the field of cognitive aging, relatively limited attention has been given to factors influencing the level of cognitive abilities in midlife (Willis \& Schaie, 2005). A high educational level may attenuate the age-related decrease in cognitive efficiency, because educational experience may provide reserve capacity in the form of a more elaborate set of basic skills or cognitive strategies (Stern, 2002). Indeed, a high educational level has been shown to attenuate age-related cognitive decline (e.g. Bosma, Van Boxtel, Ponds, Houx \& Jolles, 2003; Van der Elst, Van Boxtel, Van Breukelen \& Jolles, 2006b). In light of the potential protective effect of education, an interesting issue is whether age differences in visual word processing are smaller in higher educated persons. In addition, making a semantic judgment involves access to semantic memory, which may be more efficient in higher educated persons than in lower educated persons (Van der Elst et al., 2006a). A possible disproportionate increase of RT with depth of processing in middle-aged adults compared to younger adults may therefore be smaller in higher educated persons. Hence, another purpose of the present study was to examine whether level of education moderates age-related differences in RT on the decision tasks.

We compared differences in RTs between younger and middle-aged individuals with low and high educational attainment on three decision tasks, each designed to induce processing at a particular level: Deciding whether words were written in lower or uppercase letters was assumed to induce shallow perceptual/ orthographic processing (Bentin et al., 1999; Daselaar, Veltman, Rombouts, Raaijmakers \& Jonker, 2003). Deciding whether words contained the letter 'e' was assumed to induce more elaborate orthographic/phonological processing (Proverbio et al., 2004). Finally, deciding whether 
words referred to a living or a non-living item was assumed to invoke deep semantic processing (Daselaar et al., 2003; Tisserand, McIntosh, van der Veen, Backes \& Jolles, 2005).

In addition to the differences in level of processing, these tasks may also vary in the amount and type of search processes that are involved. In contrast to the case decision task, which hardly involves any search process, the 'e' detection and semantic decision tasks involve visual search and search of semantic memory respectively. Differences in RT between the responses on the two possible stimulus types within each decision task may provide insight into the use of search strategies. For instance, if the RT for the words containing the letter ' $\mathrm{e}$ ' is shorter than for the words not containing an 'e', this would suggest that a terminating search strategy is used, rather than an exhaustive search (Schneider \& Shiffrin, 1977). Furthermore, it has been suggested that living things are processed in specialized semantic subsystems (Caramazza \& Shelton, 1998). Mahon and Caramazza (2003) argue that evolutionary pressures have resulted in specialized systems only for those categories for which rapid and efficient identification could have had survival and reproductive advantages, i.e. living things. Thus living things should be processed faster than non-living things (Shapiro \& Olson, 2005). In this context, a shorter RT may be expected for the words referring to living things than to words referring to non-living things. To compare the use of search strategies per level of processing between young and middle-aged adults and between persons with low and high educational levels, we examined effects of age and education on response times of words in lowercase versus words in uppercase; words containing the letter ' $\mathrm{e}$ ' vs. words without the letter 'e'; and words referring to living items vs. words referring to non-living items.

\section{METHOD}

\section{Participants}

Eighty adults divided over two age groups and stratified for sex and educational level (low and high) participated in the study. The younger group consisted of 20 people with a low educational level and 20 higher educated people aged between 25 and 35 years (mean age $=29.0$ years, $S D=2.8$ ). The middle-aged group consisted of 20 people with a low educational level and 20 people with a high educational level aged between 50 and 60 (mean age $=56.1$ years, $S D=3.4$ ). Participants were recruited by advertisements in local newspapers and advertising at Maastricht University, companies and clubs (e.g. sports, music). There was a selection by telephone in order to exclude persons with health-related conditions known to interfere with normal cognitive functioning. Exclusion criteria were cerebrovascular pathology, psychiatric disturbances, neurological disorders, dyslexia, serious medical conditions with known impact on brain function such as renal dialysis, excessive use of alcohol $(>21$ consumptions/week), use of psychoactive medication or drugs, clinically overt visual or auditory deficits (van Boxtel et al 1998), and previous participation in cognitive experiments. The Ethics Committee of the Department of Psychology, Maastricht University, approved the study and participants gave their written informed consent. 
Level of education was assessed by classifying formal schooling according to a system commonly used in the Netherlands (de Bie, 1987), which is comparable to the International Standard Classification of Education (UNESCO, 1976). Educational level was scored in eight ordinal categories: 1) primary education, 2) lower vocational education, 3) intermediate secondary education, 4) intermediate vocational education, 5) higher secondary education, 6) higher vocational education, 7) higher professional education, and 8) university. In many western countries, persons between 50 and 60 are -generally- lower educated than persons between 25 and 35 . Thus, the median educational level in the population differs for the age ranges used in the present study (Mares, 2004). We attempted to deal with this cohort effect by adjusting the classification into a low and a high educational level according to the median level in each age group. A low level of education was defined in the young group as a maximum of intermediate vocational education (equivalent to a maximum of 13 years of education). A low level of education was defined in the middle-aged group as a maximum of intermediate secondary education (equivalent to a maximum of 10 years of education).

The characteristics of the sample are shown in Table 1. This table shows that the lower educated persons were a little older than the highly-educated persons in both the young, $F(1,38)=4.4, p<.05$, and the middle-aged group, $F(1,38)=6.0, p<.05$. Because the difference was at most 2.5 years, this was not considered to be a problem. The young and middle-aged participants did not perform differently on a 20 -item multiple-choice Dutch vocabulary test, which is used as a measure of Verbal Intelligence (Luteijn \& Van der Ploeg, 1983), $F(1,76)=3.1, p=.09$. The vocabulary scores of the highly-educated participants were higher than those for the poorly-educated participants, $F(1,76)=33.1, p<.01$.

Table 1. Participant characteristics

\begin{tabular}{lllll}
\hline & Young (25-35) & & Middle-aged (50-60) \\
\hline & $\begin{array}{l}\text { Low } \\
\text { educational } \\
\text { level }\end{array}$ & $\begin{array}{l}\text { High } \\
\text { educational } \\
\text { level }\end{array}$ & $\begin{array}{l}\text { Low } \\
\text { educational } \\
\text { level }\end{array}$ & $\begin{array}{l}\text { High } \\
\text { educational } \\
\text { level }\end{array}$ \\
\hline N & 20 & 20 & 20 & 20 \\
Age: mean $(S D)$ & $29.9(.64)$ & $28.1(.57)$ & $57.4(.61)$ & $54.9(.82)$ \\
Male/female ratio $(n / n)$ & $10 / 10$ & $10 / 10$ & $10 / 10$ & $10 / 10$ \\
Vocabulary $(S E M)$ & $11.7(.49)$ & $14.9(.49)$ & $12.9(.49)$ & $15.3(.49)$ \\
Left-/right-handedness $(\mathrm{n} / \mathrm{n})$ & $17 / 3$ & $16 / 4$ & $20 / 0$ & $19 / 1$ \\
\hline
\end{tabular}




\section{Design}

A cross-sectional design was used with two age groups (younger and middleaged) and two educational levels (low and high). All participants received three conditions, which yielded a $3 \times 2 \times 2$ full-factorial design with decision type (case decision, 'e' detection and semantic decision) as the within-groups variable. Age group and educational level were used as the between-groups factors.

\section{Materials and procedure}

There were three task conditions with 16 words presented in each condition. In the first condition, in which eight words were presented in uppercase and eight words in lowercase, the participants were asked to make a decision about the case of the letters. In the second condition, participants had to indicate whether or not the words contained the letter 'e'. In the last condition, participants were asked whether the words referred to a living or a non-living item. The order in which the conditions were presented was randomized within each age group per educational level. The words used in the experiment were mono- or disyllabic, varying in length between five and seven letters, and with a value of six or higher on a Dutch 7-point norm scale for imagery (Van Loon-Vervoorn, 1985). Words were centrally presented one at a time in white against black background on a computer screen (font: Arial, 50 pt.), using Eprime software (Schneider, Eschman \& Zuccolotto, 2002). The three conditions involved three word lists that were matched for word frequency, word length, and that all contained eight living items and eight words containing the letter 'e'.

Participants were seated in front of a 17" monitor at a normal viewing distance of approximately $60 \mathrm{~cm}$ ( $25 \mathrm{inch}$ ), and responded with either their left or right index finger using two response buttons. A right button press indicated 'uppercase', 'containing e', and 'living' for the three conditions respectively. The words were presented on the screen until a response was given, with a maximum of $1500 \mathrm{~ms}$, and a fixed interval of $2000 \mathrm{~ms}$ between the appearance of one word and the appearance of the next word. Participants were told to respond as quickly and accurately as possible. Although also accuracy measures were recorded, reaction time was the main dependent variable.

\section{Data analysis}

The number of correct responses (range 0 to 16) and reaction times corresponding to correct responses were checked for normality (Kolmogorov-Smirnov test) and homogeneity of variance. Based on this information, data transformation was not considered necessary. Repeated-measures ANOVAs were used to analyze between and within-group differences with sex as covariate. Statistically significant main effects of decision type were further analyzed following Fishers LSD procedure. In order to analyze differential age and education effects on reaction times of different stimulus types, a repeated-measures ANOVA was conducted per decision type with stimulus type as within-groups factor. Age group and educational level were used as betweengroups factors. Significant interactions were investigated by simple contrasts following Fishers LSD procedure. Post hoc power analyses on the number of participants (Buchner, Faul \& Erdfelder, 1992) using a medium critical effect size of 0.25 and an 
alpha level of .05 resulted in a power of 0.99 for the within-groups effects and 0.75 for the between-groups effects.

\section{RESULTS}

\section{Accuracy}

The average accuracy was high for both age groups, i.e. more than $88 \%$, although the older participants were somewhat less accurate than the young participants, $F(1,75)=7.3, p<.05$ (means are 14.8 and 14.2 for the young and middle-aged groups respectively). The accuracy scores of the highly-educated persons were higher than those for the poorly-educated persons, $F(1,75)=5.8, p<.05$ (means are 14.8 and 14.3 for the highly and poorly-educated groups respectively). Accuracy was not significantly affected by decision type, $F(2,150)=.06, p>.9$. Furthermore, age group did not interact with decision type, $F(2,150)=2.3, p>.1$. No age $\mathrm{x}$ decision type $\mathrm{x}$ education, education $\mathrm{x}$ age, and education $\mathrm{x}$ decision type interactions were found $(F$-values $<1.5, p$-values $>.2$ ).

\section{$\mathrm{RT}$ in different decision tasks}

In Figure 1 the mean reaction times corresponding to correct responses are presented per age group and decision task. A main effect of age was found, indicating that younger individuals outperformed older individuals, $F(1,75)=14.8, p<.01$, partial $\eta^{2}$ $=.17$ (mean RTs over all conditions are 690 and $769 \mathrm{~ms}$ for the young and middleaged groups respectively). A main effect of decision type and significant contrasts between the three types indicated that people had longer reaction times in the semantic decision task than in the 'e' detection task, and longer RTs in the 'e' detection task than in the case decision task, $F(2,150)=24.5, p<.01$, partial $\eta^{2}=.25$ (means are 828, 724 , and $635 \mathrm{~ms}$ for the semantic decision, 'e' detection, and case decision tasks respectively). No age by decision type interaction was found, indicating that the agerelated differences in RT performance did not differ across decision tasks, $F(2,150)=$ $1.8, p>.1$.

A main effect of education was found, indicating that people with a high educational level had shorter reaction times than people with a low educational level, $F(1,75)$ $=11.5, p<.01$, partial $\eta^{2}=.13$ (means are 764 and $695 \mathrm{~ms}$ for low and high educational levels respectively). No age $\mathrm{x}$ decision type $\mathrm{x}$ education, education $\mathrm{x}$ age, and education $\mathrm{x}$ decision type interactions were found $(F$-values $<1, p$-values $>.6)$. Results were essentially the same when left-handed participants were excluded from the analyses. 


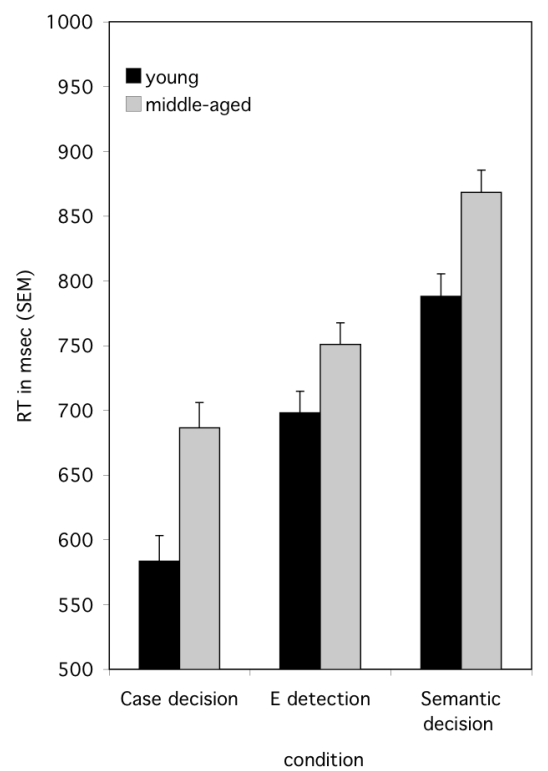

Figure 1. Mean reaction time as a function of age and condition. Error bars represent standard errors of the mean.

\section{RT split by stimulus type per decision task}

In Figure 2 the mean reaction times are presented per age group and stimulus type for each decision task. With respect to case decision, no difference in RT was found between response on uppercase and lowercase words, $F(1,75)=.08, p>.8$. Main effects of age, $F(1,75)=12.4, p<.01$, and education, $F(1,75)=8.4, p<.01$ (means are 673 and $593 \mathrm{~ms}$ for low and high educational levels respectively), but no interactions with stimulus type $(F$-values $<2$, $p$-values $>.19)$ were found. Within the 'e' detection task, a main effect of stimulus type was found, $F(1,75)=7.4, p<.05$, partial $\eta^{2}=.09$, indicating that the RT for the words containing the letter 'e' is shorter than for the words without 'e'. Besides a main effect of age, $F(1,75)=5.0, p<.05$, and education, $F(1,75)=7.8, p<.01$ (means are 756 and $691 \mathrm{~ms}$ for low and high education, respectively), an interaction between age and stimulus type was found, $F(1,75)=$ $6.7, p<.05$, partial $\eta^{2}=.08$. This indicates that the difference in RT between words with and without ' $e$ ' was larger in the old group. Regarding the semantic decision task, no main effect of stimulus type was found, $F(1,75)=.02, p>.8$, indicating that there was no difference in RT between words referring to living and non-living items. However, in addition to a main effect of age, $F(1,75)=10.4, p<.01$, and education, $F(1,75)$ $=6.0, p<.05$ (means are 858 and $798 \mathrm{~ms}$ for low and high educational levels respectively), an interaction between age and stimulus type was found, $F(1,75)=8.4, p<.01$, partial $\eta^{2}=.1$, indicating that the age difference in RT is larger for words referring to non-living than for words referring to living items. No age $\mathrm{x}$ stimulus type $\mathrm{x}$ education, education $\mathrm{x}$ age, and education $\mathrm{x}$ stimulus type interactions were found $(F$-values $<2$, 
$p$-values $>.15)$. The results were essentially the same when left-handed participants were excluded from the analyses.

A

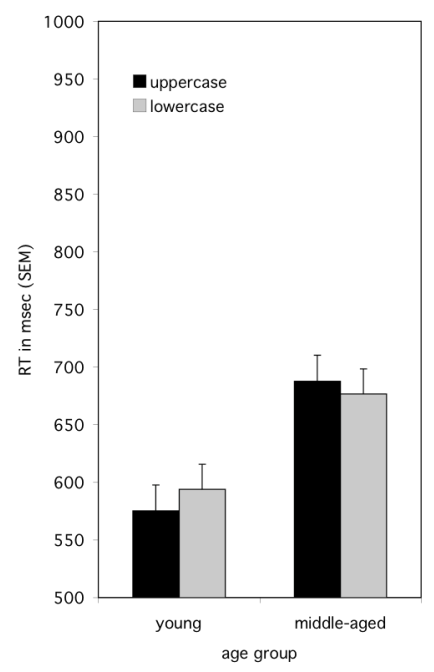

B

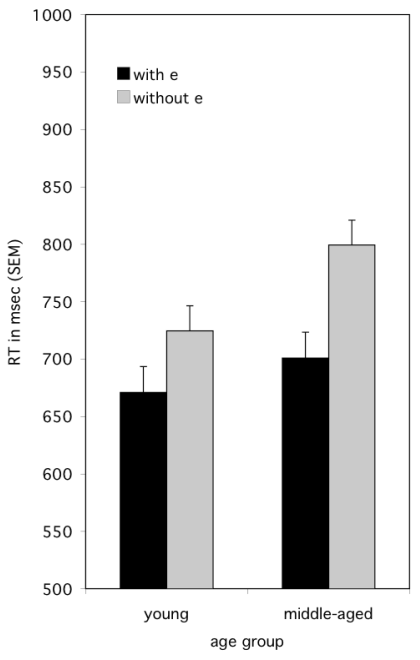

C

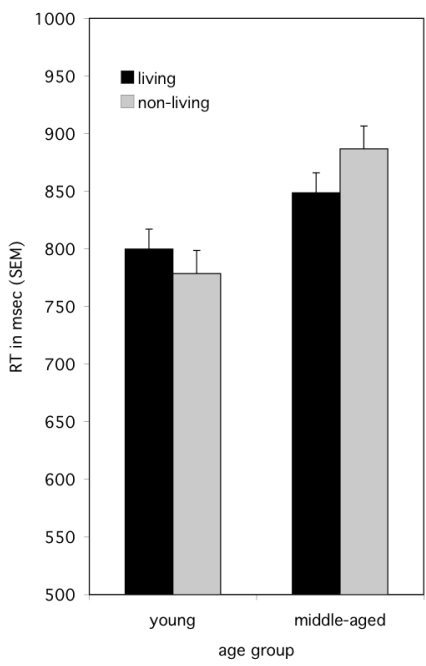

Figure 2. Mean reaction time as a function of age and case (A), age and presence of the letter 'e' (B), and age and semantic dimension (C). Error bars represent standard errors of the mean.

\section{DISCUSSION}

The first purpose of this study was to investigate whether middle-aged adults process information less efficiently than young adults in more resource-demanding conditions. We assessed age differences in RT on decision tasks that induce various levels of processing. The results indicate that middle-aged and young adults of both educational levels had longer RTs in the semantic decision than in the 'e' detection task, and longer RTs in the ' $\mathrm{e}$ ' detection than in the case decision task. This main effect of decision type suggests that the task conditions varied in their relative demands on the different components of visual word processing. Because the semantic decision task (deep processing) is assumed to incorporate shallow processing stages, this condition can be considered more complex than the shallower conditions. The effect of decision type on RT is in accordance with recent ERP studies using decision tasks to induce processing at a particular level. For instance, the findings in a study by Bentin et al. (1999) indicate that a size decision task induces visual/orthographic processing in which visual features are integrated to represent orthographic patterns. A rhyme decision task reflects the activation of a phonological representation of the printed word. Finally, a semantic decision task reflects accessing the meaning of a word. 
Most importantly, the results of the present study showed no age by decision type interaction, that is, RT differences between age groups did not vary across decision tasks. This finding suggests that different levels of word processing are equally vulnerable to slowing in middle age. Thus the implications of the theories proposed by Myerson et al., (1990) and Salthouse (1996), which predict a disproportionate increase of RT in older adults as a function of the number of processing steps, do not apply to middle age. A straightforward explanation for this result is that the aging process in adults of middle age is in such an early stage that a disproportional effect is not yet demonstrable. It is possible that elderly (over 65 years of age) compared to young adults might show a disproportionate increase as depth of processing increases. It should be noted that the participants in the present study consisted of persons in the age range between college age and retirement age. They were carefully screened for health problems to exclude potential age-extrinsic confounds. Furthermore, we did not rely on college students as the source of young participants, which is common practice in contemporary cognitive age research. To the extent that college students are not representative of their cohort in terms of intellectual ability, lifestyle, socioeconomic status or personality characteristics (such as openness to experience), the age-related changes observed in studies involving college students may not be completely attributable to intrinsic (i.e. 'pure age') processes. No age by condition interaction was found in the present sample in which age-extrinsic confounds are minimized. This might suggest that age-related cognitive change in extreme age-group designs is not necessarily attributable to intrinsic age effects. This should be investigated in future research by carefully screening and classifying participants in order to reduce age-extrinsic confounds.

Another possible explanation for the equal vulnerability to slowing in middle age for different levels of word processing may be sought in the slowing function representing age effects in sequential complexity conditions. Sequential complexity refers to any task manipulation that leads to a variation in the number of independent processing steps but that does not increase the amount of information exchange between single steps (Mayr \& Kliegl, 1993). In particular, no simultaneous storage and processing demands should be involved in these tasks, which makes working memory load comparatively low. This is in contrast to task manipulations on the coordinative complexity dimension in which working memory load is varied. Age-related slowing is found to be larger if coordinative complexity is increased than if sequential complexity is increased (Mayr \& Kliegl, 1993). The stability of age differences in RT over decision types in the current study suggests that the present task manipulation represents sequential rather than coordinative complexity. It should be investigated in future research whether there is disproportionate slowing in middle age with respect to tasks that increase in coordinative complexity.

We additionally investigated age-related differences in RT between stimulus types within decision tasks in order to provide insight into the use of search strategies. With respect to case decision, no difference in RT was found between responses on uppercase and lowercase words and there was no interaction with age. This was expected, because no search processes are involved. In the 'e' detection task, an effect of response type was found, indicating that the RT for the words containing the letter ' $\mathrm{e}$ ' is shorter than for the words not containing an ' $\mathrm{e}$ '. Interestingly, this difference was larger in the middle-aged group. This pattern of results indicates that participants ter- 
minated the search of the letter string when the 'e' was identified, and that middle-aged participants were slower in performing this search strategy than the younger ones. The suggestion that a terminating search strategy (Schneider \& Shiffrin, 1977) was adopted in which each letter was assessed, implies that the 'e' detection task does not draw on orthographic or phonological processing of the whole word. Regarding the semantic decision task, an interaction between age and stimulus type was found: the age difference in RT was larger for words referring to non-living than for words referring to living items. This suggests that middle-aged adults are more constrained by the reduced semantic accessibility of words referring to non-living items than younger adults. Thus, although no overall age by level of processing interaction was found, the age by stimulus type interactions in the deeper processing tasks suggest that a cognitive vulnerability already exists in middle age.

Concerning the role of education in visual word processing, higher educated persons had consistently shorter RTs than lower educated persons. Education did not interact with any of the other independent variables, however. This suggests that education is not a moderating factor of age-related changes in visual word processing, at least not over the age span investigated in the present study. It should be noted that people often finished schooling before 1960 for reasons other than their intellectual capacity (Jolles et al., 1995). As a consequence, there is a risk of underestimating the cognitive differences associated with age in lower educated people. By including a young and a middle-aged group, which yields fewer cohort differences than a comparison between a young and old group, and by defining the low and high level of educational achievement differently for young and middle-aged persons, this risk was minimized in the current study. It is noteworthy that the precise mechanisms for the hypothesized protective effect of education remain unclear. One of the proposed mechanisms is that education serves as a marker for other socioeconomic conditions, including health status, which is also known to influence age-related cognitive decline (van Hooren et al., 2005). Thus, a protective effect of education might not have been demonstrated in the present study because all our participants were screened for health problems to exclude potential age-extrinsic confounds.

Because the issue of the interaction between age and education has been seldom addressed by experimental studies, it is not yet clear on which cognitive domains education may have such a protective effect. The few previous studies mainly found smaller age differences in highly-educated persons in verbal memory (Ardila, OstroskySolis, Rosselli \& Gomez, 2000; Capitani, Barbarotto \& Laiacona, 1996), visual attention (Capitani et al., 1996) and some subtests of the Wechsler Adult Intelligence Scale (Heaton, Grant \& Matthews, 1986). Since the present study addresses visual word processing, which draws less on working memory and executive functioning, its results add to the accumulating evidence that education mainly affects age changes in higher order cognitive functions. Especially in tasks that tap these kinds of functions, agerelated change in performance may be attenuated by the use of cognitive skills or strategies, which is enhanced by educational experience.

In conclusion, different levels of word processing are equally vulnerable to slowing in middle age. This may suggest that particular mechanisms of cognitive aging, in which disproportionate age-related slowing as a function of the number of processing steps is predicted, do not apply to middle age. Another possibility is that the decision tasks inducing levels of word processing represent variations in sequential complexity, 
which does not interact with age. Because no age by condition interaction was found in the present sample in which age-extrinsic confounds such as health are minimized, the importance of these confounds in extreme age group designs is stressed. Although no overall age by level of processing interaction was found, the age by stimulus type interactions in the deeper processing tasks suggest that a cognitive vulnerability already exists in midlife. We also conclude that a high educational level has no protective effect on age-related changes in visual word processing.

\section{REFERENCES}

Allen, P. A., Madden, D. J., Weber, T. A., \& Groth, K. E. (1993). Influence of age and processing stage on visual word recognition. Psychology and Aging, 8, 274-282.

Ardila, A., Ostrosky-Solis, F., Rosselli, M., \& Gomez, C. (2000). Age-related cognitive decline during normal aging: the complex effect of education. Archives of Clinical Neuropsychology, 15(6), 495-513.

Bentin, S., Mouchetant-Rostaing, Y., Giard, M. H., Echallier, J. F., \& Pernier, J. (1999). ERP manifestations of processing printed words at different psycholinguistic levels: time course and scalp distribution. Journal of Cognitive Neuroscience, 11, 235-260.

Borowsky, R., \& Besner, D. (1993). Visual word recognition: a multistage activation model. Journal of Experimental Psychology: Learning, Memory and Cognition, 19, 813-840.

Bosma, H., Van Boxtel, M. P., Ponds, R. W. H. M., Houx, P., \& Jolles, J. (2003). Education and age-related cognitive decline: the contribution of mental workload. Educational Gerontology, 29, 1-9.

Buchner, A., Faul, F., \& Erdfelder, E. (1992). GPOWER: A priori-, post hoc-, and compromise power analyses for the Macintosh (Version 2.1). Bonn, Germany: Bonn University.

Capitani, E., Barbarotto, R., \& Laiacona, M. (1996). Does education influence the age-related cognitive decline? A further inquiry. Developmental Neuropsychology, 12, 231-240.

Caramazza, A., \& Shelton, J. R. (1998). Domain-specific knowledge systems in the brain the animateinanimate distinction. Journal of Cognitive Neuroscience, 10, 1-34.

Daselaar, S. M., Veltman, D. J., Rombouts, S. A., Raaijmakers, J. G., \& Jonker, C. (2003). Deep processing activates the medial temporal lobe in young but not in old adults. Neurobiology of Aging, 24, 10051011.

de Bie, S. E. (1987). Standaardvragen 1987: Voorstellen voor uniformering van vraagstellingen naar achergrondkernmerken en interviews [Standard questions 1987: Proposal for uniformisation of questions regarding background variables and interviews]. (2nd ed.). Leiden, The Netherlands: Leiden University Press.

Ellis, A. W., \& Young, A. W. (1996). Human cognitive neuropsychology: A textbook with readings. Hove \& London: Erlbaum Psychology Press.

Heaton, R. K., Grant, I., \& Matthews, C. G. (1986). Differences in neuropsychological test performance associated with age, education, and sex. In I. Grant \& K. M. Adams (Eds.), Neuropsychological assessment of neuropsychiatric disorders (pp. 100-120). New York: Oxford University Press.

Houx, P. J., \& Jolles, J. (1993). Age-related decline of psychomotor speed: effects of age, brain health, sex, and education. Perceptual and Motor Skills, 76(1), 195-211.

Houx, P. J., Jolles, J., \& Vreeling, F. W. (1993). Stroop interference: aging effects assessed with the Stroop Color-Word Test. Experimental Aging Research, 19(3), 209-224.

Houx, P. J., Vreeling, F. W., \& Jolles, J. (1991). Rigorous health screening reduces age effect on memory scanning task. Brain and Cognition, 15(2), 246-260.

Jolles, J., Houx, P., Van Boxtel, M. P., \& Ponds, R. W. (Eds.). (1995). Maastricht Aging Study: Determinants of cognitive aging. Maastricht: Neuropsych Publishers. 
Luteijn, F., \& Van der Ploeg, F. A. E. (1983). Handleiding Groninger Intelligentietest (GIT) [Manual Groningen Intelligence Test]. Lisse, The Netherlands: Swets and Zeitlinger.

Madden, D. J. (1985). Age-related slowing in the retrieval of information from long-term memory. Journal of Gerontology, 40, 208-210.

Madden, D. J. (1992). Four to ten milliseconds per year: age-related slowing of visual word identification. Journal of Gerontology, 47(2), P59-68.

Madden, D. J., Pierce, T. W., \& Allen, P. A. (1993). Age-related slowing and the time course of semantic priming in visual word identification. Psychology and Aging, 8, 490-507.

Mahon, B. Z., \& Caramazza, A. (2003). Constraining questions about the organisation and representation of conceptual knowledge. Cognitive Neuropsychology, 20, 433-450.

Mares, A. M. H. M. (Ed.). (2004). Jaarboek onderwijs in cijfers [Yearbook education in numbers]: Centraal Bureau voor de Statistiek.

Mayr, U., \& Kliegl, R. (1993). Sequential and coordinative complexity: age-based processing limitations in figural transformations. Journal of Experimental Psychology: Learning, Memory and Cognition, 19, $1297-$ 1320.

Myerson, J., Hale, S., Wagstaff, D., Poon, L. W., \& Smith, G. A. (1990). The information-loss model: a mathematical theory of age-related cognitive slowing. Psychological Review, 97, 475-487.

Petros, T. V., Zehr, D., \& Chabot, R. (1983). Adult age differences in accessing and retrieving information from long-term memory. Journal of Gerontology, 38, 589-592.

Ponds, R. W., Commissaris, K. J., \& Jolles, J. (1997). Prevalence and covariates of subjective forgetfulness in a normal population in The Netherlands. International Journal of Aging and Human Development, 45, 207-221.

Rabbitt, P. (1993). Does it all go together when it goes? The Nineteenth Bartlett Memorial Lecture. Quarterly Journal of Experimental Psychology A, 46(3), 385-434.

Salthouse, T. A. (1996). The processing-speed theory of adult age differences in cognition. Psychological Review, 103, 403-428.

Schneider, W., Eschman, A., \& Zuccolotto, A. (Eds.). (2002). E-prime User's Guide (Vol. 1.0). Pittsburgh: Psychology Software Tools.

Schneider, W., \& Shiffrin, R. M. (1977). Controlled and automatic human processing: 1. Detection, search, and attention. Psychological Review, 84, 1-66.

Schooler, C. (1999). The workplace environment: Measurement, psychological effects, and basic issues. In S. L. Friedman \& T. D. Wachs (Eds.), Measuring environment across the lifespan (pp. 229-246). Washington, DC: American Psychological Society.

Seidenberg, M. S., \& McClelland, J. L. (1989). A distributed, developmental model of word recognition and naming. Psychological Review, 96, 523-568.

Shapiro, L. R., \& Olson, A. C. (2005). Does normal processing provide evidence of specialized semantic subsystems? Language and Cognitive Processes, 20, 697-724.

Stern, Y. (2002). What is cognitive reserve? Theory and research application of the reserve concept. Journal of the International Neuropsychological Society, 8, 448-460.

Tisserand, D. J., McIntosh, A. R., van der Veen, F. M., Backes, W. H., \& Jolles, J. (2005). Age-related reorganization of encoding networks directly influences subsequent recognition memory. Cognitive Brain Research, 25, 8-18.

UNESCO. (1976). International Standard Classification of Education (ISCED). Paris: UNESCO.

Van der Elst, W., Van Boxtel, M. P., Van Breukelen, G. J., \& Jolles, J. (2005). Rey's verbal learning test: normative data for 1855 healthy participants aged 24-81 years and the influence of age, sex, education, and mode of presentation. Journal of the International Neuropsychological Society, 11, 290-302.

Van der Elst, W., Van Boxtel, M. P., Van Breukelen, G. J., \& Jolles, J. (2006a). Normative data for the Animal, Profession and Letter M Naming verbal fluency tests for Dutch speaking participants and the effects of age, education, and sex. Journal of the International Neuropsychological Society, 12, 80-89. 
Van der Elst, W., Van Boxtel, M. P., Van Breukelen, G. J., \& Jolles, J. (2006b). The stroop color-word test: influence of age, sex, and education; and normative data for a large sample across the adult age range. Assessment, 13, 62-79.

van Hooren, S. A., Valentijn, S. A., Bosma, H., Ponds, R. W., van Boxtel, M. P., \& Jolles, J. (2005). Relation between health status and cognitive functioning: a 6-year follow-up of the Maastricht Aging Study. Journal of Gerontology B: Psychological Sciences, 60, 57-60.

Van Loon-Vervoorn, W. A. (1985). Voorstelbaarheidswaarden van Nederlandse woorden: 4600 substantieven, 1000 verba en 500 adjectieven [Imagery values of Dutch words: 400 nouns, 1000 verba en 500 adjectives]. Lisse, The Netherlands: Swets \& Zeitlinger.

Willis, S. L., \& Schaie, K. W. (2005). Cognitive trajectories in midlife and cognitive funcioning in old age. In S. L. Willis \& M. Martin (Eds.), Middle adulthood: a lifespan perspective (pp. 243-277). Thousand Oaks: Sage Publications. 


\title{
CHAPTER 6
}

\section{The benefit of deep processing and high educational level for verbal learning in young and middle-aged adults}

\author{
Willemien A. Meijer, Pascal W. M. van Gerven, Renate H. M. de Groot, Martin P. J. van \\ Boxtel \& Jelle Jolles
}

Submitted for publication

\begin{abstract}
The aim of the present study was to examine whether deeper processing of words leads in middle-aged adults to a smaller increase in word-learning performance and a smaller decrease in retrieval effort, as measured by reaction times (RTs) of recognition, than in young adults. It was also assessed whether high education attenuates age-related differences in performance. Accuracy of recall and recognition and RTs of recognition after performing incidental and intentional learning tasks were compared between 40 young (25-35) and 40 middle-aged (50-60) adults with low and high educational levels. Results showed that age differences in recall increased with depth of processing, whereas age differences in accuracy and RTs of recognition did not differ across levels. High education did not moderate the age-related differences in performance. These findings suggest a reduced benefit of deep processing in middle age when no retrieval cues are available.
\end{abstract}


In the abundance of studies on age-related cognitive differences, comparisons have been made between relatively young adults (usually in their 20s), and older adults (usually older than 65). Although the age range between 30 and 60 has often been disregarded, this range may be of particular interest because the first manifestations of age-related cognitive change (Houx \& Jolles, 1993; Houx, Jolles, \& Vreeling, 1993; Houx, Vreeling, \& Jolles, 1991; Rabbitt, 1993) and cognitive complaints (Ponds, Commissaris, \& Jolles, 1997) can already be seen from age 40. Previous studies have not been able to establish a relation between subjective cognitive complaints and poor cognitive performance in middle age (Jonker, Geerlings, \& Schmand, 2000; Ponds, van Boxtel, \& Jolles, 2000). A possible explanation for this discrepancy might involve the psychological construct 'effort'. Middle-aged adults may need to invest more cognitive effort to achieve the same performance as young adults especially in resourcedemanding situations, such as in professional life. Indeed, cognitive challenges at midlife are generally high and consist of work and family environments requiring particular skills, such as organizing, planning, problem solving and multitasking (Schooler, 1999). To test the hypothesis that middle-aged adults invest more effort than young adults especially in resource-demanding situations, an experimental paradigm is needed that involves conditions varying in processing demands and that also includes a measure of cognitive effort. Such a paradigm can be derived from the levels-of-processing framework proposed by Craik and Lockhart (1972). According to their view, incoming information can be processed in different ways, which are viewed as varying from shallow to deep processing (Burke \& Light, 1981). A deeper analysis produces a richer and more elaborated memory trace (Craik \& Tulving, 1975), which is more resistant to forgetting.

Although this levels-of-processing framework has undergone several revisions since its initial formulation (e.g., Craik, 2002), it is the earliest version that has been most influential in the area of cognitive aging. Following the levels-of-processing hypothesis it has been suggested that older adults have a deficiency in deep, semantic processing, which may result in memory impairments (Burke \& Light, 1981). This hypothesis was tested by early studies in which recall and recognition by young and older adults were compared after performing incidental processing tasks (i.e. perceptual, phonological, or semantic analysis of words) and an intentional learning task (i.e. memorization of words) (White, cited in Craik, 1977; Erber, Herman, \& Botwinick, 1980; Eysenck, 1974; Mason, 1979; Rankin \& Hyland, 1983; Zelinski, Walsh, \& Thompson, 1978). The predominant pattern of results with respect to recall was that age differences were small and unreliable after shallow processing tasks and larger after deeper processing tasks (White, cited in Craik, 1977; Erber et al., 1980; Eysenck, 1974; Rankin \& Hyland, 1983). It was suggested that deep processing is cognitively effortful and places a strain on the diminished resources of older adults (Kausler, 1994). In contrast, when memory for the words was tested by recognition, age differences after deep incidental instructions (White, cited in Craik, 1977; Erber et al, 1980; Rankin \& Hyland, 1983) and intentional learning (Erber et al., 1980; Mason, 1979; Rankin \& Hyland, 1983) were much less pronounced. This suggests that mainly the self-initiated search component of retrieval, which is presumably bypassed by recognition (Kausler, 1994), is sensitive to an age-related deficiency in deep processing.

However, the aforementioned studies only examined the number of correctly recalled and recognized words. Because an age-related deficiency in deep processing is 
presumably manifested in retrieval processes, it could be relevant to examine reaction times of recognition, i.e. to measure how fast a person can decide whether a word was presented before. Although the exact nature of the retrieval processes involved in recognition is still a matter of debate, the assumption that old-new responses are initiated when sufficient evidence has accumulated to justify one response or the other is accepted and incorporated into most theories (Diller, Nobel, \& Shiffrin, 2001; Ratcliff \& Smith, 2004). The main construct to be extracted from RTs is therefore retrieval effort, the mobilization of processing resources in order to retrieve items from memory (Rugg, Allan, \& Birch, 2000). Longer RTs would then represent less efficient mobilization of processing resources and more retrieval effort. Because deeper processing results in better maintenance of words in memory, deeper processed words are expected to require less retrieval effort than shallow processed words. In this regard, we could test whether deeper processing leads in middle-aged adults to a smaller decrease in retrieval effort than in young adults. The first purpose of the present study was therefore to examine whether deeper processing of words during encoding leads in middle-aged adults to a smaller increase in word-learning performance and a smaller decrease of RTs than in young adults.

Within the study of cognitive aging, relatively limited attention has been given to factors affecting cognitive abilities in midlife (Willis \& Schaie, 2005). Protective factors in cognitive maintenance and plasticity are important as possible mechanisms to be targeted in preventive interventions. High educational level may attenuate an agerelated increase in effort investment and change in verbal learning performance, because educational experience may provide reserve capacity in the form of a more elaborate set of basic skills or cognitive strategies (Stern, 2002). Indeed, high educational level has been shown to attenuate age-related cognitive decline in older adults (e.g., Anstey \& Christensen, 2000; Bosma, Van Boxtel, Ponds, Houx, \& Jolles, 2003). In light of this protective effect of education, an interesting issue is whether a higher educational level, which stimulates language proficiency and the use of encoding and retrieval cues, compensates for a reduced benefit of deep processing in middle-aged individuals. The second purpose of the present study was therefore to examine whether age-related memory differences after performing shallow and deeper learning tasks, are moderated by level of education.

Four incidental learning tasks were used in the present study, each designed to induce processing at a particular level. The first task was to decide whether words were written in lowercase or uppercase letters, which was assumed to induce shallow perceptual processing (Bentin, Mouchetant-Rostaing, Giard, Echallier, \& Pernier, 1999; Daselaar, Veltman, Rombouts, Raaijmakers, \& Jonker, 2003). The second task was to decide whether words contained the letter 'e', which was assumed to induce more elaborate orthographic/phonological processing (Proverbio et al., 2004). In the third task, participants had to say words aloud without making a decision, which was assumed to invoke at least perceptual, orthographic and phonological processing. Access of information concerning the meaning of a word is not necessarily involved in this task (Seidenberg \& McClelland, 1989). The fourth task was to decide whether words referred to a living or a non-living item, which was assumed to invoke deep semantic processing (Daselaar et al., 2003; Tisserand, McIntosh, van der Veen, Backes, \& Jolles, 2005). Also four intentional memorizing tasks were administered. 
In contrast to the previous studies on age differences within the levels-ofprocessing framework that used a between-subject design, a more powerful mixed design in which each participant received all conditions was used in the present study. Moreover, a younger (25-35 years) group was compared with an older middle-aged (5060 years) group. These groups consisted of persons from the working population and were therefore less subject to differences in lifestyle associated with schooling or retirement. In addition, they were without age-related health problems with potential impact on brain function in order to reduce any source of bias due to age-extrinsic factors.

\section{METHOD}

\section{Participants}

Eighty adults from two age groups participated in the study. The younger group consisted of 20 people with a low education level and 20 people with a high level aged between 25 and 35 (mean age $=29.0$ years, $S D=2.8$ ). The older middle-aged group consisted of 20 people with a low education level and 20 people with a high level aged between 50 and 60 (mean age $=56.1$ years, $S D=3.4$ ). Participants were stratified for age (two age groups), education (two levels) and sex. Participants were recruited by advertisements in local newspapers and advertising at Maastricht University, local companies and clubs (e.g. sports, music). There was a selection by telephone in order to exclude persons with health-related conditions known to interfere with normal cognitive functioning. Exclusion criteria were cerebrovascular pathology, psychiatric disturbances, neurological disorders, dyslexia, serious medical conditions with known impact on brain function, excessive use of alcohol ( $>21$ consumptions/week), use of psychoactive medication or drugs, clinically overt visual or auditory deficits, and previous participation in cognitive experiments. The Ethics Committee of the Department of Psychology, Maastricht University, approved the study and participants gave their written informed consent.

Level of education was assessed by classifying formal schooling according to a system commonly used in the Netherlands (de Bie, 1987), which is comparable to the International Standard Classification of Education (UNESCO, 1976). Educational level was scored in eight ordinal categories: 1) primary education, 2) lower vocational education, 3) intermediate secondary education, 4) intermediate vocational education, 5) higher secondary education, 6) higher vocational education, 7) higher professional education, and 8) university. In many western countries, persons between 50 and 60 are -generally- lower educated than persons between 25 and 35. Thus, the median educational level in the population differs for the age ranges used in the present study (Mares, 2004). We attempted to deal with this cohort effect by adjusting the classification into a low and a high educational level according to the median level in each age group. A low level of education was defined in the young group as a maximum of intermediate vocational education (equivalent to a maximum of 13 years of education). A low level of education was defined in the older group as a maximum of intermediate secondary education (equivalent to a maximum of 10 years of education). 
The characteristics of the sample are shown in Table 1 . This table shows that persons with a low educational level were a little older than persons with a high educational level in both the young, $F(1,38)=4.4, p<.05$, and the old age group, $F(1,38)=$ $6.0, p<.05$. Because the difference was at most 2.5 years, this was not considered to be a problem. The young and middle-aged participants did not perform differently on a 20-item multiple-choice Dutch vocabulary test (Luteijn \& Van der Ploeg, 1983) measuring verbal IQ, $F(1,76)=3.1, p=.09$. The vocabulary scores of the highlyeducated participants were higher than those of the poorly-educated participants, $F(1$, 76) $=33.1, p<.01$.

Table 1. Participant characteristics

\begin{tabular}{lllll}
\hline & & Young (25-35) & & Middle-aged (50-60) \\
\hline & $\begin{array}{l}\text { Low } \\
\text { educational } \\
\text { level }\end{array}$ & $\begin{array}{l}\text { High } \\
\text { educational } \\
\text { level }\end{array}$ & $\begin{array}{l}\text { Low } \\
\text { educational } \\
\text { level }\end{array}$ & $\begin{array}{l}\text { High } \\
\text { educational } \\
\text { level }\end{array}$ \\
\hline N & 20 & 20 & 20 & 20 \\
Age: mean $(S D)$ & $29.9(.64)$ & $28.1(.57)$ & $57.4(.61)$ & $54.9(.82)$ \\
Male/female ratio $(n / n)$ & $10 / 10$ & $10 / 10$ & $10 / 10$ & $10 / 10$ \\
Vocabulary $(S E M)$ & $11.7(.49)$ & $14.9(.49)$ & $12.9(.49)$ & $15.3(.49)$ \\
Left-/right-handedness $(\mathrm{n} / \mathrm{n})$ & $17 / 3$ & $16 / 4$ & $20 / 0$ & $19 / 1$ \\
\hline
\end{tabular}

\section{Materials and Procedure}

\section{Incidental tasks}

There were four computerized tasks with 16 words presented one after another in each task. In the first task, in which eight words were presented in uppercase and eight in lowercase, the participants were asked to make a decision about the case of the letters. In the second task, participants had to indicate whether or not the words contained the letter 'e'. In the third task, participants had to read aloud the words without making a decision. In the last task, participants were asked whether the words referred to a living or a non-living item. The order in which the tasks were presented was randomized within each age group per educational level. The words used were mono- or disyllabic, varying in length between five and seven letters, and with a value of six or higher on a Dutch 7-point norm scale for imagery (Van Loon-Vervoorn, 1985). Words were presented in the center of a computer screen (font: Arial, 50 pt.). The color of the words was white against black background. The presentation software was programmed in E-prime (Schneider, Eschman, \& Zuccolotto, 2002). The four tasks involved four fixed word lists that were matched for word frequency and word length. All lists contained eight living items and eight words containing the letter 'e'. They 
were carefully matched with respect to the categories from which the words were drawn (i.e. animals, flowers, tools etc.) and with respect to phonological characteristics.

Participants were seated in front of a 17" monitor at a normal viewing distance of approximately 25 inch $(60 \mathrm{~cm})$, and responded with either their left or right index finger using two response buttons. In the three decision tasks, a right button press indicated 'uppercase', 'containing e' and 'living' respectively. In these tasks, the words were presented on the screen with a maximum of $1500 \mathrm{~ms}$ until a response was given. A fixed interval of $2000 \mathrm{~ms}$ between the appearance of a word and the appearance of a next word was used. Participants were told to respond as quickly and accurately as possible. In the reading task, the words were presented for $1000 \mathrm{~ms}$ on the screen with an interval of $2000 \mathrm{~ms}$ between the appearance of a word and the appearance of a next word.

\section{Recall and recognition of incidentally presented words}

A 5-minute delay was imposed during which the participants copied the Rey Complex Figure (Rey, 1941) that involves no verbal stimuli. After this delay, they unexpectedly had to orally recall as many of the words they had encountered in the four tasks as possible. Subsequently, the participants performed an old/new recognition task. This task consisted of 32 old words (8 from each incidental task) and 32 new words, presented in a random order. The new words were selected using the same criteria as the words that were presented in the incidental tasks (mono/disyllabic, 5-7 letters, matched for word frequency, word length, and number of living items). Participants responded with either their left or right index finger using two response buttons to indicate whether the word was seen before in the incidental tasks. A right button press indicated 'yes', a left button press indicated 'no'. The words were presented on the screen with a maximum of $2500 \mathrm{~ms}$ until a response was given. There was a fixed interval of $3000 \mathrm{~ms}$ between the appearance of a word and the appearance of a next word. Participants were told to respond as quickly and accurately as possible. Reaction times and accuracy measures were recorded.

\section{Intentional tasks}

When recognition of the incidental tasks was completed, two sustained attention tests, which did not involve the learning of verbal material, were administered for about 20 minutes, with a break of 5 minutes in between. After this delay of 25 minutes, the participants were asked to memorize a list of 16 words for subsequent recall. After presentation of the words, the participants were asked to recall as many of the presented words as possible in any order. This procedure was conducted four times with different word lists. The order in which the lists were presented was randomized within each age group per educational level. In these four tasks, the words were presented for $1000 \mathrm{~ms}$ on the screen with an interval of $2000 \mathrm{~ms}$ between the appearance of a word and the appearance of a next word. The characteristics and computerized presentation of the words were the same as in the incidental tasks.

\section{Recall and recognition of intentionally presented words}

A 5-min delay was imposed during which the participants copied the Taylor figure (Taylor, 1989) that involves no verbal stimuli. After this delay, they had to orally reproduce as many of the words they had encountered in the four intentionally pre- 
sented lists as possible. Subsequently, the participants performed an old/new recognition task. This task consisted of 32 old words (8 from each intentional task) and 32 new words, presented in a random order. The characteristics and computerized presentation of the words were the same as in the recognition of the incidental tasks.

\section{Design}

A cross-sectional design was used with two age groups (young and middle-aged) and two educational levels (low and high). All participants received four incidental conditions, and because the procedure of recall and recognition had to be similar for intentional and incidental learning, they received also four parallel intentional tasks. The mean performance of the four parallel intentional tasks was used as a measure of intentional learning. This yielded a $5 \times 2 \times 2$ design with type of task (case decision, 'e' detection, reading, semantic decision and intentional learning) as the within-groups variable and age group and educational level as the between-groups variables. The number of correctly recalled words, recognized words and mean reaction times for correctly and incorrectly recognized words were the dependent variables.

\section{Data analysis}

The assumptions of ANOVA (homogeneity of variance and normality of the residuals) were tested for each dependent variable. Homogeneity of variance was evaluated by visual inspection of the scatter plots of the residuals against the predicted values. Normal distribution of the residuals was checked by visual inspection of the histograms and the normal probability plots. Based on this information, data transformation was not considered necessary. Full-factorial repeated-measures ANOVAs were used per dependent variable. A Greenhouse-Geisser correction was applied to the degrees of freedom and the significance levels if the sphericity assumption was violated. Statistically significant main effects of task type and interactions with task type were further analyzed following Fishers LSD procedure. Repeated contrast analyses were conducted in order to analyze differences between consecutive levels of processing. Simple contrast analyses were conducted in order to analyze differences between intentional learning on the one hand and each incidental task on the other. Post hoc power analyses (Buchner, Faul, \& Erdfelder, 1992) per dependent variable on the available number of participants using a medium critical effect size of 0.25 and an alpha level of .05 resulted in a power of .99 for all three dependent variables with respect to the within-groups effects. The analyses resulted in a power of $.97, .89$ and .81 with respect to the between-groups effects for recall, accuracy, and reaction times of recognition respectively. 


\section{RESUlts}

A

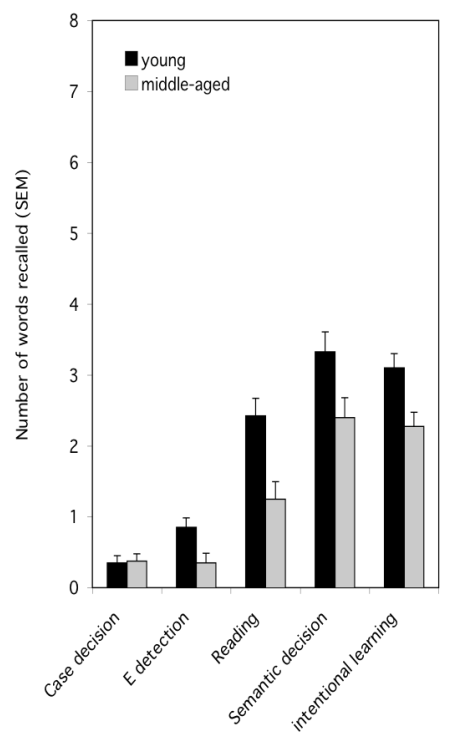

condition
B

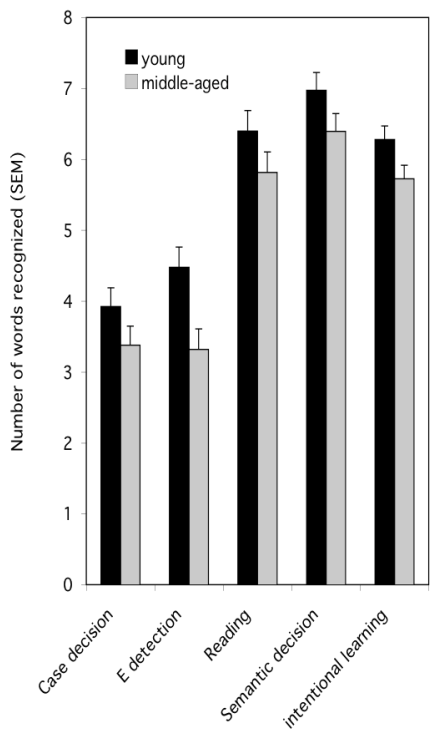

condition
C

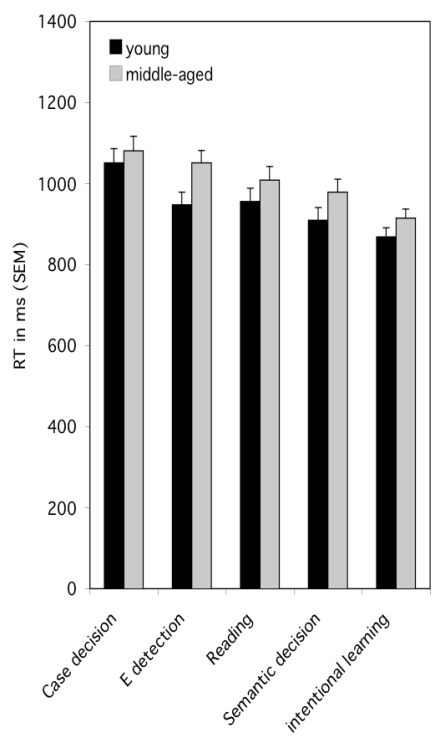

condition

Figure 1. Mean accuracy on recall (A), recognition (B), and reaction times of recognition $(C)$ as a function of age and condition. Error bars represent standard errors of the mean.

\section{Recall}

In Figure 1a the mean numbers of correctly recalled words from each incidental task and four intentional tasks are presented per age group. A main effect of age was found, indicating that younger individuals outperformed older individuals, $F(1,76)=$ 22.5, $p<.01$, partial $\eta^{2}=.23$ (means over all conditions are 2.0 and 1.3 for the young and old age groups, respectively). There was a main effect of task, $F(3,229.1)=68.1, p$ $<.01$, partial $\eta^{2}=.47$, indicating that more words were recalled as depth of processing increased (means are .36, .6, 1.8, 2.9, and 2.7 words for the case decision, 'e' detection, reading, semantic decision, and intentional learning tasks, respectively). Repeated contrasts were significant except the one between semantic decision and intentional learning. Also the simple contrasts were significant except the one between semantic decision and intentional learning. An age by task interaction was found, indicating that the age-related differences in recall increased with depth of processing, $F(3,229.1)=2.7, p$ $<.05$, partial $\eta^{2}=.035$. Only the repeated contrast case decision vs. 'e' detection and 
the simple contrast case decision vs. intentional learning were significant. However, floor effects complicate this interaction in the shallow conditions.

A significant main effect of education was found, indicating that highly-educated people recalled more words than poorly-educated people: $F(1,76)=4.9, p<.05$, partial $\eta^{2}=.061$ (means are 1.5 and 1.8 words for low and high educational level, respectively). No age $\mathrm{x}$ task $\mathrm{x}$ education, education $\mathrm{x}$ age and education $\mathrm{x}$ task interactions were found $(F$-values $<2.6, p$-values $>.1)$.

\section{Accuracy of recognition}

In Figure $1 \mathrm{~b}$ the mean numbers of correctly recognized words from each incidental task and four intentional tasks are presented per age group. A main effect of age was found, indicating that younger individuals outperformed older individuals, $F(1,75)$ $=8.1, p<.01$, partial $\eta^{2}=.1$ (means over all conditions are 5.6 and 4.9 words for the young and old age groups, respectively). There was a main effect of task, $F(3.5,263.5)$ $=81.5, p<.01$, partial $\eta^{2}=.52$ (means are 3.6, 3.9, 6.1, 6.7, and 6.0 words for the case decision, 'e' detection, reading, semantic decision and intentional learning tasks respectively). Repeated contrasts were significant except the one between case decision and 'e' detection. Also, the simple contrasts were significant except the one between reading and intentional learning. No age by task interaction was found, indicating that the age-related differences in recognition accuracy were equal across tasks, $F(3.5,263.5)=$ $.74, p>.5$.

A main effect of education was found, indicating that highly-educated people recognized more words than poorly-educated people: $F(1,75)=5.2, p<.05$, partial $\eta^{2}$ $=.065$ (means are 4.9 and 5.5 words for low and high educational level respectively). No age $\mathrm{x}$ task $\mathrm{x}$ education, education $\mathrm{x}$ age, and education $\mathrm{x}$ task interactions were found $(F$-values $<2.2, p$-values $>.06)$.

Because recognition was tested for the incidental conditions together, the number of true negatives, i.e. correctly identified new words, could not be separated for each incidental condition. The same applies to the intentional conditions. The number of true negatives did not differ between age groups with respect to the incidental tasks, $F(1,75)=.76, p>.3$ (means are 24.3 and 25.4 for the young and middle-aged group respectively), and educational levels, $F(1,75)=.83, p>.3$ (means are 25.5 and 24.3 for the low and high level respectively). An education $x$ age interaction was not found, $F(1$, $75)=.3, p>.5$. The same pattern of results was found for the intentional tasks: the number of true negatives did not differ between age groups, $F(1,75)=1.3, p>.2$ (means are 25.3 and 26.4 for the young and middle-aged group respectively), and educational levels, $F(1,75)=.43, p>.5$ (means are 26.2 and 25.6 for the low and high level respectively). An education $x$ age interaction was not found either, $F(1,75)=.6, p$ $>$.4. On the basis of these results we concluded that groups did not differ in their response bias, which would reduce the effectiveness of the recognition score as a measure of retention (Harris, Ivnik, \& Smith, 2002).

\section{RTs of recognition}

RTs of correctly recognized words were shorter than RTs of incorrectly recognized words (means collapsed over conditions are $1000 \mathrm{~ms}$ and $1179 \mathrm{~ms}$ respectively). However, no differences between age groups and educational levels were found. We 
decided therefore to collapse the mean RTs over correctly and incorrectly recognized words in order to get a more robust measure of retrieval effort. In Figure 1c, these mean RTs from each incidental task and four intentional tasks are presented per age group. There was a marginally significant main effect of age, $F(1,75)=3.4, p=.07$, partial $\eta^{2}=.043$, indicating that the two age groups did not differ much in RT (mean RTs over all conditions are 946 and $1006 \mathrm{~ms}$ for the young and old age groups respectively). There was a main effect of task, $F(4,300)=15.8, p<.01$, partial $\eta^{2}=.17$ (means are 1065, 999, 982, 944 and $891 \mathrm{~ms}$ for the case decision, 'e' detection, reading, semantic decision tasks and intentional learning respectively). Repeated contrasts were significant between case decision and 'e' detection and between semantic decision and intentional learning. All simple contrasts were significant. No age by task interaction was found, indicating that the age-related differences in RT performance did not differ across tasks, $F(4,300)=.72, p>.5$.

A main effect of education was found, indicating that highly-educated people had shorter RTs than poorly-educated people: $F(1,75)=4.3, p<.05$, partial $\eta^{2}=.055$ (means are 1011 and $942 \mathrm{~ms}$ for low and high educational level respectively). No age $\mathrm{x}$ task $\mathrm{x}$ education, education $\mathrm{x}$ age, and education $\mathrm{x}$ task interactions were found $(F$ values $<1, p$-values $>.2$ ).

\section{DisCUSSION}

The first purpose of the present study was to examine whether deeper processing of words during encoding leads in middle-aged adults to a smaller increase in wordlearning performance and a smaller decrease in retrieval effort than in young adults. A main effect of task on accuracy of recall and recognition indicated that word-learning performance indeed increased after deeper processing. A major outcome of this study is that the performance increase was smaller in middle-aged adults than in young adults with respect to recall. Age differences did not differ across levels of processing in recognition. These findings are generally in accordance with previous studies in which mainly extreme age groups were compared (White, cited in Craik, 1977; Erber et al., 1980; Eysenck, 1974; Mason, 1979; Rankin \& Hyland, 1983; Zelinski et al., 1978). Although we observed floor effects in the shallow conditions, our results are in line with previous studies that were not complicated by floor effects (Erber et al., Eysenck, 1974). Thus, the present study demonstrates already a reduced benefit of deep processing in middle-aged individuals. Moreover, these effects seem to be purely attributable to aging, since the participants in the present study were carefully screened for health problems to exclude potential age-extrinsic confounds.

To our knowledge, the present study is the first that also examined RTs of recognition, which enabled us to examine retrieval mechanisms. A main effect of task on RTs of recognition indicated that retrieval effort decreased with depth of processing. The absence of an age by task interaction demonstrates that this decrease in retrieval effort was not reduced in middle-aged adults. While we offered a definition of retrieval effort in the introduction (the mobilization of processing resources in order to retrieve stored information), the term has little explanatory power without a specification of the cognitive operations served by such resources. Most current theorists propose 
slower recall-like processes, often termed recollection, as one component and faster parallel retrieval, often termed familiarity, as the other component in a dual-route retrieval framework of recognition (see for review, Yonelinas, 2002). It has been shown that aging affects recollection more than familiarity (Yonelinas, 2002). The present main effect of age on RTs most probably reflects age-related slowing in recollection processes and of non-decision components of processing such as encoding and response execution. The absence of an age by task interaction suggests that this agerelated slowing is not dependent on the level of processing.

The general pattern of results thus suggests that a reduced benefit of deep processing in middle age is confined to the self-initiated search component of retrieval, which is required in recall and not in recognition. A major difference between recall and recognition is the amount of environmental support offered (Kausler, 1994), that is, the words themselves are reinstated on a recognition test, which diminishes the need for a constraining self-initiated search of the memory store. The present findings are therefore in line with many studies demonstrating smaller age differences when contextual or cognitive support is provided (see for review, Backman, 1989). When extended to daily life, this suggests that in more resource-demanding situations in which information has to be processed both quickly and thoroughly and when no retrieval cues are available, adults already show a cognitive vulnerability in middle age. When middle-aged adults are exposed frequently or longer to such cognitively challenging and stressful situations, for example in a professional context, their decreased processing capacities could lead to exhaustion of resources, which may result in cognitive complaints. Persistent strain on diminished cognitive resources may even lead to more pathological conditions such as mood problems, mental fatigue, neuroenergetic problems, dysthymia or 'burnout', which are common in the middle-aged working population (Lindblom, Linton, Fedeli, \& Bryngelsson, 2006; Schwarz, Krauss, \& Hinz, 2003; Sluiter, de Croon, Meijman, \& Frings-Dresen, 2003). Further longitudinal research may unravel the mechanisms proposed in this line of reasoning.

The second purpose of the present study was to examine whether a high educational level compensates for a reduced benefit of deep processing. More highly educated persons had consistently shorter RTs and higher accuracy levels than persons with a lower educational level. However, education did not interact with age or task on either of the dependent variables. This suggests that education is not a moderating factor of age-related changes in verbal learning manipulated by levels of processing, at least not over the present age-trajectory. This may be explained by one of the proposed mechanisms for the hypothesized protective effect of education. This mechanism assumes that education serves as a marker for other conditions related to socioeconomic status, such as health status (Lasheras, Patterson, Casado, \& Fernandez, 2001), which is also known to influence age-related cognitive change (van Hooren et al., 2005). A protective effect of education might therefore not have been demonstrated in the present study, because all our participants were screened for health problems to exclude potential age-extrinsic confounds. It should be noted that before the 1960s many people did not finish or continue their schooling, mostly for reasons other than their intellectual capacity (Jolles, Houx, Van Boxtel, \& Ponds, 1995). As a consequence, there is a risk of underestimating the cognitive differences associated with age in poorly educated people. By including a young and a middle-aged group, which yielded fewer cohort differences than a comparison between a young and an old group, 
and by defining the low and high levels of educational achievement differently for young and middle-aged persons, this risk was minimized in the current study.

Because the issue of the interaction between age and education has seldom been addressed by experimental studies, it is not yet clear on which cognitive domains education may have a protective effect and what are the determinants of such an effect. The few previous studies mainly found smaller age differences in highly-educated persons in verbal memory (Ardila, Ostrosky-Solis, Rosselli, \& Gomez, 2000; Capitani, Barbarotto, \& Laiacona, 1996), visual attention (Capitani et al., 1996), and some subtests of the Wechsler Adult Intelligence Scale (Heaton, Grant, \& Matthews, 1986). In a recent study, we found that education attenuates age-related differences in verbal learning, but that its protective power reached a limit when the tasks' demands were increased by the combination of the presence of irrelevant speech and a shorter interstimulus interval (Meijer, De Groot, Van Gerven, van Boxtel, \& Jolles, 2006). Since task demands are very high in the present paradigm in that words are only presented once and under rapid conditions (in contrast to frequently-used multi-trial verbal learning tasks), the absence of interactions between education, age and level-of-processing could again point at a limit of the protective power of education. Future research should delineate more precisely those tasks, task conditions and individual characteristics (such as health status) that allow older persons with a high educational level to compensate for negative age effects.

\section{REFERENCES}

Anstey, K., \& Christensen, H. (2000). Education, activity, health, blood pressure and apolipoprotein E as predictors of cognitive change in old age: a review. Gerontology, 46(3), 163-177.

Ardila, A., Ostrosky-Solis, F., Rosselli, M., \& Gomez, C. (2000). Age-related cognitive decline during normal aging: the complex effect of education. Archives of Clinical Neuropsychology, 15(6), 495-513.

Backman, L. (1989). Varieties of memory compensation by older adults in episodic remembering. In L. W. Poon \& D. C. Rubin \& B. A. Wilson (Eds.), Everyday cognition in adulthood and late life (1st ed., pp. 509-545). Cambridge: Cambridge University Press.

Bentin, S., Mouchetant-Rostaing, Y., Giard, M. H., Echallier, J. F., \& Pernier, J. (1999). ERP manifestations of processing printed words at different psycholinguistic levels: time course and scalp distribution. Journal of Cognitive Neuroscience, 11, 235-260.

Bosma, H., Van Boxtel, M. P., Ponds, R. W. H. M., Houx, P., \& Jolles, J. (2003). Education and age-related cognitive decline: the contribution of mental workload. Educational Gerontology, 29, 1-9.

Buchner, A., Faul, F., \& Erdfelder, E. (1992). GPOWER: A priori-, post hoc-, and compromise power analyses for the Macintosh (Version 2.1). Bonn, Germany: Bonn University.

Burke, D. M., \& Light, L. L. (1981). Memory and aging: the role of retrieval processes. Psychological Bulletin, 90, 513-546.

Capitani, E., Barbarotto, R., \& Laiacona, M. (1996). Does education influence the age-related cognitive decline? A further inquiry. Developmental Neuropsychology, 12, 231-240.

Craik, F. I. M. (1977). Age differences in human memory. In J. E. Birren \& K. W. Schaie (Eds.), Handbook of the psychology of aging (1st ed.). New York: Van Nostrand Reinhold.

Craik, F. I. M. (2002). Levels of processing: Past, present....and future? Memory, 10, 305-318.

Craik, F. I. M., \& Lockhart, R. S. (1972). Levels of processing: A framework for memory research. Journal of Verbal Learning and Verbal Behavior, 11, 671-684. 
Craik, F. I. M., \& Tulving, E. (1975). Depth of processing and the retention of words in episodic memory. Journal of experimental Psychology: General, 104, 268-294.

Daselaar, S. M., Veltman, D. J., Rombouts, S. A., Raaijmakers, J. G., \& Jonker, C. (2003). Deep processing activates the medial temporal lobe in young but not in old adults. Neurobiology of Aging, 24, 10051011.

de Bie, S. E. (1987). Standaardvragen 1987: Voorstellen voor uniformering van vraagstellingen naar achergrondkernmerken en interviews [Standard questions 1987: Proposal for uniformisation of questions regarding background variables and interviews]. (2nd ed.). Leiden, The Netherlands: Leiden University Press.

Diller, D. E., Nobel, P. A., \& Shiffrin, R. M. (2001). An ARC-REM model for accuracy and response time in recognition and recall. Journal of Experimental Psychology: Learning, Memory and Cognition, 27, 414-435.

Erber, J., Herman, T. G., \& Botwinick, J. (1980). Age differences in memory as a function of depth of processing. Experimental Aging Research, 6, 341-348.

Eysenck, M. W. (1974). Age differences in incidental learning. Developmental Psychology, 10, 936-941.

Harris, M. E., Ivnik, R. J., \& Smith, G. E. (2002). Mayo's Older Americans Normative Studies: expanded AVLT Recognition Trial norms for ages 57 to 98. Journal of Clinical and Experimental Neuropsychology, 24, 214-220

Heaton, R. K., Grant, I., \& Matthews, C. G. (1986). Differences in neuropsychological test performance associated with age, education, and sex. In I. Grant \& K. M. Adams (Eds.), Neuropsychological assessment of neuropsychiatric disorders (pp. 100-120). New York: Oxford University Press.

Houx, P. J., \& Jolles, J. (1993). Age-related decline of psychomotor speed: effects of age, brain health, sex, and education. Perceptio and Motor Skills, 76(1), 195-211.

Houx, P. J., Jolles, J., \& Vreeling, F. W. (1993). Stroop interference: aging effects assessed with the Stroop Color-Word Test. Experimental Aging Research, 19(3), 209-224.

Houx, P. J., Vreeling, F. W., \& Jolles, J. (1991). Rigorous health screening reduces age effect on memory scanning task. Brain and Cognition, 15(2), 246-260.

Jolles, J., Houx, P., Van Boxtel, M. P., \& Ponds, R. W. (Eds.). (1995). Maastricht Aging Study: Determinants of cognitive aging. Maastricht: Neuropsych Publishers.

Jonker, C., Geerlings, M. I., \& Schmand, B. (2000). Are memory complaints predictive for dementia? A review of clinical and population-based studies. International Journal of Geriatric Psychiatry, 15(11), 983991.

Kausler, D. H. (1994). Learning and memory in normal aging. San diego, CA: Academic Press.

Lasheras, C., Patterson, A. M., Casado, C., \& Fernandez, S. (2001). Effects of education on the quality of life, diet, and cardiovascular risk factors in an elderly Spanish community population. Experimental Aging Research, 27, 257-270.

Lindblom, K. M., Linton, S. J., Fedeli, C., \& Bryngelsson, I. L. (2006). Burnout in the working population: relations to psychosocial work factors. International Journal of Behavioral Medicine, 13, 51-59.

Luteijn, F., \& Van der Ploeg, F. A. E. (1983). Handleiding Groninger Intelligentietest (GIT) Manual Groningen Intelligence Test]. Lisse, The Netherlands: Swets and Zeitlinger.

Mares, A. M. H. M. (Ed.). (2004). Jaarboek onderwijs in cijfers [Yearbook education in numbers]: Centraal Bureau voor de Statistiek.

Mason, S. E. (1979). Effects of orienting tasks on the recall and recognition performance of subjects differing in age. Developmental Psychology, 15, 467-469.

Meijer, W. A., De Groot, R. H. M., Van Gerven, P. W. M., van Boxtel, M. P., \& Jolles, J. (2006). Verbal learning and aging: Combined effects of irrelevant speech, interstimulus interval, and education. Journals of Gerontology: Psychological Sciences., 61B, 285-294.

Ponds, R. W., Commissaris, K. J., \& Jolles, J. (1997). Prevalence and covariates of subjective forgetfulness in a normal population in The Netherlands. International Journal of Aging and Human Development, 45, 207-221.

Ponds, R. W., van Boxtel, M. P., \& Jolles, J. (2000). Age-related changes in subjective cognitive functioning. Educational Gerontology, 26, 67-81. 
Rabbitt, P. (1993). Does it all go together when it goes? The Nineteenth Bartlett Memorial Lecture. Quarterly Journal of Experimental Psychology A, 46(3), 385-434.

Rankin, J. L., \& Hyland, T. P. (1983). The effects of orienting tasks on adult age differences in recall and recognition. Experimental Aging Research, 9, 159-164.

Ratcliff, R., \& Smith, P. L. (2004). A comparison of sequential sampling models for two-choice reaction time. Psychological Review, 111, 333-367.

Rey, A. (1941). L'examen psychologique dans le cas d'encephalopathie traumatique [Psychological examination of traumatic encephalopathy]. Archives de Psychologie, 28, 286-340.

Rugg, M. D., Allan, K., \& Birch, C. S. (2000). Electrophysiological evidence for the modulation of retrieval orientation by depth of study processing. Journal of Cognitive Neuroscience, 12, 664-678.

Schneider, W., Eschman, A., \& Zuccolotto, A. (Eds.). (2002). E-prime User's Guide (Vol. 1.0). Pittsburgh: Psychology Software Tools.

Schooler, C. (1999). The workplace environment: Measurement, psychological effects, and basic issues. In S. L. Friedman \& T. D. Wachs (Eds.), Measuring environment across the lifespan (pp. 229-246). Washington, DC: American Psychological Society.

Schwarz, R., Krauss, O., \& Hinz, A. (2003). Fatigue in the general population. Onkologie, 26(2), 140-144.

Seidenberg, M. S., \& McClelland, J. L. (1989). A distributed, developmental model of word recognition and naming. Psychological Review, 96, 523-568.

Sluiter, J. K., de Croon, E. M., Meijman, T. F., \& Frings-Dresen, M. H. (2003). Need for recovery from work related fatigue and its role in the development and prediction of subjective health complaints. Occupational and Environmental Medicine, 60 Suppl 1, 62-70.

Stern, Y. (2002). What is cognitive reserve? Theory and research application of the reserve concept. Journal of the International Neuropsychological Society, 8, 448-460.

Taylor, D. C. (1989). Affective disorders in epilepsies: A neuropsychiatric review. Behavioural Neurology, 2, 49-68.

Tisserand, D. J., McIntosh, A. R., van der Veen, F. M., Backes, W. H., \& Jolles, J. (2005). Age-related reorganization of encoding networks directly influences subsequent recognition memory. Cognitive Brain Research, 25, 8-18.

UNESCO. (1976). International Standard Classification of Education (ISCED). Paris: UNESCO.

van Hooren, S. A., Valentijn, S. A., Bosma, H., Ponds, R. W., van Boxtel, M. P., \& Jolles, J. (2005). Relation between health status and cognitive functioning: a 6-year follow-up of the Maastricht Aging Study. Journal of Gerontology B: Psychological Sciences, 60, 57-60.

Van Loon-Vervoorn, W. A. (1985). Voorstelbaarheidswaarden van Nederlandse woorden: 4600 substantieven, 1000 verba en 500 adjectieven [Imagery values of Dutch words: 400 nouns, 1000 verba en 500 adjectives]. Lisse, The Netherlands: Swets \& Zeitlinger.

Willis, S. L., \& Schaie, K. W. (2005). Cognitive trajectories in midlife and cognitive functioning in old age. In S. L. Willis \& M. Martin (Eds.), Middle adulthood: a lifespan perspective (pp. 243-277). Thousand Oaks: Sage Publications.

Yonelinas, A. P. (2002). The nature of recollection and familiarity: a review of 30 years of research. Journal of Memory and Language, 46, 441-517.

Zelinski, E. M., Walsh, D. A., \& Thompson, L. W. (1978). Orienting task effects on EDR and free recall in three age groups. Journal of Gerontology, 33, 239-245. 


\title{
Chapter 7
}

\section{Interaction effects of education and health status on cognitive change: 6-year follow-up of the Maastricht Aging Study}

\author{
Willemien A. Meijer, Martin, P. J. van Boxtel, Pascal W. M. van Gerven, Susan A. van Hooren \\ \& Jelle Jolles \\ Submitted for publication
}

\begin{abstract}
The aim of this study was to test for interactions between education and health status (i.e., physical, social, and psychological functioning) with respect to baseline cognitive performance and change over 6 years. Longitudinal data from the Maastricht Aging Study of 1344 men and women aged 24 to 47 and 49 to 77 were used. Interactions were only found in the younger group. Regarding baseline performance, an interaction effect was found on working memory efficiency. Regarding change, interaction effects were found on measures of speed and executive functioning. These interactions indicated that high education attenuates age-related decline and lower baseline performance incurred by low health status in persons younger than 50 . The components of health status that most consistently interacted with education were physical functioning on baseline performance and physical and psychological functioning on longitudinal change.
\end{abstract}


The substantial heterogeneity in cognitive functioning across the lifespan and the rapidly growing proportion of older persons in the population underscore the importance to understand factors that influence age-related cognitive decline. Recently, the possibility of interactions between factors that influence cognitive decline has gained interest (Dik et al., 2001; Seeman et al., 2005). One potentially important interaction is that between health status and educational attainment. Consistent evidence supports a link between greater educational attainment, better cognitive functioning, and lower age-related cognitive decline (Anstey \& Christensen, 2000; Bosma, Van Boxtel, Ponds, Houx, \& Jolles, 2003; Cagney \& Lauderdale, 2002). Precise mechanisms for this effect of education still remain unclear. One of the proposed mechanisms is that education serves as a marker for other conditions related to socioeconomic status, such as health status (Lasheras, Patterson, Casado, \& Fernandez, 2001), which is also known to influence age-related cognitive decline (van Hooren et al., 2005). Educational level, however, has been shown to remain a significant predictor of cognitive aging, independent of factors such as health status and health behaviors (Albert et al., 1995). Other hypothesized mechanisms have included more direct effects of education on the brain. These notions focus on the possibility that education promotes brain development, resulting for example in greater dendritic outgrowth and in greater levels of network connectivity, which may in turn result in greater "brain reserve" (Stern, 2002). Educational experience may also provide "cognitive reserve" in the form of a more elaborate set of basic skills or cognitive strategies (Stern, 2002). With aging, such reserve capacities allow the individual to maintain higher levels of cognitive functioning in the face of declines in brain structure or function (Katzman, 1993; Stern, 2002). A third hypothesis posits that the protective effects of education are the result of factors related to high education that entail ongoing mental stimulation throughout the life course, such as certain leisure activities and a high occupational level (Bosma et al., 2002; Bosma et al., 2003).

Health status represents another established determinating factor of cognitive aging. According to a long-standing statement of the World Health Organization (1948), physical, psychological, and social functioning determine the health status of an individual. Previous studies have identified associations between one of the three components of health status and cognitive decline. For instance, psychological functioning, in terms of depressive complaints, has been associated with cognitive decline in older adults (Comijs, Jonker, Beekman, \& Deeg, 2001; Wilson et al., 2002; Wilson, Mendes De Leon, Bennett, Bienias, \& Evans, 2004). A possible explanation for this finding is that people who are anxious or depressed may be less motivated and have more worries that compete for resources in working memory, resulting in a reduced performance on cognitive tasks (Eysenck, 1992). Another explanation is that depression or anxiety initiates or accelerates neurodegenerative processes (Yaffe et al., 1999) or is a reaction to a perceived deterioration in cognitive function (Stewart, 2004). Psychosocial factors, such as social resources, also appeared to have an influence on age-related cognitive decline in persons (Barnes, Mendes de Leon, Wilson, Bienias, \& Evans, 2004; Seeman, Lusignolo, Albert, \& Berkman, 2001). For example, it was demonstrated in 6102 adults over 65 years of age that a higher number of social networks and a high level of social engagement were positively associated with initial level of cognitive function and with a reduced rate of cognitive decline over 5.3 years (Barnes et al., 2004). 
It was suggested that participation in social activities might be cognitively challenging, which accounts for its protective effects against cognitive decline. Finally, poor physical function, as indexed by self-rated health, was related to cognitive decline in an older population (Carmelli, Swan, LaRue, \& Eslinger, 1997; Tranel, Benton, \& Olson, 1997). It has been suggested that self-perceived health can be seen as an individual's global assessment of disability in that it often reflects early stages of pathology, residual impairments of illness, and functional limitations (Johnson \& Wolinsky, 1993; Liang, 1986). A limitation of these studies is that they highlight only one aspect of health status. To our knowledge, only one prior study (van Hooren et al., 2005) investigated the relative importance of health status components. Using data from the Maastricht Aging Study of 669 individuals aged 60 to 81, van Hooren et al. demonstrated that physical functioning (in terms of perceived health and instrumental activities of daily living) and psychological functioning (determined by psychopathological complaints) were related to several measures of cognitive functioning at baseline, but only psychological functioning was related to memory functioning six years later.

Despite the fact that educational attainment and health status have each been linked to cognitive decline, there has been no research, to our knowledge, on the possibility of an interaction between these two modifying factors. If educational attainment, as has been hypothesized, is associated with more complex brain development and a more elaborate set of basic skills or cognitive strategies, educational experience might well serve as a counterweight to cognitive deterioration induced by poor health status. In a parallel vein, one might hypothesize that lower educated individuals are more at risk of cognitive decline incurred by low health status. An alternative hypothesis might emanate from interactions between APOE-e4 status, education, and time (seven years follow-up) that were found on cognitive functioning in persons aged 70 to 79 (Seeman et al., 2005). The presence of an e4 allele, a risk factor for cognitive decline, was associated with more pronounced cognitive decline in individuals with more than eight years of formal education than in individuals with less than eight years of education. This suggests that higher educated individuals have more to lose in terms of cognitive capacity when faced with a risk factor for cognitive decline than lower educated individuals. One might thus alternatively hypothesize that higher educated individuals are more at risk of cognitive decline incurred by low health status.

In the present study, we seek to test whether there are interactions between health status and education on cognitive decline and if so, whether higher or lower educated individuals are more at risk of cognitive decline incurred by low health status. Using longitudinal data from the Maastricht Aging Study, we examine the possible interaction effects between education and health status (a combination of physical, psychological, and social functioning) on cognitive functioning and cognitive change over a six-year period in both younger (24 to 47 years) and older (49 to 76 years) individuals. We also studied whether the three components of health status show similar joint effects with education and whether the effects change with age. 


\section{METHODS}

\section{Participants}

The data used in the present study were derived from the Maastricht Aging Study (MAAS), a longitudinal study examining determinants of normal cognitive aging (Van Boxtel et al., 1998). Participants were drawn from a register of general practices (Metsemakers, Hoppener, Knottnerus, Kocken, \& Limonard, 1992). MAAS involved 1823 participants aged between 24 and 81 years, who were stratified according to age (12 classes, ranging from $25 \pm 1,30 \pm 1,35 \pm 1, \ldots$, to $80 \pm 1$ years), sex, and occupational achievement (low, high). Participants had no documented medical conditions known to interfere with normal cognitive functioning (e.g., dementia, mental retardation, and cerebrovascular pathology) and had a score of 24 or higher on the MiniMental State Examination (Folstein, Folstein, \& McHugh, 1975) at the moment of inclusion. In the baseline period between 1993 and 1995, participants underwent a cognitive and physical examination (Jolles et al., 1995). Six years after the baseline measurements, all participants were invited for reassessment. Due to refusal $(n=275)$, death $(n=116)$, loss to follow-up $(n=37)$, or other reasons $(n=19), 1376$ participants were actually tested $(74 \%)$. Data for 1350 participants aged 24 to 76 were used in the present study. Individuals with clinically verified major depression or dementia at sixyear follow-up were excluded from further analyses, which resulted in a sample of 1344 participants in the present study (696 men, 648 women). Because participants aged 49 years and older received an additional neuropsychological assessment three years after baseline, we analyzed younger ( 24 to 47 years) and older individuals (49 to 77 years) separately.

\section{Health status}

Health status was based on three components: Physical functioning, social functioning, and psychological functioning (World Health Organization, 1948). Physical functioning was measured as perceived health: Participants were asked how they would rate their health on a scale ranging from extremely good (1) to extremely poor (5). Individual scores were standardized into z-scores. Social functioning was defined by the number of hours per week a person was engaged in club life. In order to combine this measure with physical and psychological functioning, number of hours was first inverted and subsequently standardized. Psychological functioning was determined by the subscales depression and anxiety of the Symptom-Check-List 90 (SCL-90). The SCL90 is a widely used multidimensional checklist for psychopathological complaints (Arrindell \& Ettema, 1986). Scores range from 0 (no complaints) to 80 (many complaints) for depression, and from 0 (no complaints) to 50 (many complaints) for anxiety. The individual scores from the two scales were first standardized and subsequently averaged.

The three standardized health components, physical, social, and psychological functioning, were summed in order to obtain a single score for health status. 


\section{Education}

Level of education was assessed by classifying formal schooling according to a system commonly used in the Netherlands (de Bie, 1987), which is comparable to the International Standard Classification of Education (UNESCO, 1976). Educational level was scored in eight ordinal categories: 1) primary education, 2) lower vocational education, 3) intermediate general secondary education, 4) intermediate vocational education, 5) higher general secondary education, 6) higher vocational education, 7) higher professional education, and 8) university. Education was used as a continuous variable in the analyses and inverted in order to better interpret the effects of the interaction term of education and health status.

\section{Assessment of cognitive functioning}

A broad range of cognitive tests was administered to assess speed of information processing, cognitive flexibility, interference, memory, and verbal fluency. These tests have been shown to be sensitive to age-related changes, level of education, and subtle differences in health (Van der Elst, Van Boxtel, Van Breukelen, \& Jolles, 2005, 2006a, 2006b; Van der Elst, van Boxtel, Van Breukelen, \& Jolles, 2006c; Van der Elst, Van Boxtel, Van Breukelen, \& Jolles, in press).

The Stroop Color-Word Test (SCWT) (Stroop, 1935) is a test of selective attention (Van der Elst et al., 2006b). The test involves three subtasks with different cards displaying a hundred stimuli each. The first card contains color names printed in black ink, which have to be read out aloud. The second card contains rectangle patches in red, blue, green, and yellow, which have to be named by their color. The last card displays color names printed in incongruously colored ink. Participants were instructed to name the ink colour of the printed words. As measure of general information processing speed the mean time needed to complete cards 1 and 2 was calculated. Stroop interference was calculated as the time taken to complete the third card minus the mean of the time taken to complete the first two cards. Resistance to interference from a habitual response (word reading) can be considered as an executive function.

The Concept Shifting Task (CST) is a modified version of the Trail Making Test (Vink \& Jolles, 1985) and is used as an instrument to measure simple cognitive speed and cognitive flexibility (Van der Elst et al., in press). This test consists of three sheets of paper with sixteen small circles grouped to form a larger circle. The smaller circles contain numbers on the first sheet, letters on the second, and both numbers and letters on the third sheet. Letters and numbers are printed in a random order, which is the same for all participants. Participants were requested to cross out the items in a numerical or alphabetical order as fast as possible. On the third sheet, participants had to alternately cross out numbers and letters (i.e, 1-A-2-B-3-C ..., etc.). General information processing speed was calculated as the mean time needed to complete sheets 1 and 2. Concept shifting (i.e., shifting between numbers and letters), which can be considered as an executive function, was calculated as the time taken to complete the third sheet minus the mean of the time taken to complete the first two sheets.

The Letter-Digit Substitution Test (LDST) is a modified version of the SymbolDigits-Modalities Test (Smith, 1968). This test measures the efficiency of processing in working memory (Van der Elst et al., 2006c). Individuals were instructed to copy numbers in cells that were indexed by a letter as fast as possible. The letter refers to 
nine fixed letter-number combinations at the top of the form. The dependent variable (LDST) was the number of correctly copied numbers within 60 seconds.

The Visual Verbal Learning Test (VVLT) measures intentional learning and verbal memory (Van der Elst et al., 2005). Fifteen monosyllabic words were presented one after another on a computer screen. After presentation, the participant was asked to recall as many words as possible in any order. This procedure was conducted five times with the same word list. After twenty minutes, delayed recall was tested. The sum of the scores in the first three learning trials (immediate recall) and the delayed recall score were used as measures of verbal memory in this study.

In the Verbal Fluency Test (Lezak, 2004), participants were asked to produce as many words as possible from a given semantic category (i.e., animals) within $60 \mathrm{sec}$ onds. The variable of interest is the number of correct animal names. The score can be seen as a measure for strategy-driven retrieval of information from semantic memory (Van der Elst et al., 2006a).

\section{Cognitive compound scores}

In order to reduce the number of test variables while improving the robustness of the underlying cognitive constructs (Lezak, 2004), we calculated compound scores for different cognitive domains. Raw scores of baseline assessment and follow-up were first transformed into z-scores for the young and old group separately. A memory compound score was calculated by averaging the immediate and delayed recall scores of the VVLT. A speed compound score consisted of the averaged general speed measures of the SCWT and CST. An executive function compound score was calculated by averaging the interference score of the SCWT and the concept shifting score of the CST. LDST, and fluency were not included in the compound scores, but treated as separate dependent variables.

\section{Data analysis}

Hierarchical linear regression analyses were used to study the interaction effects of health status, education, and age (measured at baseline) on cognitive functioning at baseline and follow-up. For all dependent variables, the same steps in the regression analyses were used. With respect to the cross-sectional models, sex was entered in the first step to adjust for it in all the next steps. Age, education, and health status were entered in the second step. The two-way interaction term between health status and education was entered in the third step. The two-way interaction terms age by education and age by health status were entered in the fourth step. Finally, the three-way interaction term age by education by health status was entered in the fifth step. The longitudinal model formation followed the same procedure, but baseline performance was additionally entered in the first step of the analysis. Age, education, and health status were standardized before multiplication. This was done to avoid multicollinearity and for appropriate computation of standardized regression coefficients (Aiken \& West, 1991).

The relative importance of each health status component was examined by introducing the three components (i.e., physical, social, and psychological functioning) simultaneously in the cross-sectional and longitudinal regression models. Age and education were entered in the second step, the health components in the third step, the 
two-way interaction terms with education in the fourth step, the two-way interaction terms with age in the fifth step, and the three-way interaction terms with age and education in the sixth step.

The assumptions of regression analysis (homogeneity of variance, normal distribution of the residuals, absence of multicollinearity and "influential cases") were checked for each model. Analyses were performed using the SPSS program series for Apple Macintosh, version 10.

\section{RESULTS}

The mean age of the study population was 36 years $(\mathrm{SD}=7.1)$ in the young group and 61.7 years $(\mathrm{SD}=8.3)$ in the older group. The mean educational level was $4.3(\mathrm{SD}=1.7)$ in the young group and $3.2(\mathrm{SD}=1.8)$ in the old group. The main ratings of physical functioning were $4(\mathrm{SD}=.6)$ and $3.7(\mathrm{SD}=.6)$ in the young and old group respectively. Younger persons engaged in club life on average $2.33(\mathrm{SD}=3.7$ ) hours per week and older persons 2.89 ( $\mathrm{SD}=4.3$ ) hours. The mean score on the depression subscale of the SCL-90 was $20.2(\mathrm{SD}=6)$ in the young group and 20.8 (SD = 6.1) in the older group. The mean score on the anxiety subscale was $12.2(\mathrm{SD}=3.6)$ in the younger group and $12.6(\mathrm{SD}=3.9)$ in the older group.

Complete data sets with respect to the predictors were available for 626 younger participants (327 men, 299 women) and 697 older participants (364 men, 333 women). Collapsed over the young and old group and the two measurements, there were missing data for 52 persons on executive functioning, for 25 persons on speed, for 8 persons on memory, for 5 persons on LDST and for 2 persons on fluency.

\section{Health status, education, age, and cognitive functioning}

Significant correlations between age and education in the young group $(r=.17, p$ $<.05)$ and the old group $(r=.16, p<.05)$ demonstrated that level of education decreased with age. Significant correlations between education and health status in the young $(r=.22, p<.05)$ and old group $(r=.15, p<. .05)$ demonstrated that health status decreased with higher levels of education. Health status decreased with age in the young group $(r=.1, p<.05)$, but not in the old group, indicating that the older group consists of relatively healthy older persons.

Tables 1 and 2 show the standardized regression coefficients from the steps in which the predictors were entered in the model. Cross-sectional regression analyses showed that for both age groups, the second step in the models, entering health status, education, and age, explained significant proportions of variance in all the cognitive measures (ranging between $6.8 \%$ and $15.5 \%$ in the younger group and between $11.9 \%$ and $25.8 \%$ in the older group). Table 1 shows that age was associated with lower performance on all variables in both age groups, except on fluency in the young group. Lower educational attainment was related to lower performance on all cognitive variables in both age groups. Poor health status was associated with lower performance on speed and LDST in the young group and with lower performance on all cognitive variables in the old group. In addition to these main effects, interactions between age 
and education were found in the young group (with an explained variance of $1.3 \%$ ), indicating that the effect of age was larger in lower than in higher educated persons on LDST and executive functioning. Furthermore, there was an interaction between education and health status on LDST in the young group, suggesting that poor health status was more related to low cognitive performance in lower educated persons than in higher educated persons (explained variance $0.5 \%$ ).

Longitudinal regression analyses revealed that for both age groups, the first step in the model, entering sex and baseline performance, explained proportions of variance ranging between $35.8 \%$ and $68.9 \%$ in the younger group and between $35.6 \%$ and $71.8 \%$ in the older group. The second step in the model, entering main effects of health status, education, and age, explained additional proportions of variance in all the cognitive measures (ranging between 1\% and 5.1\% in the younger group and between $4 \%$ and $6 \%$ in the older group). Table 2 shows that age was associated with cognitive decline on all variables in both age groups, except on fluency in the young group. Lower educational attainment was related to decline on all cognitive variables in the young group and on memory and LDST in the old group. An age by education interaction in the young group indicated that the effect of education on speed increased with age $(0.8 \%$ explained variance). Poor health status was related to decline of memory and executive functioning in the young group and of all variables, except speed, in the old group. An age by health status interaction in the old group indicated that the effect of health status on memory $(0.7 \%$ explained variance) and LDST $(0.3 \%$ explained variance) increased with age.

The analyses also yielded evidence for the hypothesized interaction between health status and education. More specifically, poor health status was related to more cognitive decline in lower educated persons than in higher educated persons on speed $(0.4 \%$ explained variance) and executive functioning $(0.9 \%$ explained variance) in the young group. Figure 1 provides graphical representations of these interactions, showing predicted values for speed (Figure 1a) and executive functioning (Figure 1b) at follow-up. The mean values are shown separately for those with poor and good health status in a low and high education group. Groups were based on a median-split. An interaction effect between age, education, and health status on speed in the young group indicated that the joint effect of low education and poor health status increased with age $(0.3 \%$ explained variance) . 
Table 1. Hierarchical regression analyses predicting cognitive performance at baseline from age, education, health status, and their interactions.

\begin{tabular}{llllll}
\hline & Memory & Speed & LDST & $\begin{array}{l}\text { Executive } \\
\text { functioning }\end{array}$ & Fluency \\
\hline Young (24-47 yrs) & & & & & \\
\hline Age & $-.18^{* *}$ & $.10^{* *}$ & $-.23^{* *}$ & $.12^{* *}$ & -.01 \\
Educ & $-.24^{* *}$ & $.24^{* *}$ & $-.21^{* *}$ & $.22^{* *}$ & $-.24^{* *}$ \\
Health & -.01 & $.07^{* *}$ & $-.08^{* *}$ & .03 & -.03 \\
Educ x Health & -.01 & .02 & $-.04^{*}$ & .01 & -.01 \\
Age x Health & -.01 & .03 & -.01 & .02 & -.01 \\
Age x Educ & .01 & -.007 & $-.11^{* *}$ & $.07^{*}$ & -.06 \\
Age x Educ x Health & -.02 & .01 & -.01 & .01 & -.04 \\
\hline
\end{tabular}

\begin{tabular}{llllll}
\hline \multicolumn{1}{l}{ Old (49-76 yrs) } & & & & \\
\hline Age & $-.22^{* *}$ & $.3^{* *}$ & $-.34^{* *}$ & $.21^{* *}$ & $-.11^{* *}$ \\
Educ & $-.18^{* *}$ & $.24^{* *}$ & $-.35^{* *}$ & $.21^{* *}$ & $-.3^{* *}$ \\
Health & $-.05^{* *}$ & $.06^{* *}$ & $-.05^{* *}$ & $.03^{*}$ & $-.05^{* *}$ \\
Educ x Health & -.003 & .002 & -.02 & .01 & -.02 \\
Age x Health & .02 & .003 & .02 & .02 & -.01 \\
Age x Educ & .05 & .01 & .02 & .01 & .04 \\
Age x Educ x Health & -.02 & .003 & -.001 & .007 & .001 \\
\hline Notes* $*$ p $<.05 ; * * 0.01$ & & & & \\
\hline
\end{tabular}

Notes: $*=\mathrm{p}<.05 ; * * \mathrm{p}<.01$

Standardized regression coefficients are shown from the steps in which the predictors were entered in the models. Analyses were adjusted for sex.

Educ $=$ education. 
Table 2. Hierarchical regression analyses predicting cognitive performance at 6 years follow-up from age, education, health status, and their interactions.

\begin{tabular}{|c|c|c|c|c|c|}
\hline & Memory & Speed & LDST & $\begin{array}{l}\text { Executive } \\
\text { functioning }\end{array}$ & Fluency \\
\hline \multicolumn{6}{|l|}{ Young (24-47 yrs) } \\
\hline Age & $-.06^{*}$ & $.09 * *$ & $-.05^{*}$ & $.13^{* *}$ & -.006 \\
\hline Educ & $-.1 * *$ & $.08 * *$ & $-.05^{*}$ & $.11^{* *}$ & $-.08^{*}$ \\
\hline Health & $-.03 *$ & .01 & -.01 & $.03^{*}$ & -.03 \\
\hline Educ $x$ Health & .009 & $.03 *$ & .003 & $.04 * *$ & -.02 \\
\hline Age $x$ Health & -.02 & -.003 & -.004 & .02 & -.01 \\
\hline Age x Educ & -.002 & $.08 * *$ & .01 & -.003 & -.007 \\
\hline Age $x$ Educ x Health & .002 & $.02 *$ & .01 & .001 & .002 \\
\hline \multicolumn{6}{|l|}{ Old (49-76 yrs) } \\
\hline Age & $-.14^{* *}$ & $.18^{* *}$ & $-.2^{* *}$ & $.19 * *$ & $-.18^{* *}$ \\
\hline Educ & $-.11 * *$ & .01 & $-.06^{* *}$ & .04 & -.05 \\
\hline Health & $-.03^{*}$ & .004 & $-.03^{* *}$ & $.03^{*}$ & $-.04 * *$ \\
\hline Educ x Health & -.02 & .001 & -.01 & .007 & -.002 \\
\hline Age $x$ Health & $-.04 * *$ & .006 & $-.03^{* *}$ & .004 & .02 \\
\hline Age x Educ & .03 & -.01 & .01 & -.0005 & .01 \\
\hline Age $x$ Educ x Health & .008 & -.0004 & -.001 & .005 & -.006 \\
\hline
\end{tabular}

Notes: $*=\mathrm{p}<.05 ; * * \mathrm{p}<.01$

Standardized regression coefficients are shown from the steps in which the predictors were entered in the models. Analyses were adjusted for sex and baseline performance.

Educ $=$ education . 


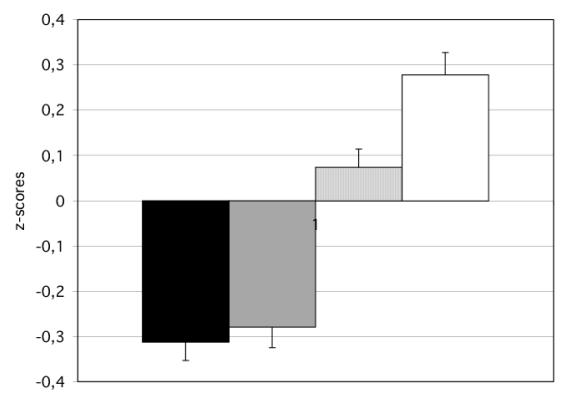

B

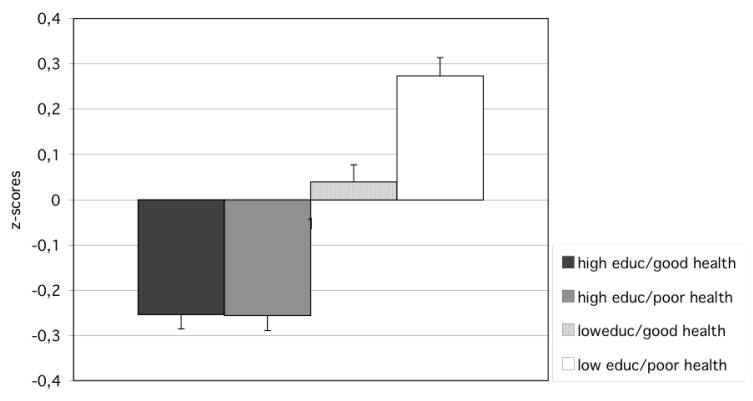

Figure 1. Predicted values for speed (A) and executive functioning (B) at follow up for persons aged 24-47 years. Higher z-scores indicate longer performance time. Error bars represent standard errors of the mean.

\section{Relative importance of psychological, social, and physical functioning}

There was a significant correlation between physical functioning and psychological functioning in the young $(r=.27, p<.05)$ and old group $(r=.3, p<.05)$. The correlations between social and physical functioning and between social and psychological functioning were not significant in either age group. Education was correlated with physical functioning in the young $(r=.19, p<.05)$ and old $(r=.16, p<.05)$ group, and with psychological functioning in the young $(r=.14, p<.05)$ and old $(r=.08, p<$ $.05)$ group, but not with social functioning. Physical functioning decreased with age in the young group $(r=.19, p<.05)$ and psychological functioning increased with age in the old group $(r=-.12, p<.05)$. Social functioning was not correlated with age in either of the age groups.

Tables 3 and 4 show the standardized regression coefficients from the steps in which the predictors were entered in the model. Main effects of age, education, and two-, and three-way interactions with age are not tabulated. Cross-sectional regression analyses (Table 3) showed that poor physical and social functioning were related to poor performance in both the young and old group. Psychological functioning did not predict cognitive functioning. Interaction effects between age and health components indicated that the relation between physical functioning and performance on speed $(\beta$ $=.09, p<.01), \operatorname{LDST}(\beta=-.1, p<.01)$, and executive functioning $(\beta=.07, p<.05)$ increased with age in the young group. Interactions between education and physical functioning in the young group indicated that poor physical functioning was related to lower cognitive performance in lower educated persons than in higher educated persons. A three-way interaction in the young group indicated that a joint effect of social functioning and education on fluency $(\beta=-.09, p<.05)$ increased with age.

Longitudinal regression analyses (Table 4 ) revealed a different pattern. Only physical functioning predicted cognitive functioning six years later in both age groups. However, age by psychological functioning interaction effects on memory $(\beta=-.07, p$ $<.05)$ and LDST $(\beta=-.08, \mathrm{p}<.01)$ indicated that the effect of psychological func- 
tioning increased with age in the old group. With respect to the interactions between each health component and education in the young group, it was shown that poor physical functioning was related to more decline of speed in lower than in higher educated persons and that poor psychological functioning was related to more decline of executive functioning in lower than in higher educated persons.

Table 3. Hierarchical regression analyses predicting cognitive performance at baseline from different health status components, and their interactions with educational level.

\begin{tabular}{|c|c|c|c|c|c|}
\hline & Memory & Speed & LDST & $\begin{array}{l}\text { Executive } \\
\text { functioning }\end{array}$ & Fluency \\
\hline \multicolumn{6}{|c|}{ Young (24-47 yrs) } \\
\hline Phys & -.01 & $.1 * *$ & $-.09 *$ & .04 & -.02 \\
\hline Soc & -.04 & $.06^{*}$ & $-.09 *$ & .01 & -.03 \\
\hline Psych & .003 & .03 & -.05 & .02 & -.04 \\
\hline Ed x Phys & .001 & $.08^{* *}$ & $-.11 * *$ & $.07 *$ & -.01 \\
\hline Ed x Soc & -.0006 & .004 & -.01 & .01 & -.01 \\
\hline Ed x Psych & -.05 & -.01 & -.003 & -.05 & -.007 \\
\hline \multicolumn{6}{|c|}{ Old (49-76 yrs) } \\
\hline Phys & -.04 & $.06^{*}$ & -.03 & .04 & -.05 \\
\hline Soc & -.05 & $.08^{* *}$ & $-.08^{*}$ & $.06^{*}$ & -.06 \\
\hline Psych & -.04 & .03 & -.05 & -.002 & -.03 \\
\hline Ed x Phys & .0002 & .02 & -.04 & -.0003 & -.06 \\
\hline Ed x Soc & -.02 & -.001 & -.01 & .02 & -.04 \\
\hline Ed x Psych & .008 & -.007 & -.01 & .01 & -.02 \\
\hline
\end{tabular}

Notes: $*=\mathrm{p}<.05 ;{ }^{* *} \mathrm{p}<.01$

Standardized regression coefficients are shown from the steps in which the predictors were entered in the models. Analyses were adjusted for sex.

$\mathrm{Ed}=$ education $;$ Phys $=$ physical functioning; Soc $=$ social functioning; Psych $=$ psychological functioning . 
Table 4. Hierarchical regression analyses predicting cognitive performance at 6 years follow-up from different health status components, and their interactions with educational level.

\begin{tabular}{|c|c|c|c|c|c|}
\hline & Memory & Speed & LDST & $\begin{array}{l}\text { Executive } \\
\text { functioning }\end{array}$ & Fluency \\
\hline \multicolumn{6}{|c|}{ Young (24-47 yrs) } \\
\hline Phys & $-.06^{*}$ & .03 & -.03 & .02 & $-.07 *$ \\
\hline Soc & -.03 & -.03 & .02 & .03 & -.007 \\
\hline Psych & .0001 & .004 & -.01 & .03 & -.004 \\
\hline Ed x Phys & .008 & $.06^{* *}$ & -.006 & .05 & -.006 \\
\hline Ed x Soc & .01 & .03 & -.001 & -.002 & -.03 \\
\hline Ed x Psych & -.005 & .02 & .03 & $.09 * *$ & -.03 \\
\hline \multicolumn{6}{|c|}{ Old (49-76 yrs) } \\
\hline Phys & -.04 & .02 & $-.06^{* *}$ & .03 & $-.09 * *$ \\
\hline Soc & .002 & -.008 & -.01 & .02 & -.03 \\
\hline Psych & -.05 & -.01 & -.01 & .03 & .008 \\
\hline Ed x Phys & -.01 & -.01 & -.01 & .01 & -.005 \\
\hline Ed $x$ Soc & -.02 & .003 & -.01 & .01 & .01 \\
\hline Ed x Psych & -.02 & .01 & -.001 & -.006 & -.01 \\
\hline
\end{tabular}

Notes: $*=\mathrm{p}<.05 ; * * \mathrm{p}<.01$

Standardized regression coefficients are shown from the steps in which the predictors were entered in the models. Analyses were adjusted for sex and baseline performance.

$\mathrm{Ed}=$ education; Phys $=$ physical functioning; Soc $=$ social functioning; Psych $=$ psychological functioning.

\section{DiscussiON}

The main aim of this study was to test the possibility of an interaction between education and health status with respect to cognitive functioning and change over a period of six years as measured by performance across multiple domains of cognitive functioning. Longitudinal data were used from 1344 men and women aged between 24 
and 47 years and between 49 and 77 years, who participated in the Maastricht Aging Study. We found a significant interaction between education and health status with respect to baseline performance on working memory efficiency (LDST), and interactions with respect to age-related change in speed and executive functioning (CST and SCWT) in the younger group. The general pattern of these interactions indicated that lower educated individuals show more cognitive decline and a lower baseline performance incurred by low health status than higher educated persons.

A straightforward explanation for the finding that these interactions between health status and education were only demonstrated in the younger group is that the younger persons finished their schooling more recently than older persons. The effects of education on cognitive change might diminish when people grow older, as is suggested by a smaller number of significant effects of education on change in the older group. Thus the mental stimulation due to education may not continue throughout life. Educational experience may therefore only serve as a counterweight to health-related cognitive deterioration in younger persons, who still benefit from direct effects of education on brain structure and function.

Another plausible explanation is that the appropriateness of education as an estimate of brain- or cognitive reserve differs across age groups. Educational level is probably more influenced by social and economic factors in older than in the younger cohorts. Indeed, before the 1960s, many people did not finish or continue their schooling, mostly for reasons other than their intellectual capacity. Educational experience might serve as a counterweight to cognitive deterioration incurred by low health status, especially in younger persons, for whom educational experience might be a more appropriate proxy of reserve capacity.

A final explanation for the selective presence of interactions between health status and education in the younger group is that self-report measures of health status and objective indicators of the presence of disease are not entirely corresponding (Elias, Elias, \& Elias, 1990). Additional analyses indicated that objective health problems, such as diabetes, occur more frequently in the older group, whereas subjective health status does not differ between the old and young group. Thus, the presence of disease might undo the protective effect of education in older individuals.

The component of health status that most consistently interacted with education on cognitive functioning at baseline was physical functioning. This suggests that high education attenuates the effects of poor physical functioning on cognition. With respect to cognitive performance at six-year follow-up, physical functioning interacted with education on speed, and psychological functioning interacted with education on executive functioning. This pattern might be explained by the differential effect of physical and psychological functioning on cognition. It was suggested that physical functioning, as measured by self-rated health, particularly influences basic speed (Earles \& Salthouse, 1995; Hultsch, Hammer, \& Small, 1993). Therefore, educational experience might attenuate the effect of reduced physical functioning on decline in basic information processing speed in particular. With regard to psychological functioning, it was suggested that people who are anxious or depressed have more worries and other intrusive thoughts that compete for attentional resources in working memory (Klein \& Boals, 2001). Educational experience might therefore especially serve as a counterweight for poor psychological functioning in relation to the decline of executive functions that draw on working memory capacity. 
The findings in this study demonstrate that the predicting value of health status and education is age-dependent. First, main effects of education and health status differ between the younger and older group. Second, there are synergistic effects of low education and low health status on cognitive functioning and change in persons aged 24 to 47 , but not in persons aged 49 to 76 . Third, interaction effects between health status and age on cognitive change in persons aged 49 to 76 indicate that the effects of health status on decline become larger with age in older persons. Fourth, there are only interaction effects between age and education on cognitive functioning and change in the group aged between 24 and 47 years. This indicates that age-related differences and decline are attenuated by high education only in the younger persons.

Our ability to develop more effective strategies to prevent or slow down agerelated cognitive decline, depends on a more complete understanding of the multiple and likely interactive factors that determine patterns of cognitive aging. The current findings stress the importance of further research on interaction effects between various predictors of cognitive decline throughout the lifespan. Education, lifestyle, psychosocial, and health measures, but also occupational attainment and verbal intelligence, which may be more appropriate estimates of reserve capacity in older persons (Schmand, Smit, Geerlings, \& Lindeboom, 1997), are factors that may have joint effects on cognitive decline. The present study suggests that these joint effects may be dependent on the selected age range.

\section{REFERENCES}

Aiken, L. S., \& West, S. G. (1991). Multiple regression: Testing and interpreting interactions. Newbury Park, CA: SAGE Publications, Inc.

Albert, M. S., Jones, K., Savage, C. R., Berkman, L., Seeman, T., Blazer, D., \& Rowe, J. W. (1995). Predictors of cognitive change in older persons: MacArthur studies of successful aging. Psychology and $\mathrm{Ag}$ ing, 10, 578-589.

Anstey, K., \& Christensen, H. (2000). Education, activity, health, blood pressure and apolipoprotein E as predictors of cognitive change in old age: a review. Gerontology, 46(3), 163-177.

Arrindell, W. A., \& Ettema, J. H. M. (1986). SCL-90. Een multidimensionele psychopathologie indicator (The SCL-90. A multidimensional instrument for the assessment of psychopathology). Lisse, The Netherlands: Swets \& Zeitlinger.

Barnes, L. L., Mendes de Leon, C. F., Wilson, R. S., Bienias, J. L., \& Evans, D. A. (2004). Social resources and cognitive decline in a population of older African Americans and whites. Neurology, 63(12), 2322-2326.

Bosma, H., Van Boxtel, M. P., Ponds, R. W., Jelicic, M., Houx, P., Metsemakers, J., \& Jolles, J. (2002). Engaged lifestyle and cognitive function in middle and old-aged, non-demented persons: a reciprocal association? Zeitscbrift für Gerontologie und Geriatrie, 35, 575-581.

Bosma, H., Van Boxtel, M. P., Ponds, R. W. H. M., Houx, P., \& Jolles, J. (2003). Education and age-related cognitive decline: the contribution of mental workload. Educational Gerontology, 29, 1-9.

Cagney, K. A., \& Lauderdale, D. S. (2002). Education, wealth, and cognitive function in later life. Journal of Gerontology B: Psychological Sciences and Social Sciences, 57, P163-172.

Carmelli, D., Swan, G. E., LaRue, A., \& Eslinger, P. J. (1997). Correlates of change in cognitive function in survivors from the Western Collaborative Group Study. Neuroepidemiology, 16(6), 285-295. 
Comijs, H. C., Jonker, C., Beekman, A. T., \& Deeg, D. J. (2001). The association between depressive symptoms and cognitive decline in community-dwelling elderly persons. Int J Geriatr Psycbiatry, 16(4), 361367.

de Bie, S. E. (1987). Standaardvragen 1987: Voorstellen voor uniformering van vraagstellingen naar achergrondkernmerken en interviews [Standard questions 1987: Proposal for uniformisation of questions regarding background variables and interviews]. (2nd ed.). Leiden, The Netherlands: Leiden University Press.

Dik, M. G., Jonker, C., Comijs, H. C., Bouter, L. M., Twisk, J. W., van Kamp, G. J., \& Deeg, D. J. (2001). Memory complaints and APOE-epsilon4 accelerate cognitive decline in cognitively normal elderly. Neurology, 57(12), 2217-2222.

Earles, J. L., \& Salthouse, T. A. (1995). Interrelations of age, health, and speed. Journals of Gerontology B: Psychological Sciences and Social Sciences, 50, P33-P41.

Elias, M. F., Elias, J. W., \& Elias, P. K. (1990). Biological and health influences on behavior. In J. E. Birren \& K. W. Schaie (Eds.), Handbook of the psychology of aging (3rd ed., pp. 79-102). San Diego: Academic Press.

Eysenck, M. W. (1992). Anxiety: The cognitive perspective. Hillsdale, NJ: Erlbaum.

Folstein, M. F., Folstein, S. E., \& McHugh, P. R. (1975). Mini-mental state: A practical method for grading the cognitive state of patients for the clinician. Journal of Psychiatric Research, 12, 189-198.

Hultsch, D. F., Hammer, M., \& Small, B. J. (1993). Age differences in cognitive performance in later life: relationships to self-reported health and activity life style. Journal of Gerontology, 48, P1-11.

Johnson, R. J., \& Wolinsky, F. D. (1993). The structure of health status among older adults: Disease, disability, functional limitation, and perceived health. Journal of Health and Social Behaviour, 34, 105-121.

Katzman, R. (1993). Education and the prevalence of dementia and Alzheimer's disease. Neurology, 43(1), 13-20.

Klein, K., \& Boals, A. (2001). The relationship of life stress and working memory. Journal of Applied Cognitive Psychology, 15, 565-579.

Lasheras, C., Patterson, A. M., Casado, C., \& Fernandez, S. (2001). Effects of education on the quality of life, diet, and cardiovascular risk factors in an elderly Spanish community population. Experimental Aging Research, 27, 257-270.

Lezak, M. D. (2004). Neuropsychological Assessment (4rd ed.). New York: Oxford University Press.

Liang, J. (1986). Self-reported physical health among aged adults. Journal of Gerontology, 41, 248-260.

Metsemakers, J. F., Hoppener, P., Knottnerus, J. A., Kocken, R. J., \& Limonard, C. B. (1992). Computerized health information in The Netherlands: a registration network of family practices. British Journal of General Practice, 42(356), 102-106.

Schmand, B., Smit, J. H., Geerlings, M. I., \& Lindeboom, J. (1997). The effects of intelligence and education on the development of dementia. A test of the brain reserve hypothesis. Psychological Medicine, $27,1337-1344$.

Seeman, T. E., Huang, M. H., Bretsky, P., Crimmins, E., Launer, L., \& Guralnik, J. M. (2005). Education and APOE-e4 in longitudinal cognitive decline: MacArthur Studies of Successful Aging. Journal of Gerontology B: Psychological Sciences and Social Sciences, 60, P74-83.

Seeman, T. E., Lusignolo, T. M., Albert, M., \& Berkman, L. (2001). Social relationships, social support, and patterns of cognitive aging in healthy, high-functioning older adults: MacArthur studies of successful aging. Health Psychology, 20, 243-255.

Smith, A. (1968). The Symbol Digit Modalities Test: a neuropsychologic test for economic screening of learning and other cerebral disorders. Learning Disorders, 3, 83-91.

Stern, Y. (2002). What is cognitive reserve? Theory and research application of the reserve concept. Journal of the International Neuropsychological Society, 8, 448-460.

Stewart, R. (2004). Depressive symptoms and cognitive decline--disentangling the effect of affect. Journal of Neurology, Neurosurgery and Psycbiatry, 75, 5.

Stroop, J. R. (1935). Studies of interference in serial verbal reactions. Journal of Experimental Psychology, 18, 643-662. 
Tranel, D., Benton, A., \& Olson, K. (1997). A 10-year longitudinal study of cognitive change in elderly persons. Developmental Neuropsychology, 13, 87-96.

UNESCO. (1976). International Standard Classification of Education (ISCED). Paris: UNESCO.

Van Boxtel, M. P., Buntinx, F., Houx, P. J., Metsemakers, J. F., Knottnerus, A., \& Jolles, J. (1998). The relation between morbidity and cognitive performance in a normal aging population. Journals of Gerontology series A: Biological Sciences and Medical Sciences, 53, M147-154.

Van der Elst, W., Van Boxtel, M. P., Van Breukelen, G. J., \& Jolles, J. (2005). Rey's verbal learning test: normative data for 1855 healthy participants aged 24-81 years and the influence of age, sex, education, and mode of presentation. Journal of the International Neuropsychological Society, 11, 290-302.

Van der Elst, W., Van Boxtel, M. P., Van Breukelen, G. J., \& Jolles, J. (2006a). Normative data for the Animal, Profession and Letter M Naming verbal fluency tests for Dutch speaking participants and the effects of age, education, and sex. Journal of the International Neuropsychological Society, 12, 80-89.

Van der Elst, W., Van Boxtel, M. P., Van Breukelen, G. J., \& Jolles, J. (2006b). The stroop color-word test: influence of age, sex, and education; and normative data for a large sample across the adult age range. Assessment, 13, 62-79.

Van der Elst, W., van Boxtel, M. P. J., Van Breukelen, G. J. P., \& Jolles, J. (in press). The concept shifting test: adult normative data. Psychological Assessment.

Van der Elst, W., Van Boxtel, M. P. J., Van Breukelen, G. J. P., \& Jolles, J. (2006c). The Letter Digit Substitution Test: Normative data for 1,858 healthy participants aged 24-81 from the Maastricht Aging Study (MAAS): influence of age, education, and sex. Journal of Clinical and Experimental Neuropsychology, 28, 998-1009.

van Hooren, S. A., Valentijn, S. A., Bosma, H., Ponds, R. W., van Boxtel, M. P., \& Jolles, J. (2005). Relation between health status and cognitive functioning: a 6-year follow-up of the Maastricht Aging Study. Journal of Gerontology B: Psychological Sciences, 60, 57-60.

Vink, M., \& Jolles, J. (1985). A new version of the Trail-Making Test as an information processing task. Journal of Clinical Neuropsychology, 7, 162.

Wilson, R. S., Barnes, L. L., Mendes de Leon, C. F., Aggarwal, N. T., Schneider, J. S., Bach, J., Pilat, J., Beckett, L. A., Arnold, S. E., Evans, D. A., \& Bennett, D. A. (2002). Depressive symptoms, cognitive decline, and risk of AD in older persons. Neurology, 59(3), 364-370.

Wilson, R. S., Mendes De Leon, C. F., Bennett, D. A., Bienias, J. L., \& Evans, D. A. (2004). Depressive symptoms and cognitive decline in a community population of older persons. Journal of Neurology, Neurosurgery and Psychiatry, 75, 126-129.

Yaffe, K., Blackwell, T., Gore, R., Sands, L., Reus, V., \& Browner, W. S. (1999). Depressive symptoms and cognitive decline in nondemented elderly women: a prospective study. Arcbives of General Psychiatry, 56, 425-430. 


\section{CHAPTER 8}

\section{Concluding remarks}

The aim of the present dissertation was twofold. First, additional insight was sought with respect to the cognitive processes that are most affected by aging and the underlying mechanisms of these age effects. Special attention was paid to age-related differences in cognitive performance in pre-senescence, that is, between young and old-middle aged adults, an age range that is often disregarded in cognitive aging research. The second aim was to investigate the extent to which individual characteristics influence age-related differences and longitudinal change. In particular, cognitive processes were identified for which a higher level of education may serve as a protective factor. The general pattern that emerged from the empirical findings was that young middle-aged persons around 40 years of age already show decreased performance on several cognitive measures within the domain of memory and information processing when compared to young adults. Furthermore, the results show that age differences become more pronounced as cognitive challenges increase. With regard to the second aim, a high level of education was found to attenuate age-related differences mainly in cohorts younger than 50 years. Accordingly, education moderates the effects of health status on cognitive functioning and change only in persons younger than 50. Furthermore, the attenuating effect of a higher educational level was found for only some aspects of cognitive functioning. Together, these findings underscore the role of education in cognitive aging.

This final chapter continues with some methodological considerations before the results of the studies reported in the previous chapters are discussed on a general level. More specifically, age differences across adulthood and effects of task demands are discussed. Subsequently, the role of education in cognitive aging is addressed. The chapter closes with some recommendations for further research.

\section{METHODOLOGICAL CONSIDERATIONS}

In research on age-related cognitive change, two typical approaches to data collection can be found. Either a cross-sectional design is used with calendar age as the between-person variable of interest, or a longitudinal design is used in which performances at different time points within individuals are evaluated. Most research has been cross-sectional because these kinds of designs are considerably less time-consuming and less expensive than longitudinal designs. In the present dissertation, cross-sectional designs were used in Chapters 2 to 7 in order to compare age differences between task conditions and cognitive variables. Tests of interactions in an analysis of variance with age as a categorical variable were preferred because the absolute age effect, which can 
be examined more accurately with age as a continuous variable, was not the primary focus. The main questions were rather: a) Which age group differences in performance are maximal? and b) At what age do interactions between age and task condition emerge? In this context, education, sex, and health status were examined as proximal determinants of age-related differences, that is, as correlates of the age differences observed at the time of measurement. Health status and education were also investigated as more distal determinants in a longitudinal design using regression analysis (Chapter 7). These predictors were measured at baseline to examine their contribution to cognitive change over six years.

The results of cross-sectional comparisons may not directly reflect the effects of aging because people of different ages may also differ in other characteristics. Consequently, age effects may be confounded by cohort effects, such as social and economical circumstances (Salthouse, 2000). For example, a low level of education in older persons is often related to the low socioeconomic status of their parents instead of the true intellectual ability of such individuals. As a consequence, cognitive differences between younger and older persons with a low educational level might be underestimated. The true cognitive level of the older persons who have a low educational status may be higher. We dealt with this cohort effect in the present dissertation by including adjacent age groups (Chapters 2, 3, and 4), instead of groups with extremely different mean ages, which is the rule in the majority of cognitive aging studies. In addition, low and high educational achievement was defined differently for young and middle-aged persons (Chapters 5 and 6).

In order to evaluate the extent of age-related cognitive decline, repeated observations in the same individuals is preferred. However, in a longitudinal design, one has to deal with other sources of bias, such as retest effects and selective attrition, which are often difficult to disentangle from the age effects under study (Salthouse, 2000). Moreover, this approach requires retest intervals of several decades in order to make it comparable with the age range used in a typical cross-sectional design (Salthouse, 2000). To combine the strengths of the different approaches, both cross-sectional and longitudinal designs were used in the studies described in this dissertation.

\section{COGNITIVE PERFORMANCE ACROSS ADULTHOOD}

Although most of the work on cognitive aging has compared older adults (above 65 years) to young adults, some longitudinal and cross-sectional studies have examined cognitive functioning throughout adulthood (Dixon, de Frias, \& Maitland, 2001; Houx \& Jolles, 1993; Houx, Jolles, \& Vreeling, 1993; Schaie, 1996). Results have shown that some aspects of cognitive functioning are maintained or even improved in midlife (Schaie, 1996). These include the pragmatic aspects of functioning such as knowledge that depends on experience (Baltes, Staudinger, \& Lindenberger, 1999; Sternberg, Grigorenko, \& Oh, 2001). In contrast, aspects of the mechanics of cognition, including speed of processing and working memory, begin to show declines in midlife (Baltes et al., 1999). The present dissertation adds to this evidence by demonstrating that the first manifestations of age-related change can be seen as early as 40 years of age. Persons aged 39 to 51 already perform poorer than persons aged 24 to 37 on information proc- 
essing in speeded tasks (Chapter 2) and on word-learning performance (Chapters 3 and 4). Accordingly, the study described in Chapter 7 demonstrated that age influences baseline performance and change over six years on word-learning performance, general information processing speed, and executive functioning in persons aged 24 to 47 . Performance and change on the verbal fluency task were only influenced by age in individuals between 49 to 76 years (Chapter 7). These results are in line with the general notion that age differences in verbal fluency, reflecting the accumulation of semantic knowledge, develop later in adulthood than differences in episodic memory and speed of information processing (Schaie, 1994).

In contrast to the more established literature with respect to functioning on standard neuropsychological tasks across adulthood, very few experimental studies have included middle-aged persons. The present dissertation presented four studies that investigated the effects of task demands on cognitive differences between younger, middle-aged, and older groups. These studies demonstrated that the wordlearning performance of older individuals is not disproportionately compromised by a short interstimulus interval (Chapter 3) and irrelevant speech (Chapter 4, Experiment 1) alone. However, when these factors are combined in order to increase task demands, age differences become more pronounced already from middle age on (Chapter 4, Experiment 2). In addition, larger age differences in intrusion errors were found in the short, relative to the long, interstimulus interval condition (Chapter 4, Experiment 2). Together, these findings suggest that inhibitory processes in older adults are less efficient under time pressure. The other task manipulation that was used in the present dissertation was an increase in the level of word processing (Chapters 5 and 6). This was accomplished by inducing perceptual, phonological and semantic processing in a case decision, an 'e' detection, and a living/nonliving task, respectively. Reading and intentional learning additionally induced deep processing in Chapter 6. Deeper processing resulted in a larger increase in free recall performance in the group aged 25 to 35 than in the group aged 50 to 60 , whereas age differences in recognition performance did not differ across levels (Chapter 6). Additionally, age differences in reaction time did not differ across levels during the processing phase (Chapter 5). This suggests that when deeper processed information has to be retrieved from memory without cues, middle-aged adults are especially compromised compared to young adults.

In conclusion, the results from chapters $3,4,5$, and 6 suggest that middle-aged adults already show a cognitive vulnerability, particularly in more resource-demanding conditions. In these conditions with increased cognitive demands, individuals have to perform more processing steps in less time. The load in working memory is higher and information has to be retrieved from memory with fewer cues. Indeed, numerous situations and environments are conceivable in which information has to be processed quickly, attention has to be divided between multiple sources of information, and irrelevant stimuli have to be ignored. Professional environments, such as noisy office spaces, but also family environments with young children, or busy traffic situations, may demand many cognitive resources that are already limited in middle age. 


\section{COGNITIVE AGING: THE ROLE OF EDUCATION}

Education was studied in this dissertation as a potential source of cognitive reserve capacity. Cognitive reserve can be conceived as more efficient information processing in the brain, for example, through an increase in the efficiency of neurotransmission and the complexity of neuronal networks (Coffey, Saxton, Ratcliff, Bryan, \& Lucke, 1999; Meguro et al., 2001). The cognitive reserve hypothesis suggests that the cognitive performance of people with more reserve capacity is assumed to be less vulnerable to age-related changes of the brain as compared to people with less reserve capacity (Stern, 2002). In this context, the present dissertation investigated the extent to which education influences age-related differences and longitudinal change in cognitive performance. The findings show that a high level of education attenuated age differences in working memory efficiency (Chapter 2 and 7) and executive functioning (Chapter 7) until the approximate age of 50 years. Accordingly, age-related longitudinal decline in verbal memory, general processing speed, efficiency of working memory, executive functioning, and verbal fluency was attenuated by education in persons younger than 50 years, whereas only decline in the efficiency of working memory and verbal memory was attenuated in persons older than 50 years (Chapter 7 ). These findings suggest that education acts as a protective factor mainly at a younger age. This notion is substantiated by the finding that a level of higher education serves as a counteracting force to reduce the cognitive decline in speed and executive functioning incurred by low health status only in persons younger than 50 years (Chapter 7).

There are several plausible explanations for this pattern of results. One straightforward explanation is that younger people finished their schooling more recently than older people did. Educational experience may only serve as a protective factor in younger persons, who still benefit from direct effects of education on brain structure and function. Thus, the mental stimulation due to a high educational level that is achieved relatively early in life may not continue into later adulthood. This is of profound importance in relation to the 'lifelong learning' concept that has been advocated in recent years (e.g., Collins, 2004; OECD, 2002). Educational interventions or adult education in later life may extend the effects of formal training in younger adulthood and thus prevent cognitive decline in persons older than 50 .

Another explanation for the finding that education acts as a protective factor mainly at a younger age is that educational level is more closely related to the actual abilities of younger persons than to those of older persons. The reason for this is twofold. First, the presence of disease and other factors such as toxic, nutritional, and environmental factors that have influenced cognition throughout life, might undo the protective effect of education in older individuals. Another reason is that educational attainment is probably less influenced by social and economic factors in the younger cohorts than in the older cohorts. Therefore, education might be a better estimate of cognitive reserve capacity in younger persons than in older persons. In the latter group, other measurements might be more appropriate estimates of cognitive reserve, such as verbal intelligence. This estimate is probably less influenced by social and economic factors than is educational level. A comparison of four estimates of cognitive reserve in the Maastricht Aging Study indeed substantiated that verbal intelligence is the optimal estimate in persons older than 50 years (Meijer, van Boxtel, \& Jolles, 2004). Vocabu- 
lary, as a measure for verbal intelligence, was more consistently related to cognitive change over six years than education, mental stimulation due to professional activities or an active lifestyle. In contrast, these other estimates of cognitive reserve, including education, were more related to cognitive change in persons younger than 50 years. This suggests that mental ability is the most appropriate estimate of cognitive reserve in older persons, whereas measures that reflect the complexity of the individual's environment are the most appropriate estimates of cognitive reserve in younger persons.

Although the empirical findings of the present dissertation indicate that education mainly serves as a protective factor until 50 years of age, previous studies have suggested that a high educational level is associated with less cognitive decline and a lower risk of dementia and Alzheimer's disease also in older persons (Anstey \& Christensen, 2000; Gilleard, 1997). This discrepancy might be due to the type of cognitive test included in the study. In a review of 14 studies reporting on the effect of education on cognitive change (Anstey \& Christensen, 2000), only three studies included persons younger than 55 years and two of these studies used the Mini-Mental State Examination (Farmer, Kittner, Rae, Bartko, \& Regier, 1995; Lyketsos, Chen, \& Anthony, 1999). All seven studies using mental status measures found a protective effect of education. It is already known that the range of scores of mental status scales such as the MMSE is attenuated at the upper end of the scoring distribution (Tombaugh \& McIntyre, 1992). The scales are therefore insensitive to cognitive decline in highly educated people (Christensen et al., 1997). In this regard, finding a reduced decline on the MMSE in higher, compared to lower, educated persons might overestimate the protective effect of education.

In persons older than 65 years, four of the seven studies that included measures of memory showed protective effects (Colsher \& Wallace, 1991; Evans et al., 1993; Schmand, Smit, Geerlings, \& Lindeboom, 1997; Shichita, Hatano, Ohashi, Shibata, \& Matuzaki, 1986). In comparison, none of the studies using measures of reasoning and information processing speed found protective effects of education. This is in accordance with the present dissertation in which, in persons older than 50, education was found to attenuate a decline in verbal memory but not in speeded performance (Chapter 7). This discrepancy between cognitive domains may provide insight with respect to the mechanism underlying the protective effect of education. One of the major implications of Chapter 3 was that higher educated individuals probably make better use of elaborate rehearsal processes that facilitate the encoding of the to-be-learnt words. Thus, in the second half of life, higher educated persons may experience less decline in verbal memory than persons with a lower educational level not because they process stimuli faster but because they use more elaborate encoding strategies.

The observations that are described above suggest a differential effect of education on age-related change in cognitive abilities. In future research, caution should be applied when using general mental status measures and composite measures that are based on a combination of tests from different cognitive domains. Furthermore, the knowledge that the protective effect of education is age-dependent should be taken into account. 


\section{IMPLICATIONS FOR FUTURE RESEARCH}

The results described in this dissertation indicate that cognitive limitations with respect to memory and speed of information processing already exist in middle age, especially in conditions that demand many cognitive resources. People in their fourth, fifth, and sixth decade of life generally encounter considerable cognitive challenges in our hectic society. For instance, stressful situations such as deadlines at work together with having children that demand attention may require significant cognitive effort. Focusing on a task while ignoring distractions demands more effort and leads to more fatigue than focusing on a task in a setting with few distractions. For middle-aged and older adults who have less cognitive resources than younger adults, it is likely that disproportionally more effort has to be invested to finish a job. Persistent strain on diminished cognitive resources may even lead to more pathological conditions such as mood problems, mental fatigue syndrome, neuroenergetic problems, dysthymia, or burnout. Indeed, these conditions are common in the middle-aged working population (Lindblom, Linton, Fedeli, \& Bryngelsson, 2006; Schwarz, Krauss, \& Hinz, 2003; Sluiter, de Croon, Meijman, \& Frings-Dresen, 2003). Future longitudinal studies should explore whether age-related cognitive problems are a causal factor in the development of energetic or stress-related complaints. It would be worthwhile to identify those professions or characteristics of professions in which individuals may be at risk.

Energetic or stress-related complaints may, in turn, further decrease the cognitive resources of middle-aged and older individuals. That the experience of stress impairs working memory performance, presumably by reducing available attention resources, has already been demonstrated in young adults (Klein \& Boals, 2001). One could predict amplified stress and fatigue effects on cognition in middle-aged and older adults who already have less cognitive resources. In conclusion, it is conceivable that a vicious cycle develops that results in pathological conditions in some circumstances (den Hartog, 2002). The causal relationship between mental health problems and agerelated reduction of cognitive abilities should therefore be investigated in future longitudinal and experimental studies.

This dissertation has demonstrated that varying the demands of cognitive tasks is a successful approach to delineating the cognitive limitations of different age groups. The use of different combinations of constraining factors, such as various distractive stimuli in the visual or auditory modality, reduced interstimulus intervals, dual task demands, and degraded stimuli in the visual or auditory modality, could impose even more constraints on cognitive performance in future research. These constraining conditions may mimic the complexity of everyday life. For example, difficult traffic situations, noisy environments, or time pressure could cause errors. In this context, it would be advantageous to examine which conditions and thus which kind of daily life situations are most problematic across the entire adult age-range.

Another important area of research worthy of further pursuit is whether persons with more cognitive reserve are less vulnerable to the compromising effects of increased task demands in older individuals. For example, the age by interstimulus interval by education interaction described in Chapter 4 suggests the existence of age differences in short-term memory in the lower educated group regardless of the interval used. In contrast, age differences were only observed in the higher educated group 
when the short interval was used. This suggests that education protects against agerelated cognitive change, but also that its protective power levels off when the task demands are increased. Education, lifestyle, psychosocial, and health measures, occupational attainment, and verbal intelligence could be related to performance under various conditions. It would be beneficial to sort out the extent to which factors that determine inter-individual differences in cognitive reserve interact with task demands. In doing so, one should keep in mind that the appropriateness of the various cognitive reserve measures may depend on the age-range under investigation.

In conclusion, the present dissertation has increased our insight with respect to the multiple and interactive factors that determine age-related cognitive differences and change. The relative influence of educational level and various task demands on agerelated differences across adulthood has been firmly established. Young middle-aged persons around 40 years of age already perform poorer on several cognitive measures when compared to young adults, especially in cognitively challenging conditions. Furthermore, high education attainment mainly attenuates age differences until approximately 50 years. These findings warrant more attention to middle age in cognitive aging research.

\section{REFERENCES}

Anstey, K., \& Christensen, H. (2000). Education, activity, health, blood pressure and apolipoprotein E as predictors of cognitive change in old age: a review. Gerontology, 46(3), 163-177.

Baltes, P. B., Staudinger, U. M., \& Lindenberger, U. (1999). Lifespan psychology: theory and application to intellectual functioning. Annual Review of Psychology, 50, 471-507.

Christensen, H., Korten, A. E., Jorm, A. F., Henderson, A. S., Jacomb, P. A., Rodgers, B., \& Mackinnon, A. J. (1997). Education and decline in cognitive performance: compensatory but not protective. International Journal of Geriatric Psycbiatry(3), 323-330.

Coffey, C. E., Saxton, J. A., Ratcliff, G., Bryan, R. N., \& Lucke, J. F. (1999). Relation of education to brain size in normal aging: implications for the reserve hypothesis. Neurology, 53, 189-196.

Collins, J. (2004). Education techniques for lifelong learning: principles of adult learning. Radiograpbics, 24(5), 1483-1489.

Colsher, P. L., \& Wallace, R. B. (1991). Longitudinal application of cognitive function measures in a defined population of community-dwelling elders. Annals of Epidemiology, 1(3), 215-230.

den Hartog, M. H. (2002). Cognitive functions in depression: patterns and determinants. Dissertation, Maastricht: Neuropsych Publishers.

Dixon, R. A., de Frias, C. M., \& Maitland, S. B. (2001). Memory in Midlife. In M. E. Lachman (Ed.), Handbook of midlife development. New York: Wiley.

Evans, D. A., Beckett, L. A., Albert, M. S., Hebert, L. E., Scherr, P. A., Funkenstein, H. H., \& Taylor, J. O. (1993). Level of education and change in cognitive function in a community population of older persons. Annals of Epidemiology, 3, 71-77.

Farmer, M. E., Kittner, S. J., Rae, D. S., Bartko, J. J., \& Regier, D. A. (1995). Education and change in cognitive function. The Epidemiologic Catchment Area Study. Annals of Epidemiology, 5(1), 1-7.

Gilleard, C. J. (1997). Education and Alzheimer's disease: A review of recent epidemiological studies. Aging and Mental Health, 1, 33-46.

Houx, P. J., \& Jolles, J. (1993). Age-related decline of psychomotor speed: effects of age, brain health, sex, and education. Perceptual and Motor Skills, 76, 195-211. 
Houx, P. J., Jolles, J., \& Vreeling, F. W. (1993). Stroop interference: aging effects assessed with the Stroop Color-Word Test. Experimental Aging Research, 19, 209-224.

Klein, K., \& Boals, A. (2001). The relationship of life stress and working memory. Journal of Applied Cognitive Psychology, 15, 565-579.

Lindblom, K. M., Linton, S. J., Fedeli, C., \& Bryngelsson, I. L. (2006). Burnout in the working population: relations to psychosocial work factors. International Journal of Behavioral Medicine, 13, 51-59.

Lyketsos, C. G., Chen, L. S., \& Anthony, J. C. (1999). Cognitive decline in adulthood: an 11.5-year followup of the Baltimore Epidemiologic Catchment Area study. American Journal of Psychiatry, 156, 58-65.

Meguro, K., Shimada, M., Yamaguchi, S., Ishizaki, J., Ishii, H., Shimada, Y., Sato, M., Yamadori, A., \& Sekita, Y. (2001). Cognitive function and frontal lobe atrophy in normal elderly adults: Implications for dementia not as aging-related disorders and the reserve hypothesis. Psychiatry and Clinical Neurosciences, 55, 565-572.

Meijer, W. A., van Boxtel, M., \& Jolles, J. (2004). Proxies of cognitive reserve and patterns of cognitive aging. Paper presented at the Cognitive Aging Conference, Atlanta.

OECD. (2002). Understanding the brain: towards a new learning science. Paris: OECD.

Salthouse, T. A. (2000). Methodological assumptions in cognitive aging research. In F. I. Craik \& T. A. Salthouse (Eds.), The handbook of aging and cognition (2nd ed.). Mahwah, NJ: Lawrence Erlbaum Associates.

Schaie, K. W. (1994). The course of adult intellectual development. American Psychologist, 49, 304-313.

Schaie, K. W. (Ed.). (1996). Intellectual Development in Adulthood. New York: Cambridge University Press.

Schmand, B., Smit, J. H., Geerlings, M. I., \& Lindeboom, J. (1997). The effects of intelligence and education on the development of dementia. A test of the brain reserve hypothesis. Psychological Medicine, $27,1337-1344$.

Schwarz, R., Krauss, O., \& Hinz, A. (2003). Fatigue in the general population. Onkologie, 26(2), 140-144.

Shichita, K., Hatano, S., Ohashi, Y., Shibata, H., \& Matuzaki, T. (1986). Memory changes in the Benton Visual Retention Test between ages 70 and 75. Journal of Gerontology, 41, 385-386.

Sluiter, J. K., de Croon, E. M., Meijman, T. F., \& Frings-Dresen, M. H. (2003). Need for recovery from work related fatigue and its role in the development and prediction of subjective health complaints. Occupational and Environmental Medicine, 60 Suppl 1, 62-70.

Stern, Y. (2002). What is cognitive reserve? Theory and research application of the reserve concept. Journal of the International Neuropsychological Society, 8, 448-460.

Sternberg, S., Grigorenko, E. L., \& Oh, S. (2001). The development of intelligence at midlife. In M. E. Lachman (Ed.), Handbook of Midlife Development. New York: Wiley.

Tombaugh, T. N., \& McIntyre, N. J. (1992). The mini-mental state examination: a comprehensive review. Journal of the American Geriatric Society, 40, 922-935. 


\section{Summary}

The studies described in this dissertation had two main objectives. The first was to gain additional insight on the cognitive processes that are most affected by aging, notably in pre-senescence, that is, between young and old-middle aged adults. This is an age range that is often disregarded in cognitive aging research. Mechanisms and causes of age-related cognitive differences were investigated. The second aim was to investigate the extent to which individual characteristics influence age-related differences and longitudinal change. In particular, the cognitive processes whereby education is a modifying factor were identified. In Chapter 1, a brief overview is given of the methodological/theoretical approaches that are the basis of the research questions addressed in this dissertation. Furthermore, background information about determinants of cognitive aging is presented. Education was studied in this dissertation as a potential source of cognitive reserve capacity. The central notion was that a high level of education might attenuate age-related cognitive change and support the individual in coping with increased cognitive challenges.

The aim of the study presented in Chapter 2 was to investigate whether education and sex modify the well-documented effects of age on information processing speed. The interacting effects of age (three age groups), educational attainment (low, intermediate or high), and sex on information processing performance were tested in 1469 individuals ranging in age from 24 to 67 years. Performance on the Letter Digit Substitution Task (LDST), Stroop Color-Word Test (SCWT) and Memory Scanning Task (MST) was negatively affected by older age, lower educational level and male sex. A high educational level reduced age differences on the LDST. Furthermore, women demonstrated larger age differences than men on the LDST and the MST. The overall findings suggest that the effects of education and sex on age-related differences in information processing are substantial in pre-senescence.

The experimental studies outlined in Chapters 3 and 4 investigated the interrelated effects of age, education, interstimulus interval, and irrelevant speech on verbal learning. Word-learning performance was assessed in samples of low and higheducated persons from four age groups, namely young (24 to 37 years), young middleaged (39 to 51 years), old middle-aged (54 to 66 years), and old (69 to 77 years).

In the study described in Chapter 3 , the effects of a narrow range of interstimulus intervals (ISI, 1, 2, or $3 \mathrm{~s}$ ) were investigated in relation to age and education in 338 individuals. Word-learning performance was adversely affected by older age, lower education, and shorter ISI. However, age differences in performance were not affected by ISI. This suggests that increasing the ISI to provide older adults with a way to compensate for their slower processing rate is not effective in the sense that it does not reduce the performance gap between the age groups. With respect to the effect of education, the results show that individuals with a lower education level needed more time to achieve the same performance as individuals with a higher level of education.

Chapter 4 describes two experiments in which the effects of irrelevant speech on word-learning performance were evaluated. Older or lower educated individuals may be less able than younger or higher educated individuals to inhibit irrelevant speech when learning new visual information. In Experiment 1, we investigated the effects of age, education, and verbal noise (spoken words or silence) in 230 individuals. Perform- 
ance was negatively affected by age, a lower level of education and irrelevant speech. However, age-related differences in performance were not affected by irrelevant speech. In Experiment 2, we increased the difficulty of the word-learning task by using both irrelevant speech and a short interstimulus-interval (ISI, 2 or 0.5 seconds). This was done with 105 individuals that were not included in Experiment 1. Age differences became more pronounced due to the simultaneous occurrence of irrelevant speech and a short ISI. In addition, larger age differences in intrusion errors were found in the short ISI condition when compared to the long ISI condition. Together, these findings suggest that inhibitory processes in older adults are less efficient under time pressure. An implication may be that older individuals need more time to learn new information in noisy environments than younger individuals.

Chapters 5 and 6 describe experimental studies in which the level of word processing was increased in 40 young (aged 25 to 35) and 40 middle-aged (aged 50 to 60) individuals with low and high level of education. A task manipulation was used in which different levels of processing were induced.

The study described in Chapter 5 examined the influence of the level of processing on reaction times (RTs). A case decision, an 'e' detection, and a living/nonliving task were used to induce shallow perceptual, more elaborated phonological, and deep semantic processing of words. Because deeper processing involves more cognitive operations, it was hypothesized that differences in reaction time between younger and middle-aged individuals would increase with deeper processing. It was also hypothesized that this increase is less pronounced in individuals with a higher education. RTs were found to increase with age and level of processing. There were no interactions between age, task and education, suggesting that different processing levels are equally sensitive to slowing in midlife and that high education is not a moderating factor. Although no overall age by level of processing interaction was found, the age by stimulus type interactions in the deeper processing tasks suggest that a cognitive vulnerability already exists in middle age. The results show that age-related differences in RT on words containing the letter 'e' were smaller than on words without the letter 'e'. This suggests that middle-aged adults are slower than younger adults with respect to performing a terminating search strategy. Furthermore, it was found that age-related differences in RT on words referring to living items were smaller than on words referring to non-living items. This suggests that middle-aged adults are more constrained by the reduced semantic accessibility of non-living words than younger adults.

Because deeper processing results in better maintenance of words in memory, deeper processed words were expected to require less retrieval effort than shallow processed words. The aim of Chapter 6 was therefore to examine whether deeper processing of words during encoding leads to a smaller increase in word-learning performance and a smaller decrease in retrieval effort in middle-aged adults than in young adults. Whether a high level of education attenuates age-related differences in performance was also assessed. In addition to the three decision tasks that were used in the previous chapter, reading and intentional learning were used to induce deeper levels of processing. RTs of recognition were used to measure retrieval effort. Results showed that age differences in free recall increased with depth of processing, whereas age differences in accuracy and RTs of recognition did not differ across levels. A high level of education did not moderate the age-related differences in performance. These findings 
suggest a reduced benefit of deep processing in middle age but only when no retrieval cues are available.

The study described in Chapter 7 aimed to test for interactions between education and health status (i.e., physical, social, and psychological functioning) with respect to baseline cognitive performance and change over six years. Longitudinal data of 1344 individuals aged 24 to 47 and 49 to 77 were used. A broad range of cognitive tests was administered to assess speed of information processing, cognitive flexibility, inhibition, memory, and verbal fluency. Interactions were only found in the younger group. Regarding baseline performance, an interaction effect was found on working memory efficiency. With respect to longitudinal change, interaction effects were found on measures of speed and executive functioning. These interactions indicated that high level of education attenuates age-related decline and lower baseline performance incurred by low health status in persons younger than 50 . The components of health status that most consistently interacted with education were the effect of physical functioning on cognitive performance at baseline and physical and psychological functioning on longitudinal change.

Lastly, Chapter 8 presents some methodological considerations and subsequently discusses the results of the studies in this dissertation on a more general level. The pattern that emerged from the empirical findings was that young middle-aged persons around 40 years of age already show decreased performance on several cognitive measures within the domain of memory and information processing when compared to young adults. Furthermore, the results show that age differences become more pronounced from 40 years onwards when cognitive demands increase. This may have implications for daily life, because middle-aged individuals generally encounter considerable cognitive challenges, such as activities at work and in family environments that require organizing, planning, problem solving, and multitasking skills. Often, these skills must be applied in situations where the individual is subjected to time pressure.

With regard to the role of education in cognitive aging, the findings suggest that a high educational level attenuates age-related differences mainly in cohorts younger than 50 years. Accordingly, education moderated effects of health status on cognitive functioning and change only in persons younger than 50. This attenuating effect of higher education was found for specific cognitive functions. Together, these findings underscore the complex role of education in cognitive aging. Moreover, they emphasize that middle age is worth investigating in cognitive aging research. 


\section{Samenvatting}

Het onderzoek dat beschreven is in dit proefschrift diende twee doelen.

- Ten eerste ging het erom het inzicht te vergroten in cognitieve processen die sterk beïnvloed worden door veroudering. Dit werd onderzocht door de prestatie op cognitieve taken van jong volwassenen te vergelijken met die van mensen van middelbare en oudere leeftijd. De mechanismen en oorzaken van prestatieverschillen tussen leeftijdsgroepen stonden centraal.

- Het tweede doel was te onderzoeken in hoeverre persoonskenmerken van invloed zijn op de cognitieve veranderingen die gepaard gaan met het ouder worden. In het bijzonder werden de cognitieve processen geïdentificeerd die door opleiding worden beïnvloed.

In hoofdstuk 1 wordt een kort overzicht gegeven van de methodologische en theoretische benaderingen die de basis vormden voor de onderzoeksvragen in dit proefschrift. Verder is achtergrondinformatie gepresenteerd over determinanten van cognitieve veroudering. In dit proefschrift werd opleiding beschouwd als een potentiële bron van cognitieve reserve. Het centrale idee was dat hoge opleiding de leeftijdsgerelateerde cognitieve achteruitgang zou kunnen vertragen en een positieve uitwerking zou kunnen hebben op vaardigheden die het individu helpen om te gaan met taken die een groot beroep doen op zijn cognitieve vermogens.

Het doel van de studie beschreven in hoofdstuk 2 was te onderzoeken of opleiding en sekse de leeftijdsgerelateerde verschillen in snelheid van informatieverwerking kunnen veranderen. De op elkaar inwerkende effecten van leeftijd (jong, jong middelbaar, oud middelbaar), opleidingsniveau (laag, middel, hoog) en sekse werden onderzocht bij 1469 personen die varieerden in leeftijd van 24 tot 67 jaar. Deze effecten werden nagegaan voor drie cognitieve taken. De Letter Digit Substitution Taak (LDST) meet de algemene snelheid van informatieverwerking, waaronder de efficiëntie van processen die operationeel zijn in het werkgeheugen. De Stroop Color-Word Task meet algemene snelheid van informatieverwerking en selectieve aandacht. De Memory Scanning Task (MST) wordt gebruikt om de snelheid van zoeken in het geheugen te meten.

De resultaten van deze studie lieten zien dat prestatie op alle drie de taken negatief werd beïnvloed door hogere leeftijd en een lager opleidingsniveau. Tevens presteerden mannen slechter dan vrouwen. Bij mensen met een hoog opleidingsniveau waren de leeftijdsverschillen kleiner op de LDST. Verder werd gevonden dat leeftijdsgerelateerde verschillen groter waren bij vrouwen dan bij mannen op de LDST en de MST.

Deze bevindingen wijzen erop dat effecten van opleiding en sekse op leeftijdsgerelateerde verschillen in informatieverwerking substantieel zijn.

De experimentele studies die zijn beschreven in hoofdstuk 3 en 4 beoogden de onderling samenhangende effecten van leeftijd, opleiding, interstimulus interval en irrelevante spraak op verbaal leren te onderzoeken. Het memoriseren van woorden uit een aangeboden reeks werd gemeten bij laag en hoog opgeleide personen in vier leeftijds- 
groepen: jong (24 tot 37 jaar), jong middelbaar (39 tot 51 jaar), oud middelbaar (54 tot 66 jaar) en oud (69 tot 77 jaar).

In de studie beschreven in hoofdstuk 3 is bij 338 individuen nagegaan in hoeverre het leren van woorden wordt beïnvloed door het interstimulus interval (ISI, 1, 2, of 3 s). Een langer ISI, oftewel een langer tijdsinterval tussen de aangeboden woorden, levert meer mogelijkheden op voor organisatie en strategiegebruik. De resultaten lieten zien dat het leren van woorden negatief werd beïnvloed door hogere leeftijd, lagere opleiding en een korter ISI. De leeftijdsgerelateerde verschillen in prestatie werden echter niet beïnvloed door ISI. Dit wijst erop dat het verlengen van de ISI ouderen niet in staat stelde tot effectieve compensatie van hun tragere informatieverwerking. Het verschil in prestatie tussen jongeren en ouderen werd immers niet kleiner bij een langere ISI. Wat betreft het effect van opleiding werd gevonden dat lager opgeleiden meer tijd nodig hadden om eenzelfde prestatieniveau als hoger opgeleiden te bereiken.

Hoofdstuk 4 beschrijft twee experimenten die de effecten van omgevingsgeluid op het leren van woorden evalueerden. Dit omgevingsgeluid werd geoperationaliseerd door de proefpersoon tijdens het uitvoeren van de taak te confronteren met irrelevante spraak. Dit gebeurde door via de computer gesproken woorden te laten klinken op hetzelfde moment dat de proefpersonen visueel aangeboden woorden moesten leren. De verwachting was dat oudere en lager opgeleide personen minder goed in staat zouden zijn dan jongere en hoger opgeleide personen om irrelevante spraak tijdens het leren van nieuwe informatie te inhiberen, d.w.z. te onderdrukken.

In experiment 1 zijn de effecten van leeftijd, opleiding en irrelevante spraak bestudeerd in een groep van 230 personen. Uit de resultaten bleek dat prestatie negatief werd beïnvloed door hogere leeftijd, lagere opleiding en de toevoeging van irrelevante spraak. De leeftijdsverschillen in prestatie werden echter niet beïnvloed door irrelevante spraak.

In experiment 2 is de moeilijkheid van de leertaak vergroot door zowel irrelevante spraak als een kort interstimulus interval (ISI, 2 of 0.5 seconden) te gebruiken bij 105 andere personen. Leeftijdsgerelateerde verschillen bleken groter te worden door het gelijktijdig toepassen van irrelevante spraak en een korte ISI. Verder werd gevonden dat ouderen meer woorden bleken te onthouden uit de lijst met irrelevante woorden. Bovendien onthielden zij disproportioneel meer van deze woorden in de korte ISIconditie dan in de langere.

Tezamen wijzen deze bevindingen erop dat onder tijdsdruk inhibitieprocessen bij ouderen minder efficiënt verlopen. Een implicatie zou kunnen zijn dat ouderen meer tijd nodig hebben dan jongeren om in een lawaaiige omgeving nieuwe informatie te leren.

De hoofdstukken 5 en 6 beschrijven experimentele studies waarin het niveau van woordverwerking werd gemanipuleerd bij 40 jonge ( 25 tot 35 jaar) en 40 middelbare (50 tot 60 jaar) personen met lage en hoge opleiding.

Hoofdstuk 5 had als doel de invloed van het verwerkingsniveau op reactietijden (RT's) te bepalen. Er werden diverse beslistaken gebruikt om drie verschillende verwerkingsniveaus, toenemend in diepte, te induceren. 
- In de meest oppervlakkige taak diende beslist te worden of een woord met hoofd- of kleine letters was geschreven. Hierbij werd een beroep gedaan op perceptuele processen.

- In de tweede taak werd gevraagd te beslissen of de letter ' $\mathrm{e}$ ' in het woord aanwezig was. Bij het uitvoeren van deze opdracht werd een beroep gedaan op fonologische verwerkingsprocessen.

- $\quad$ Bij de derde taak moest de persoon beslissen of een woord aan levende of nietlevende objecten refereerde waarbij semantische verwerkingsprocessen betrokken waren.

Diepere verwerking vereist meer cognitieve stappen dan oppervlakkige verwerking. Daarom werd verwacht dat het verschil in RT tussen jongeren en mensen van middelbare leeftijd toe zou nemen bij een diepere verwerking. Op basis van de cognitieve-reserve-hypothese werd tevens verwacht dat deze toename minder groot zou zijn bij hoger opgeleide personen.

De resultaten lieten echter geen interacties zien tussen leeftijd, taak en opleiding. Dit wijst erop dat de verschillende verwerkingsniveaus even gevoelig zijn voor vertraging op middelbare leeftijd en dat opleiding hierbij geen rol speelt. Hoewel er dus geen interacties tussen leeftijd en verwerkingsniveau waren gevonden, wijzen interacties tussen leeftijd en stimulus-type binnen een taak erop dat er al een kwetsbaarheid is op middelbare leeftijd met betrekking tot specifieke cognitieve processen. We vonden dat RT's na de presentatie van woorden mét een 'e' korter waren dan na de presentatie van woorden zónder een 'e'. Dit verschil was groter in de middelbare leeftijdsgroep. Dit suggereert dat men een zoekstrategie gebruikt, waarbij gestopt wordt met zoeken zodra de 'e' gevonden is en dat mensen van middelbare leeftijd langzamer zijn in het uitvoeren van deze strategie dan jongeren. Verder werd gevonden dat leeftijdsgerelateerde verschillen in RT op woorden die refereren aan iets levends kleiner waren dan de verschillen in RT op woorden die verwijzen naar niet-levende zaken. Dit suggereert dat mensen van middelbare leeftijd bepaalde semantische categorieën van woorden minder snel verwerken.

Aangezien diepere verwerking resulteert in het beter vasthouden van woorden in het geheugen, werd verwacht dat het minder moeite zou kosten om dieper verwerkte woorden uit het geheugen op te halen dan oppervlakkiger verwerkte woorden. Het doel van hoofdstuk 6 was daarom te onderzoeken of mensen van middelbare leeftijd minder profijt hebben van het dieper verwerken van woorden dan jongeren wanneer gekeken wordt naar geheugenprestatie en moeite met het ophalen van woorden uit het geheugen. Ook werd onderzocht of leeftijdsgerelateerde verschillen in prestatie minder groot zijn in een hoog opgeleide groep. Behalve de drie beslistaken die gebruikt werden in het vorige hoofdstuk, zijn ook het hardop voorlezen en doelbewust leren van woorden gebruikt om diepere niveaus van verwerking te bewerkstelligen. RT's van een herkenningstaak werden gebruikt om moeite met ophalen uit het geheugen te meten. De resultaten lieten zien dat het leeftijdsgerelateerde verschil ten aanzien van de actieve reproductie van woorden toenam met de diepte van verwerking. Leeftijdsgerelateerde verschillen in accuratesse en in RT's op een herkenningstaak veranderden echter niet met de diepte van verwerking. Deze bevindingen wijzen erop dat mensen van middelbare leeftijd in ieder geval minder profijt hebben van diepe verwerking bij het actief reproduceren van woorden. 
De studie die is beschreven in hoofdstuk 7 was gericht op het toetsen van de interacties tussen opleiding en gezondheidsstatus (oftewel fysiek, sociaal en psychologisch functioneren) met betrekking tot cognitieve prestatie en de verandering hiervan na een periode van zes jaar. Hiervoor zijn longitudinale gegevens van 1344 personen in de leeftijden 24 tot 47 jaar en 49 tot 77 jaar gebruikt. Er werden diverse cognitieve taken opgelegd om informatieverwerkingssnelheid, cognitieve flexibiliteit, inhibitie, geheugen en "verbale vloeiendheid" te meten.

De resultaten lieten slechts interactie-effecten tussen gezondheidsstatus en opleiding zien in de jongere groep. Wat betreft prestatie op het eerste meetmoment werd er een interactie-effect gevonden op een variabele voor algemene snelheid van informatieverwerking. Wat betreft longitudinale verandering werden er interacties gevonden op variabelen voor snelheid en executief functioneren. Deze interacties suggereren dat bij mensen jonger dan 50 jaar hoge opleiding een compensatie kan bieden voor leeftijdsgerelateerde cognitieve achteruitgang als gevolg van minder welbevinden.

In het laatste hoofdstuk zijn enkele methodologische punten besproken en vervolgens zijn de bevindingen van dit proefschrift op een algemener niveau bediscussieerd.

Het patroon van resultaten wijst erop dat mensen van rond de 40 jaar reeds minder goed presteren dan personen omstreeks 25 jaar met betrekking tot verscheidene cognitieve maten in het domein van geheugen en informatieverwerking. Voorts werd gevonden dat deze leeftijdsverschillen groter werden als de cognitieve eisen toenamen. Dit zou implicaties voor het dagelijks leven kunnen hebben, omdat mensen van middelbare leeftijd in het algemeen meer dan mensen uit andere leeftijdsgroepen situaties tegenkomen waarbij een groot beroep wordt gedaan op hun cognitieve vermogens. In deze levensfase worden veelvuldig vaardigheden vereist als organiseren, plannen en problemen oplossen, vaak onder omstandigheden van tijdsdruk.

Met betrekking tot de rol van opleiding in cognitieve veroudering werd bij mensen jonger dan 50 jaar meer bewijs gevonden dat een hoge opleiding bescherming biedt tegen cognitieve veroudering dan bij mensen ouder dan 50 jaar. Dit beschermend effect van hoge opleiding werd niet op alle cognitieve functies gevonden.

Tezamen benadrukken deze bevindingen de complexe rol van opleiding in cognitieve veroudering. Bovendien is aangetoond dat de middelbare leeftijd een periode is waarin belangrijke veranderingen optreden in het cognitief functioneren en dat het daarom zinvol is deze periode te bestuderen. 


\section{Dankwoord}

De afgelopen vier jaar heeft een groot aantal mensen op allerlei manieren bijgedragen aan de wording van dit proefschrift. Ook zou ik zonder veel van hen lang niet zo'n mooie tijd hebben gehad in Maastricht. Dank jullie wel hiervoor! Ik wil op deze plek een aantal personen in het bijzonder noemen. Allereerst het promotieteam: Jelle, ondanks dat wij in de loop van de vier jaar niet altijd gelijk gestemd waren, heb ik veel van je geleerd. Zo heb ik aan jou bijvoorbeeld het inzicht te danken dat wetenschap (bijna) gelijk is an marketing. Met dit besef hoop ik ook in de toekomst nog mijn voordeel te kunnen doen. Martin, dank voor alle scherpende discussies (al dan niet in de deuropening) en het kritische commentaar op mijn stukken. Pascal, dank je wel voor de fijne samenwerking en je nooit wankelende vertrouwen in mij. Renate, dank voor je steun in de voor mij penibele periode (gelukkig alweer een poos geleden).

Bij NP zijn er vele anderen die betrokken zijn geweest bij mij en bij m'n project: de lunchclub bijvoorbeeld, steeds een andere samenstelling, maar altijd gezellig. Ook nog bedankt dat jullie elke dag weer aanklopten, ook al haakte ik vaak af. Nico en Ron: dank voor alle computerhulp en het IVO-bestand, jullie waren goud waard voor mij! Astrid, dank voor het intrainen en Lia, Angelique en ook Climmy voor het testen, jullie waren geweldige stagiaires. Elsa, dank je wel voor de kameraadschap en het niet zeuren over mijn troep. Desiree bedank ik voor het promotiegeregel, Anita voor het zo geduldig programmeren van de MIND, Dick voor zijn statistische hulp en Ankie, Laurent en Marco voor het beheren van de financiële kant van de zaak. Alle AIO's wil ik bedanken voor het meeleven, meedenken, overleggen en voor de gezelligheid. Medecongresgangers tenslotte: bedankt voor de fantastische (en leerzame) tripjes!

Ook buiten de afdeling ben ik veel personen erkentelijk. Alle proefpersonen bedank ik: zonder jullie was er sowieso geen proefschrift geweest. Alle vrienden en vriendinnen uit Utrecht, Maastricht en elders ben ik dankbaar voor de steun, luisterende oren en de nodige afleiding (Moniek, als huisgenoot heb jij hier een belangrijke rol in gespeeld). Sjoerd en Ron, dank voor de mooie voorkant en Ron, laat ik je ook vooral niet vergeten te bedanken voor alle logistieke hulp alweer twee jaar geleden. Eise, dank voor je onmisbare hulp met de lay-out. Ook de klimclub wil ik hier even noemen: dat oude tijden maar weer mogen herleven en we allemaal onze klimlust hervinden. En niet te vergeten het universiteitsorkest: jullie waren goede proefpersonen en voorlopig ben ik nog niet weg. David, Martine, Ellen en Sharon (thanks reserveparanimf!), bedankt voor het commentaar op mijn eerste, één na laatste en laatste hoofdstuk. Paardennymfen Martine en Karin: jullie zijn geweldige vriendinnen en waren fijne kamergenoten. Zonder jullie waren de afgelopen vier jaar een stuk minder plezierig geweest! Tenslotte wil ik mijn familie bedanken en met name papa en mama voor het meedenken in de laatste fase en het van A tot $Z$ lezen van dit proefschrift. 


\section{Curriculum Vitae}

Willemien Meijer werd geboren op 14 juli 1979 te Leiden. In 1997 behaalde zij haar gymnasiumdiploma aan de Rijksscholengemeenschap in Steenwijk. Hierna begon zij met de studie Psychologie aan de Universiteit Utrecht. Zij deed een klinische stage neuropsychologische diagnostiek in het Universitair Medisch Centrum Utrecht op de afdeling Psychiatrie voor volwassenen. Haar afstudeeronderzoek deed zij naar de ontwikkeling van het geheugen bij kinderen met epilepsie in het Wilhelmina Kinderziekenhuis Utrecht, sector Neuropsychologie. In 2002 studeerde zij af in de Psychologie met als specialisatie Neuropsychologie. Van 2002 tot en met 2006 werkte zij als Assistent in Opleiding bij de afdeling Psychiatrie en Neuropsychologie van de Faculteit der Geneeskunde aan de Universiteit Maastricht. Het onderzoek dat zij daar deed staat beschreven in dit proefschrift. 


\section{Publications}

Meijer, W., De Groot, R., Van Boxtel, M., Van Gerven, P., \& Jolles, J. (2006) Verbal learning and aging: Combined effects of irrelevant speech, interstimulus interval, and education. Journals of Gerontology: Psychological Sciences Vol. 61B, No. 5. P285-P294

Meijer, W., De Groot, R., Van Boxtel, M., Van Gerven, P., \& Jolles, J. Are age differences in verbal learning related to interstimulus interval and education? Experimental Aging Research (accepted for publication).

Van Gerven, P., Meijer, W., Vermeeren, A., Vuurman, E., \& Jolles, J. The irrelevant speech effect and the level of interference in aging. Experimental Aging Research (accepted for publication).

Van Gerven, P., Van Boxtel, M., Meijer, W., Willems, D., \& Jolles, J. On the relative role of inhibition in age-related working memory decline. Aging, Neuropsychology and Cognition (accepted for publication).

Meijer, W., De Groot, R., Van Gerven, P., Van Boxtel, M., \& Jolles, J. Level of processing and reaction time in young and middle-aged adults and the effect of education (submitted for publication).

Meijer, W., Van Gerven, P., De Groot, R., Van Boxtel, M., \& Jolles, J. The benefit of deep processing and high educational level for verbal learning in young and middle-aged adults (submitted for publication).

Meijer, W., Van Gerven, P., Van Boxtel, M., Van Hooren, S., \& Jolles, J. Interaction effects of education and health status on cognitive change: 6-year follow-up of the Maastricht Aging Study (submitted for publication).

Meijer, W., De Groot, R., Van Boxtel, M., \& Jolles, J. Education and sex influence age differences in information processing (submitted for publication).

Meijer, W., Postma, A., Van Teeseling, H., Smeets-Schouten, A., Peters, B., \& Jennekens-Schinkel, A. Object-location memory in children with non-symptomatic epilepsy: a longitudinal study (submitted for publication).

Van Gerven, P., Meijer, W., Prickaerts, J., Van der Veen, F. Effects of aging on switching focal attention in working memory: Results from an adapted n-back paradigm (submitted for publication).

Van Gerven, P., Meijer, W., \& Jolles, J. Education does not protect against age-related decline of switching focal attention in working memory (submitted for publication). 